\title{
Learning Demonstration
} Progress Report - Spring 2008

Technical Report NREL/TP-560-42986 April 2008

K. Wipke, S. Sprik, and J. Kurtz 


\section{Learning Demonstration} Progress Report - Spring 2008

Technical Report NREL/TP-560-42986 April 2008

K. Wipke, S. Sprik, and J. Kurtz

Prepared under Task No. H270.8100

National Renewable Energy Laboratory 1617 Cole Boulevard, Golden, Colorado 80401-3393 303-275-3000 • www.nrel.gov

Operated for the U.S. Department of Energy

Office of Energy Efficiency and Renewable Energy

by Midwest Research Institute • Battelle

Contract No. DE-AC36-99-G010337

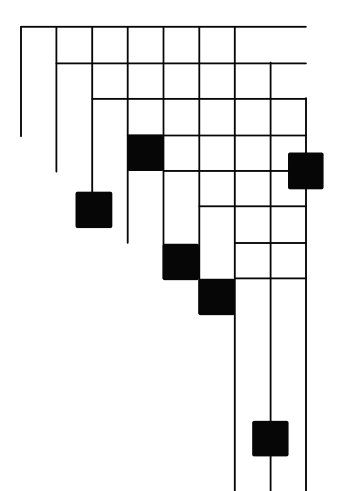




\section{NOTICE}

This report was prepared as an account of work sponsored by an agency of the United States government. Neither the United States government nor any agency thereof, nor any of their employees, makes any warranty, express or implied, or assumes any legal liability or responsibility for the accuracy, completeness, or usefulness of any information, apparatus, product, or process disclosed, or represents that its use would not infringe privately owned rights. Reference herein to any specific commercial product, process, or service by trade name, trademark, manufacturer, or otherwise does not necessarily constitute or imply its endorsement, recommendation, or favoring by the United States government or any agency thereof. The views and opinions of authors expressed herein do not necessarily state or reflect those of the United States government or any agency thereof.

Available electronically at http://www.osti.gov/bridge

Available for a processing fee to U.S. Department of Energy and its contractors, in paper, from:

U.S. Department of Energy

Office of Scientific and Technical Information

P.O. Box 62

Oak Ridge, TN 37831-0062

phone: 865.576 .8401

fax: 865.576 .5728

email: mailto:reports@adonis.osti.gov

Available for sale to the public, in paper, from:

U.S. Department of Commerce

National Technical Information Service

5285 Port Royal Road

Springfield, VA 22161

phone: 800.553.6847

fax: 703.605.6900

email: orders@ntis.fedworld.gov

online ordering: http://www.ntis.gov/ordering.htm 


\section{Executive Summary}

This purpose of this report is to document and discuss key results based on data through December 2007 from the U.S. Department of Energy's (DOE) Controlled Hydrogen Fleet and Infrastructure Validation and Demonstration Project, also referred to as the Fuel Cell Vehicle (FCV) and Infrastructure Learning Demonstration. This report serves as one of many mechanisms to help transfer knowledge and lessons learned within various parts of DOE's hydrogen program, as well as externally to other stakeholders.

The DOE's National Renewable Energy Laboratory (NREL) has now analyzed data from almost three years of the five-year project. During this time, 92 vehicles have been deployed, 14 project refueling stations have been placed in use, and no fundamental safety issues have been identified. We've analyzed data from over 200,000 individual vehicle trips covering 1,100,000 miles traveled and over 40,000 $\mathrm{kg}$ hydrogen produced or dispensed. With additional hours of operation accumulated on the stacks, the fuel cell degradation projections have been updated and the four-team average projection is at 1,200 hours. In the next six months NREL will improve the accuracy of its projections by adding a non-linear fit (or a two-step linear fit) to avoid overestimating the projected time that could occur as the accumulated hours continues to grow.

To understand what is causing the stacks to gradually degrade, NREL continues to characterize how each stack is used and performs multivariate analysis on this dataset to examine dominant variables affecting stack voltage degradation rate. Results to date indicate that trends across all four teams are probably not possible to extract due to differences among the teams, but that individual results may be useful to the teams individually and for feeding trends back into the research and development $(R \& D)$ program. We've analyzed fuel cell system efficiency at $1 / 4-$ power and compared it to the DOE target of $60 \%$; system efficiency results from the four teams ranged from $52.5 \%$ to $58.1 \%$.

Using data on communication vs. non-communication fills we found that communication fills demonstrated a higher rate of fill than non-communication; the slowest of the noncommunication fill rates are being phased out. We also examined refueling and driving behavior, and found the Learning Demonstration fleet to be representative of national statistics with the exception of fewer late afternoon and weekend trips, an abundance of short trips, and a shorter average distance traveled per day. Finally, we've now published a total of 47 composite data products (CDPs) to date and made them directly accessible to the public from our Hydrogen Technology Validation Web site. 


\section{Contents}

Executive Summary ..............................................................................................................................iii

1. Learning Demonstration Progress Report - Spring 2008 ............................................................

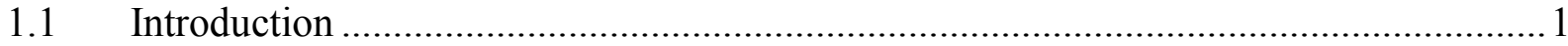

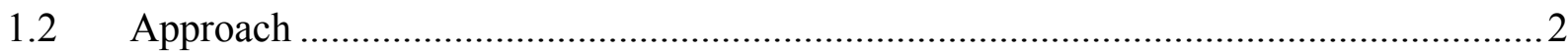

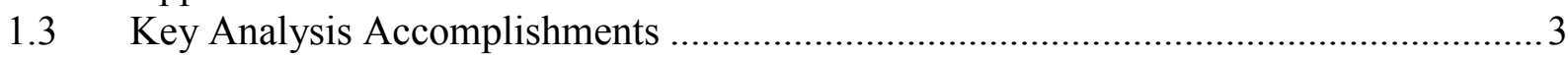

2. Results...................................................................................................................................

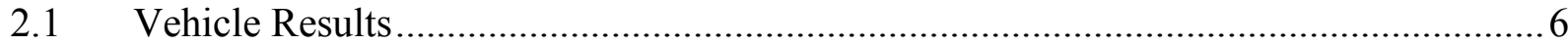

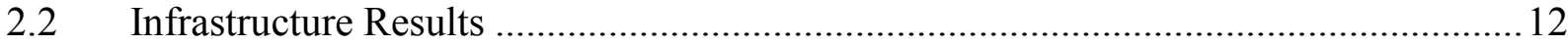

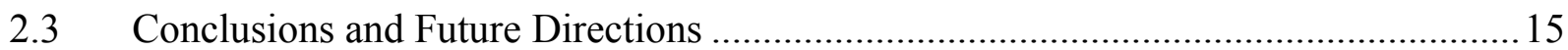

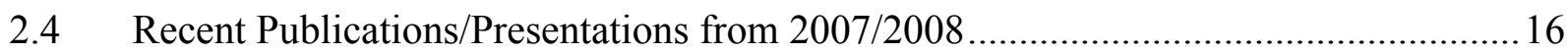

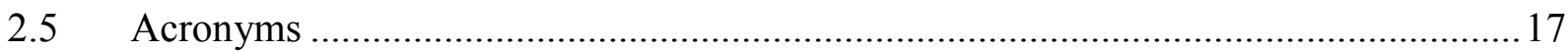

2.6 Composite Data Products Referenced in Previous Discussion ....................................... 18

\section{Figures}

Figure 1: Photographs of the Four Teams' First-Generation Vehicles with Small Inset Photos Showing the Second-Generation Vehicles .............................................................. 1

Figure 2: Four Examples of Hydrogen Production and Refueling Facilities.................................2

Figure 3: Data Flow for Hydrogen Secure Data Center (HSDC) Analysis and Results, Overlaid on Top of Quantity of Data Received at HSDC ......................................................... 3

Figure 4: Screen Capture from NREL's Composite Data Product Web Site ..................................5

Figure 5: Fuel Cell System Efficiency at $25 \%$ Net Power (CDP8) .......................................... 18

Figure 6: Histogram of Time Spent At FC Power Levels (CDP46) ........................................... 18

Figure 7: Fuel Cell System Energy within Power Levels (CDP53) ……………………........... 19

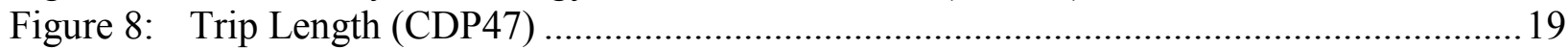

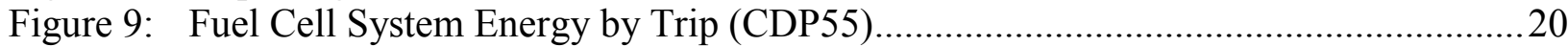

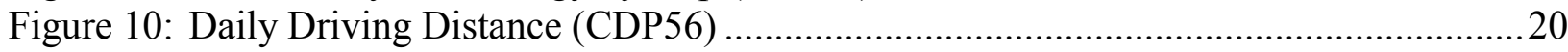

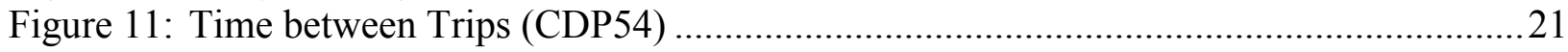

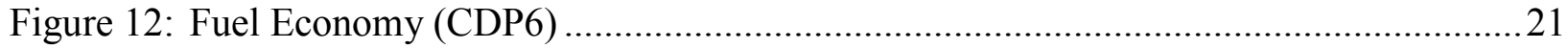

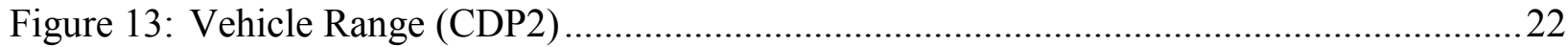

Figure 14: Percentage of Theoretical Range Traveled between Refuelings (CDP33) ..................22

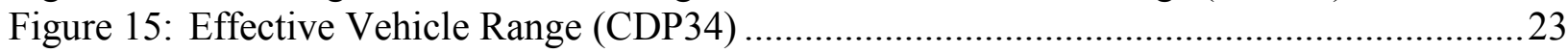

Figure 16: Weight \% Hydrogen Stored (CDP10) ....................................................................2

Figure 17: Volumetric Capacity of Hydrogen Storage (CDP11)..............................................24

Figure 18: Hydrogen Storage System Mass and Volume Breakdown (CDP 57) ..........................24

Figure 19: Vehicle Hydrogen Tank Cycle Life (CDP12) .......................................................25

Figure 20: Hours Accumulated and Projected Hours to 10\% Stack Voltage

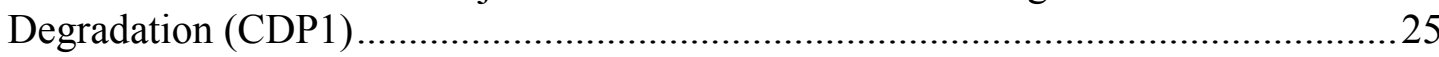

Figure 21: Primary Factors Affecting Learning Demo Fleet Fuel Cell Degradation (CDP48)....26

Figure 22: Primary Factors Affecting Learning Demo Team Fuel Cell Degradation (CDP49)...26

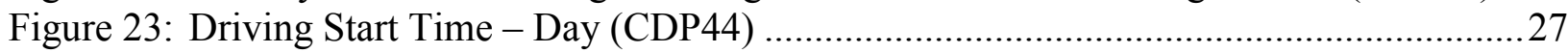

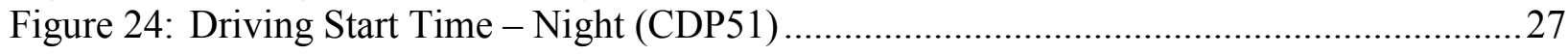

Figure 25: Driving by Day of Week (CDP45) …………........................................................2 


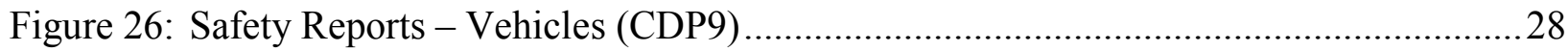

Figure 27: Range of Ambient Temperature during Vehicle Operation (CDP21).........................29

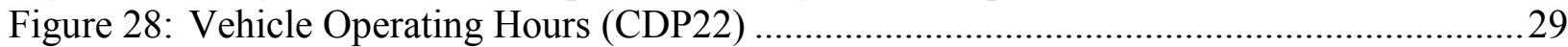

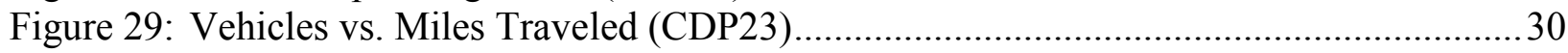

Figure 30: Cumulative Vehicle Miles Traveled (CDP24) …………………............................... 30

Figure 31: Vehicle Hydrogen Storage Technologies (CDP25) ..................................................31

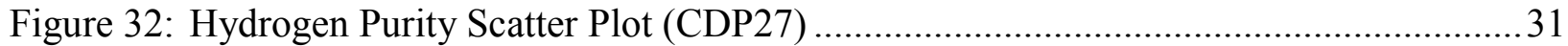

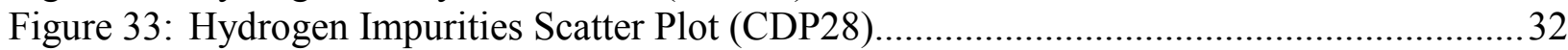

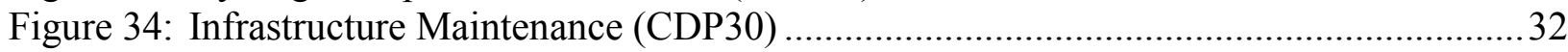

Figure 35: Safety Reports - Infrastructure (CDP20) ……………………………………........ 33

Figure 36: Primary Factors of Infrastructure Safety Reports (CDP37) ……………….................33

Figure 37: Average Refuelings between Infrastructure Safety Reports (CDP35) ..........................34

Figure 38: Type of Infrastructure Safety Report by Quarter (CDP36) ..........................................34

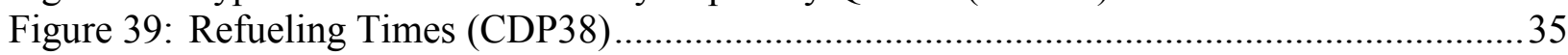

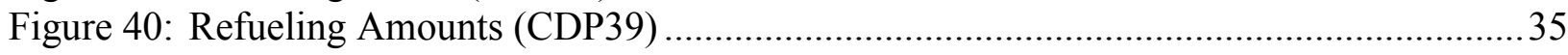

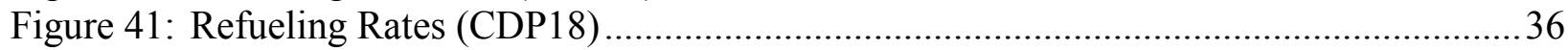

Figure 42: Fueling Rates - Communication and Non-Communication Fills (CDP29) .................36

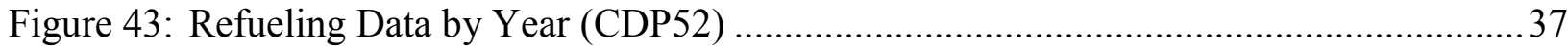

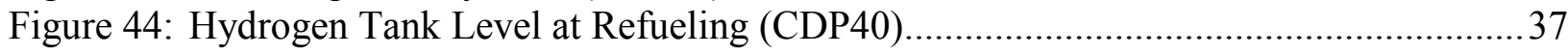

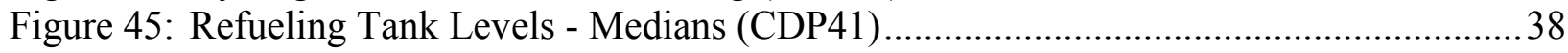

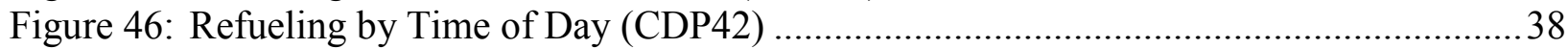

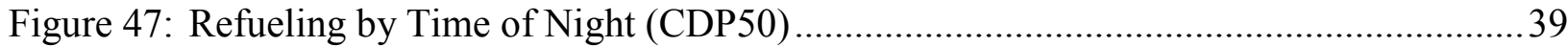

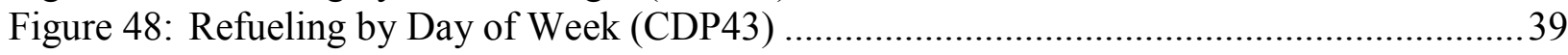

Figure 49: Cumulative Hydrogen Produced or Dispensed (CDP26) ............................................. 40

Figure 50: Infrastructure Hydrogen Production Methods (CDP32) .............................................40

Figure 51: Number of Reporting Stations (CDP31) ................................................................ 41 


\section{Learning Demonstration Progress Report - Spring 2008}

\subsection{Introduction}

This purpose of this report is to document and discuss key results to date (based on data through December 2007) from the U.S. Department of Energy's (DOE) Controlled Hydrogen Fleet and Infrastructure Validation and Demonstration Project, also referred to as the Fuel Cell Vehicle (FCV) and Infrastructure Learning Demonstration. This report is one of many mechanisms we use to help transfer knowledge and lessons learned within various parts of DOE's hydrogen program, as well as externally to other stakeholders. Other mechanisms have included: briefings to FreedomCAR and Fuels technical teams, presentations at technical conferences, postings of individual results to the National Renewable Energy Laboratory's (NREL) Web site, presentations at DOE's Annual Merit Review, and participation in groups such as the California Hydrogen Business Council, US Fuel Cell Council Joint Hydrogen Quality Task Force, and various California Fuel Cell Partnership working groups.
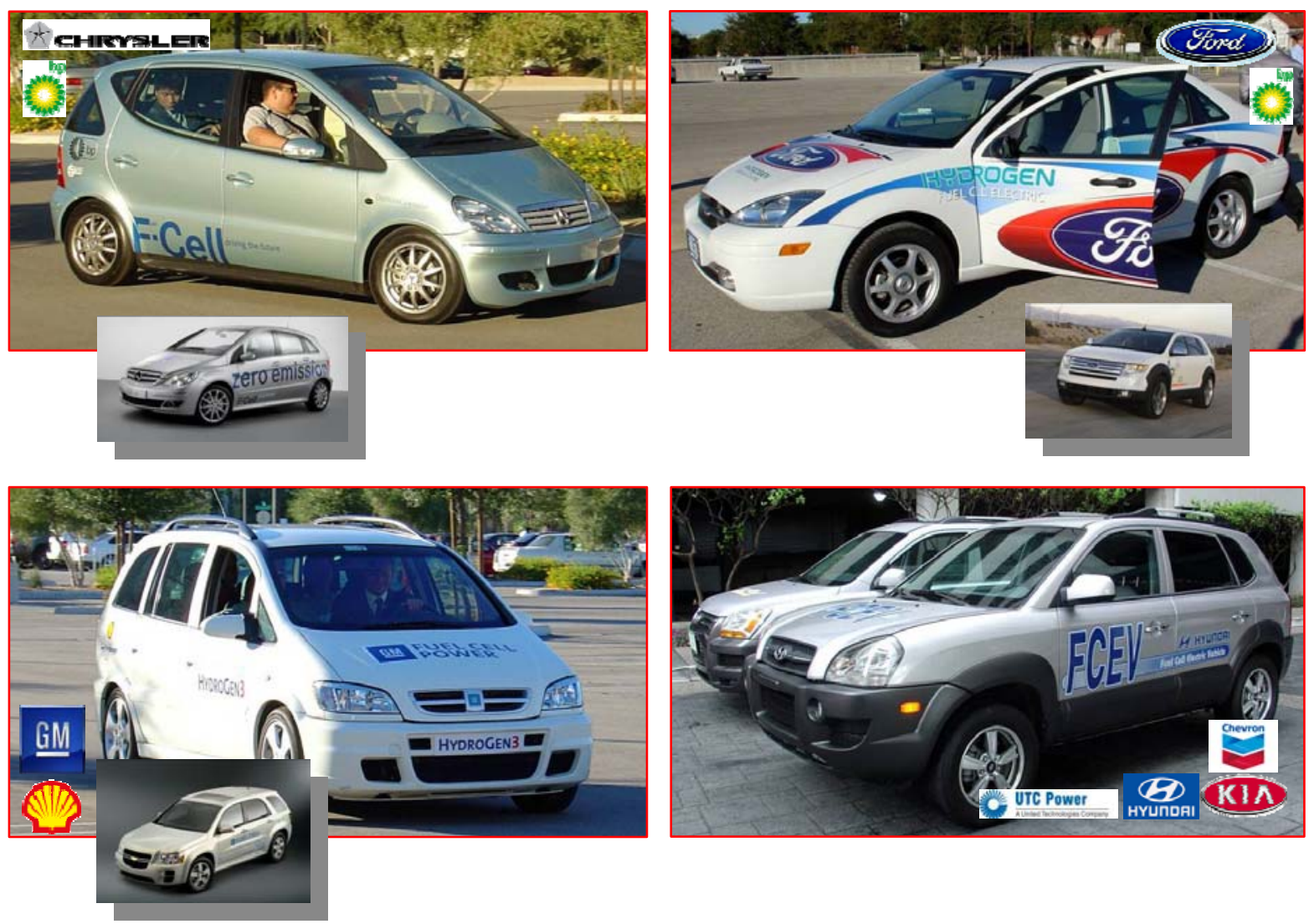

Figure 1: Photographs of the Four Teams' First-Generation Vehicles with Small Inset Photos Showing the Second-Generation Vehicles

The primary goal of this project is to validate vehicle and infrastructure systems using hydrogen as a transportation fuel for light-duty vehicles. This means validating the use of FCVs and hydrogen refueling infrastructure under real-world conditions using multiple sites, various climates, and a variety of hydrogen sources. See Figure 1 for photographs of the first-generation 
vehicles and logos of the four teams and Figure 2 for photographs representing examples of the four types of hydrogen refueling stations.

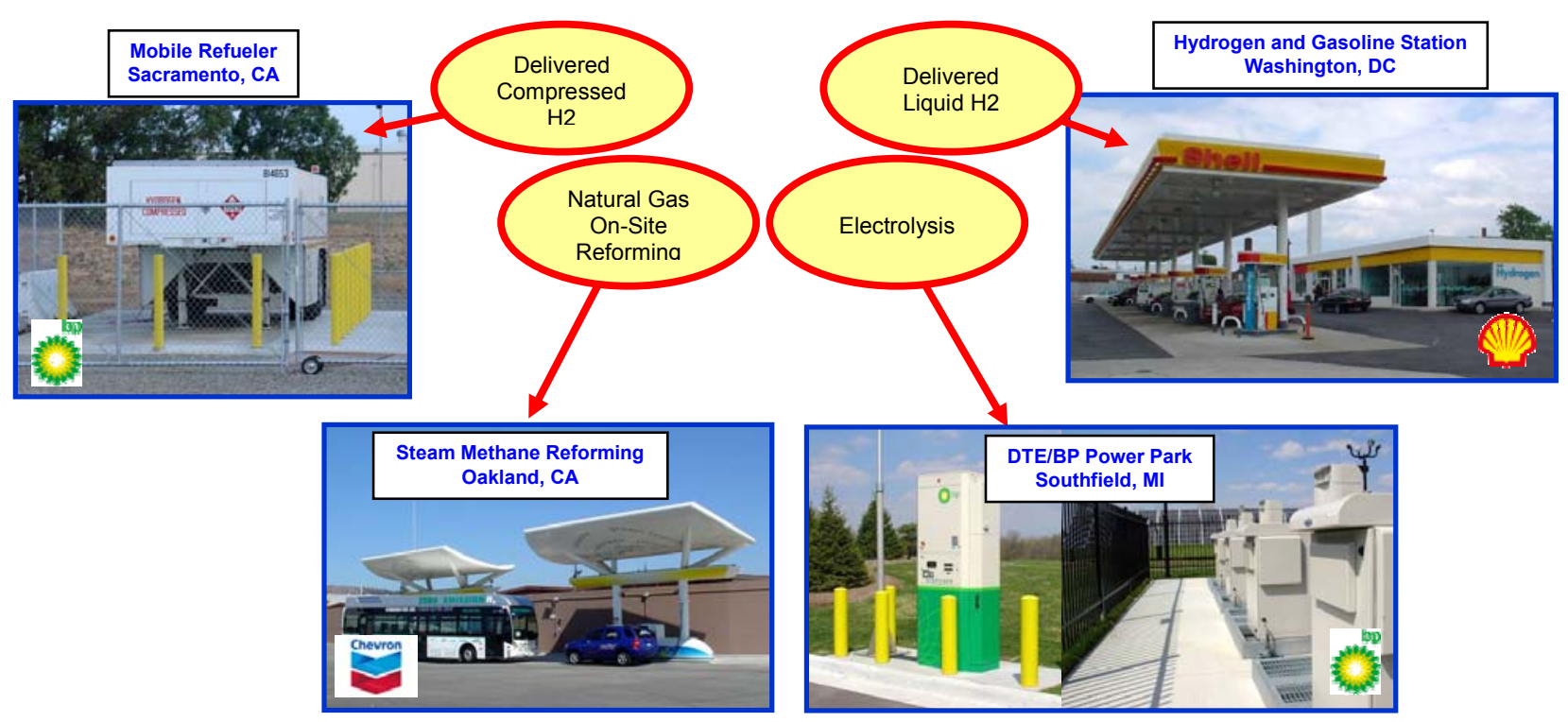

Figure 2: Four Examples of Hydrogen Production and Refueling Facilities

By 2009 we will validate hydrogen vehicles and infrastructure against the following targets:

- 250-mile range

- 2,000-hour fuel cell durability

- $\$ 3 /$ gge hydrogen production cost (based on volume production).

We are identifying the current status of the technology and tracking its evolution over the fiveyear project duration. In particular, we are tracking differences between the first- and secondgeneration FCVs. NREL works to provide DOE and industry with maximum value from the data produced by this "learning demonstration." We seek to understand the progress toward the technical targets, and provide that information to the Hydrogen Fuel Cells and Infrastructure Technologies (HFCIT) research and development (R\&D) activities. This information will allow the program to move more quickly toward cost-effective, reliable hydrogen FCVs and supporting refueling infrastructure.

\subsection{Approach}

NREL's approach to accomplishing the project's objectives is structured around a highly collaborative relationship with each of the four industry teams: Chevron/Hyundai-Kia, Chrysler/BP, Ford/BP, and GM/Shell. We are receiving raw technical data on both the hydrogen vehicles and refueling infrastructure that allows us to perform unique and valuable analyses across all four teams. Our primary objectives are to feed the current technical challenges and opportunities back into the DOE Hydrogen R\&D Program and assess the current status and progress toward targets. 
To protect the commercial value of these data for each company, we established the Hydrogen Secure Data Center (HSDC) to house the data and perform our analysis (Figure 3 shows the flow of data and results, overlaid on top of the quantity of data received at the HSDC). To ensure value is fed back to the hydrogen community, we publish composite data products (CDPs) twice a year at technical conferences. These data products report on the progress of the technology and the project, focusing on the most significant results. Additional CDPs are conceived as additional trends and results of interest are identified. We also provide our detailed analytical results from each individual company's data back to them to maximize the industry benefit from NREL's analysis work and obtain feedback on our methodologies. These individual results are not made available to the public.

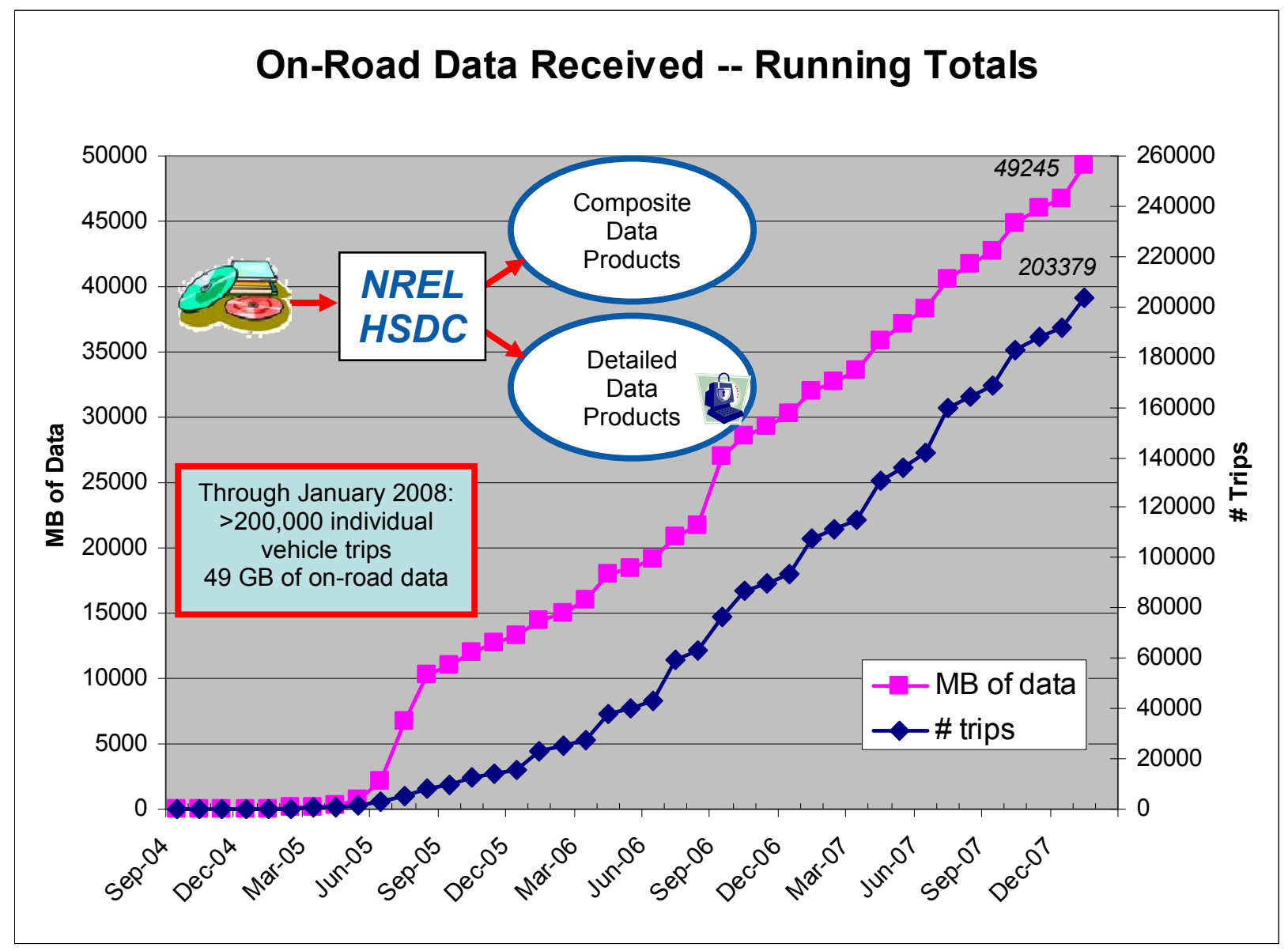

Figure 3: Data Flow for Hydrogen Secure Data Center (HSDC) Analysis and Results, Overlaid on Top of Quantity of Data Received at HSDC

\subsection{Key Analysis Accomplishments}

- Created and published 47 new or updated CDPs (the fifth such set of public results) representing results of analyzing almost three years of Learning Demonstration data. The results will be presented publicly at the National Hydrogen Association conference (Sacramento, CA) and DOE's Annual Merit Review (Washington, DC). 
- Provided all CDPs on an NREL Web page at http://www.nrel.gov/hydrogen/cdp topic.html to allow direct public access to the latest CDPs organized by topic, date, and CDP number. This also allows the results to be indexed directly by search engines.

- Made major improvements to NREL's Fleet Analysis Toolkit (FAT) to include multivariate analysis of primary factors affecting stack degradation. We have also improved the creation and organization of detailed data product generation to allow easier distribution of protected results to the respective industry teams.

- Further developed the collaborative technical relationship with all four industry teams by giving presentations to each team. The presentations included detailed results from NREL's analysis of their vehicle and infrastructure data.

- Received and processed information from over 200,000 individual vehicle trips, amounting to over $49 \mathrm{~GB}$ of data, since project inception.

\section{Results}

The results discussed here came from analyzing almost three years of vehicle and infrastructure data (through December, 2007). This resulted in a total of 47 new or updated CDPS that we could present at technical conferences. To accomplish the analysis, we continued to improve and revise our in-house fleet analysis tool, FAT.

Since there are now so many technical results from the project, they cannot normally all be discussed during 15-20 minute conference presentations. Therefore, in January 2007 NREL launched a new Web page at http://www.nrel.gov/hydrogen/cdp topic.html to provide the public with direct access to the results (see Figure 4 for a screen capture of this Web page). The Web site makes current and archived CDPs available to the public. The most recent results are scheduled to be presented publicly at the National Hydrogen Association conference (4/08) and the DOE Annual Hydrogen Program Merit Review (6/08) as the "Spring 2008 Results." In order to focus on high-level results, conclusions, and trends, this report will discuss the results in bullet form, organized by technical topic. The last section includes all of the CDPs in the order they are referenced. 


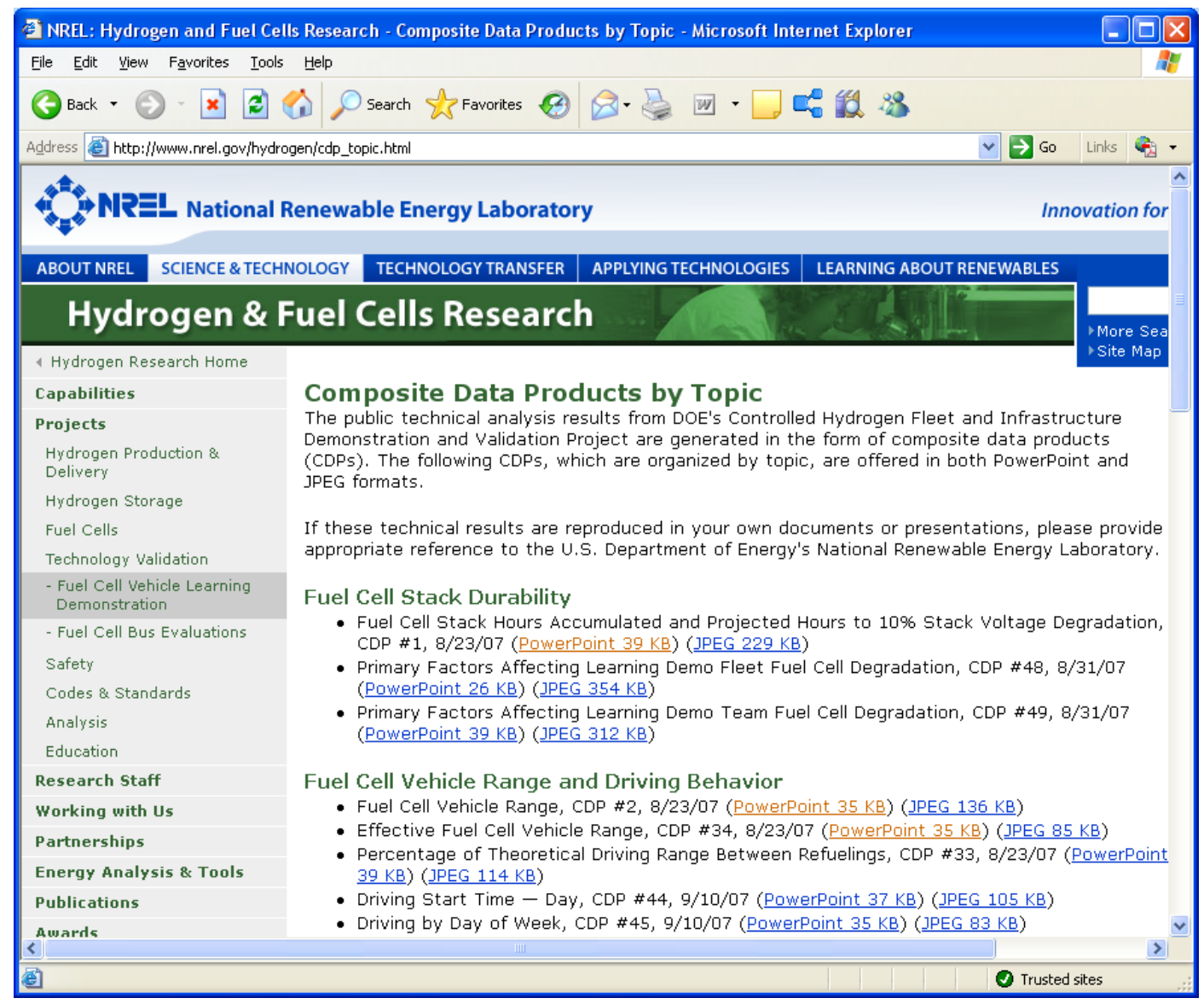

Figure 4: Screen Capture from NREL's Composite Data Product Web Site 


\subsection{Vehicle Results}

- Fuel Cell System Efficiency: Researchers from the car companies measured fuel cell system efficiency from select vehicles on a vehicle chassis dynamometer at several steady-state points of operation. NREL worked with the data and the companies to ensure that appropriate balance-of-plant electrical loads were included. This ensured that the results were comparable to the target and based on the entire system rather than just the stack. DOE's technical target for net system efficiency at $1 / 4$-power is $60 \%$. Baseline data from the four Learning Demonstration teams showed a range of net system efficiency from $52.5 \%$ to $58.1 \%$ (Figure 5), which is very close to the target. These results have not changed since they were first published because they are baseline results for first-generation vehicles, but the teams will test second-generation systems as soon as they are introduced in the next year to evaluate any efficiency changes as the systems get closer to technology readiness.

- Fuel Cell Operating Points: Since a fuel cell system's peak efficiency is normally at low powers (typically $10 \%$ to $25 \%$ ), we evaluated the fuel cell system operation from a number of different perspectives to better understand whether the unique performance characteristics of the fuel cell system were being maximized. As reported in the last progress report (September 2007), a significant amount of time is being spent at low fuel cell system power (Figure 6). In fact, the teams' average amount of time spent at $<5 \%$ of peak power was over 50\%. However, for overall vehicle fuel efficiency, the amount of energy spent at various power levels and the efficiency at those power levels is the critical metric. We found that much of the fuel cell energy (about $40 \%$ ) is expended at fuel cell power levels between $20 \%$ and $50 \%$ of peak power (Figure 7 ). This matches up very well with the peak fuel cell system efficiency points (at $\sim 25 \%$ power) previously discussed. Only about $20 \%$ of the energy is expended at powers $<15 \%$ of peak power, indicating that low power efficiency is not as important as the percentage of time spent there would imply.

- Trip Length Evaluation: In order to understand why so much time was spent at low power, we analyzed the length of trips and compared the results to national statistics (Figure 8). With more than $40 \%$ of the Learning Demonstration trips being less than one mile long, it is clear that the amount of time spent at low fuel cell power is due in part to a large number of short trips for which the vehicle is not likely accelerated to higher speeds. This differs from the national driving statistics, which show that only about $10 \%$ of the trips are less than one mile long. If a large number of starts/hour is one of the major degradation factors, as has been reported at the laboratory scale, then this large number of short driving trips could be prematurely shortening the life of the Learning Demonstration fuel cells. Further investigation is necessary before that linkage can be made based on our analysis of the real-world data.

- The Impact of Short Trips: Recently there has been much public attention on the potential for plug-in hybrid-electric vehicles (PHEVs) to improve the United States' oildependency situation without waiting for fuel cell vehicles to be commercialized. The Learning Demonstration vehicle data were evaluated to see how these early fuel cell vehicles were being used (mostly in fleet operation) and what impact these duty cycles would have on plug-in vehicles and potentially future plug-in versions of these fuel cell vehicles. We first looked at the amount of energy consumed by all Learning 
Demonstration vehicle trips (Figure 9) and found that almost $40 \%$ of the trips required less than $0.5 \mathrm{kWh}$ of energy to be produced by the fuel cell system. This indicates that a battery would not have to be very large to handle several plug-in FCV trips for the Learning Demonstration vehicles, provided that the battery could also provide the peak power required and survive the larger swings in state-of-charge. However, this is not the entire story, and if the assumption is that PHEVs will primarily be recharged slowly during off-peak/night times, then these data need to be analyzed with both the daily miles traveled (Figure 10) and the amount of time between trips (Figure 11) in mind.

What we find is that an effective 20 -mile electric range would electrify about $1 / 2$ of the Learning Demonstration fleet's daily miles traveled. However, this would satisfy only about $1 / 4$ of the national daily average miles traveled. While the large number of Learning Demonstration vehicle "hot-starts" could be beneficial for fuel efficiency (about $60 \%$ of trips occur within one hour of the previous trip) this also indicates that not all of the short trips could necessarily be electrified because there may not be sufficient time to recharge the battery from the grid in between trips, even if day-time opportunity charging is used. The bottom-line is that a thorough analysis of actual target-market duty cycles must occur for the benefits of PHEVs to be understood, preferably through using actual PHEV fleets and recharging behavior. Such an evaluation is envisioned through DOE's current solicitation for a PHEV Learning Demonstration (see Web site for details: http://www.netl.doe.gov/business/solicitations/\#00360).

- Vehicle Fuel Economy: Vehicle fuel economy was measured using city and highway drive-cycle tests (Figure 12) on a chassis dynamometer using draft SAE J2572 (left blue bar, representing the range of four points, one from each original equipment manufacturer $[\mathrm{OEM}])$. These raw test results were then adjusted according to U.S. Environmental Protection Agency (EPA) methods to create the "window-sticker" fuel economy that consumers see when purchasing the vehicles $(0.78 \mathrm{x}$ Hwy, $0.9 \mathrm{x}$ City) (center blue bar). This resulted in an adjusted fuel-economy range of 42 to $56.5 \mathrm{miles} / \mathrm{kg}$ hydrogen for the four teams. As with all vehicles sold today, including gasoline hybrids, actual on-road fuel economy is slightly lower than this rated fuel economy (right blue bar). The on-road fuel economy spans the range of $30 \mathrm{miles} / \mathrm{kg}$ hydrogen to about $45 \mathrm{miles} / \mathrm{kg}$ hydrogen. Note that the EPA has adjusted its testing and reporting methodology beginning with model-year 2008 vehicles to try to make the window-sticker fuel economy better reflect on-road driving performance, but this project is using the EPA adjustment that was in place when the vehicles were introduced.

- Vehicle Driving Range: Vehicle driving range was calculated using the fuel economy results discussed above and multiplying them by the usable hydrogen stored onboard each vehicle (Figure 13). Using the EPA-adjusted fuel economy resulted in a range from just over 100 miles up to 190 miles from the four teams. The second-generation vehicles will strive to push this range up to 250 miles to reach the 2009 DOE target. Note that two other CDPs relating to range were also generated. Figure 14 shows a histogram of the distance vehicles actually traveled between fuelings as a percentage of each vehicle's dynamometer range. This shows that the majority of the vehicles $(75 \%)$ travel less than $50 \%$ of the dynamometer range between fuelings. This is due to several factors, but the dominant ones are limited hydrogen infrastructure, fear of running out of fuel, and actual on-road fuel economy being lower than the dynamometer fuel economy, as has already 
been discussed. Figure 15 shows the on-road range of the four teams (green bar) as a percentage of their dynamometer range. The spread of this on-road range has decreased significantly in the last year, indicating that the vehicles' on-road fuel economy as a percentage of their dynamometer fuel economy ( $\sim 63 \%-73 \%)$ is similar across all four teams. There is a good potential for a greater range from the second-generation vehicles due to higher hydrogen storage pressure (700 bar) and more vehicles that may be designed with storage system limitations (packaging, in particular) in mind.

- On-Board Hydrogen Energy Storage System Status: In the last six months, additional hydrogen storage data have been reported to NREL using a more detailed hydrogen storage system breakdown spreadsheet. This spreadsheet includes the breakdown of the mass and volume due to the hydrogen itself, the pressure vessel, and the balance-of-plant. The balance-of-plant category includes:

○ Controls and measurement (hydrogen storage-specific electronics)

- Fuel delivery to powerplant (plumbing)

○ Hazard mitigation components (hydrogen sensors, pressure release devices (PRD), venting)

- Fueling equipment (filters, nozzle receptacle, piping, communications, grounding)

○ Mounting brackets, auxiliary equipment (thermal management, etc.).

While previous published results only included first-generation vehicle data, the recent detailed data were supplied for both first- and second-generation hydrogen storage systems. Figure 16 shows the difference in the ranges of mass (as a percentage of the total mass) stored in the teams' 350 bar and 700 bar systems. We can see the potential for the percentage of system mass to increase in the second-generation systems, but we need to realize that the second-generation ( 700 bar) systems also typically have the benefit of economies of scale because they will have a larger total mass of hydrogen stored to meet the 250-mile range target.

Figure 17 shows the same type of 350 bar vs. 700 bar comparison but for the volumetric capacity (how much hydrogen can be stored per storage system volume). This is where the advantage of going to a higher pressure really shines, showing the potential for a significant increase in the mass of hydrogen stored per liter, making the packaging of the system on a vehicle more attractive. Finally, the percentage breakdown by each of these categories was averaged across the four teams so that pie-charts of the differences between 350 bar and 700 bar could be examined for the mass and volumetric characteristics (Figure 18). The comparison shows that while the average hydrogen weight percentages are similar for 350 and 700 bar, and the pressure vessel and balanceof-plant for 700 bar take up a larger percentage of the system volume, the 700 bar systems allow for a more compact package and extended range. Figure 19 shows the tank cycle life, which may be updated in the future if data can be obtained for this metric for second-generation systems at 700 bar.

- Fuel Cell Durability: Fuel cell stacks will need roughly a 5,000 hour life to enter the market for light-duty vehicles. For this demonstration project, targets were set by DOE at 1,000 hours in 2006 and 2,000 hours in 2009. Results were first published in the fall of 2006. These results were relatively preliminary because most stacks at that time only had a few hundred hours of operation or less accumulated on-road. Since DOE's target for 
2006 was 1,000 hours, NREL developed a methodology for projecting the gradual degradation of the voltage based on the data received to date. This involved creating periodic fuel cell polarization curve fits from the on-road stack voltage and current data, and calculating the voltage under high current. This enabled us to track the gradual degradation of the stacks with time and do a linear fit through each team's data. We then compared these results to the first-generation target of 1,000 hours for 2006.

In the past year and a half, many more hours have been accumulated on the fuel cell stacks, and the range of fleet averages is $\sim 200$ to 700 hours, with the range of fleet maximums spanning $\sim 300$ to 1,200 hours (Figure 20). This is the first time, to our knowledge, that a light-duty passenger fuel cell car has accumulated more than 1,000 hours in real-world operation without repair, which is a significant project accomplishment. Therefore, the amount of extrapolation we have to make using the slope of the linear voltage degradation method $(10 \%$ voltage drop target divided by the $\mathrm{mV}$ /hour slope), continues to decrease. However, with the additional data we have received, we are also finding that the accuracy of the $10 \%$ voltage degradation target could be improved by using a non-linear fit to account for the more rapid degradation that occurs within the first few hundred hours. It appears as though the current linear fit may be overestimating the time to a $10 \%$ voltage drop for the stacks that have a significant number of accumulated hours, and we will be pursuing a non-linear or two-step linear fit to improve the accuracy in the future.

The projected times to $10 \%$ fuel cell stack voltage degradation from the four teams using the linear technique had an average of more than 1,200 hours with a high projection of more than 1,900 hours from one team, surpassing the 1,000-hour DOE target. Note that the $10 \%$ criterion, which is used for assessing progress toward DOE targets, may differ from the OEM's end-of-life criterion and does not address "catastrophic" failures such as membrane failure. The second-generation stacks introduced in this project beginning in late 2007 will be compared to the 2,000-hour target for 2009 .

- Factors Affecting Fuel Cell Durability: We have continued the multivariate analysis that was initiated in 2007 to determine the dominant factors that are affecting the rates of degradation. We started out by creating a database of all of the Learning Demonstration stacks and various performance attributes. Each individual stack was examined for the hours of data accumulated to date and the confidence in the fit of the degradation slope. We then manually removed about one-third of the stacks from the degradation factors analysis to try to have as clean a data set as possible for the analysis. The database now includes the following key factors for each stack:

- Average voltage degradation rate (key dependent variable)

- Ambient temperature

- Time at various voltages

- Time at various currents

- Number of cold and hot starts (based on time between trips)

O Idle time

- Trip length

- Average number of stack starts/hour. 
After trying many techniques, we focused on partial least squares regression (PLS) analysis because it was the most direct way of measuring how much of the variance in voltage degradation could be explained by specific groups of factors. We first performed the PLS on the stack data from all four teams to see if there were any overall trends that covered all of the technology involved (Figure 21). The trends across all four teams were not strong, which we soon discovered was because the trends among the companies were often different.

Next we looked at each team's data individually and performed the same PLS analysis (Figure 22). The connection between voltage degradation rate and the variables improved, and we were able to pull out groupings of factors that appeared to cause either higher or lower than average decay rates within each team. Note that the teams' PLS models have a high percentage of explained decay rate variance, but the models are not very robust and results are scattered. We found that while there were some common factors among several team's results, there were also normally contradictory trends from one of the teams (an example of this conflicting trend is for high voltage time and low current time for team four vs. team two). This analysis effort is continuing in close collaboration with each of our industry partners. NREL will work closely with each team to carefully examine the inputs and outputs from this analysis and see if there are valuable lessons that can be fed back into the companies' research as well as into DOE's R\&D program.

- Time of Day Vehicles Are Driven: Some questions have arisen about whether the Learning Demonstration vehicles are being used like conventional vehicles, or whether their usage is being too "controlled" to match typical driving behavior. To investigate this we looked at the time of day people initiated their trips and which day of the week the trips were occurring on. Figure 23 shows a clock-face radial histogram, with the green data representing the time of day when people initiated their trips. Overlaid on top of that we have placed pink diamonds to show the national statistics based on the 2001 National Household Travel Survey (NHTS) data. What we find is that the Learning Demonstration vehicles are driven at similar times of day to the national statistics, with the exception of the late afternoon between 4 and 6 p.m. when the average person (nationally) is likely either picking up kids from school, driving home from work, or running errands. Since the first-generation Learning Demonstration vehicles are primarily used for professional or fleet activities, it is not surprising that there would be a difference. The percentage of trips taken between $6 \mathrm{a} . \mathrm{m}$. and 6 p.m. corresponds relatively closely to the national statistics $(88.7 \%$ vs. $81.5 \%)$. The nighttime driving behavior trend is also similar to the national statistics (Figure 24), although there are overall more evening trips driven nationally than within the Learning Demonstration.

- Day of Week Vehicles Are Driven: We examined the days of the week that people drove the Learning Demonstration FCVs and compared this with the national statistics. Figure 25 shows a bar for each day of the week, beginning with Sunday, and overlays a diamond symbol for the national statistics. We can easily see that nationally the trips are relatively uniform on weekdays, with a slight dip on the weekends, but that the Learning Demonstration vehicles are rarely driven on the weekends. Additionally, Learning Demonstration vehicles have significantly more trips Tuesday through Thursday as compared to Monday and Friday, which does not reflect typical national behavior. While 
the day of the week doesn't matter to the car's performance, it might be an indication that some of the weekend types of trips (for example: long trips to mountains or lots of short trips to the hardware store) are not being captured in the first-generation vehicle duty cycles.

- Vehicle Safety: The Learning Demonstration has had a very strong safety record to date. Figure 26 shows the latest number and type of vehicle safety reports by quarter. In the last six months there have been two safety report additions: one traffic accident and two hydrogen tanks that were removed from service due to minor scratches noted during inspection. In the case of the traffic accident, there was no hydrogen release and only minor injuries due to the two-vehicle impact (not hydrogen related). In the case of the two tanks that were removed for service, the team determined that the tanks had been scratched during service of a nearby system and that the scratches could be easily repaired without affecting the safety of the tanks.

- Other Vehicle Metrics: There are several other vehicle-related CDPs that will be briefly mentioned here. Figure 27 shows the range of ambient temperature during vehicle operation spanning from $1{ }^{\circ} \mathrm{F}-123^{\circ} \mathrm{F}$, with no change from what has previously been reported. Fuel cell vehicles are currently able to operate in extreme temperature conditions, and second-generation vehicle tests will determine their ability to also start from sub-freezing temperatures. Figure 28 shows the distribution of vehicle operating hours, showing a total of over 50,000 hours with a median of about 600 hours. The introduction of second-generation vehicles has introduced a second bulge on the left side of the histogram at low vehicle operating hours. Similarly, with vehicle miles traveled (shown in Figure 29), the peak number of vehicles occurs at 10,500-14,000 miles. The fleet has now accumulated over 1.1 million miles. Figure 30 shows that after the first few quarters, mileage accumulation has been relatively linear. The rate of mileage accumulation should rise with the introduction of the second-generation vehicles. Figure 31 tracks the total number of Learning Demonstration vehicles deployed by quarter and the on-board hydrogen storage systems that they use. Figure 31 also shows many of the second-generation deployments with 700 bar tanks. 


\subsection{Infrastructure Results}

- Hydrogen Quality: Hydrogen quality was determined by measuring the impurities and calculating the hydrogen fuel quality index as a percentage. SAE J2719 has established a $99.99 \%$ hydrogen fuel quality index target. The hydrogen fuel quality index from all the stations sampled ranged from $99.73 \%$ to $99.999 \%$, as shown in Figure 32. The values on the lower end were due to some high detection limits on inert gases, and likely do not really represent hydrogen fuel quality that low. This result has not changed significantly in the last six months with most of the new data coming in very close to the $99.99 \%$ target.

- Hydrogen Impurities: More important than the absolute hydrogen fuel quality index is the actual level of impurities by constituent. Impurities evaluated include particulates, inert gases $\left(\mathrm{N}_{2}+\mathrm{H}_{2}+\mathrm{Ar}\right), \mathrm{NH}_{3}, \mathrm{CO}, \mathrm{CO}_{2}, \mathrm{O}_{2}$, total $\mathrm{HC}, \mathrm{H}_{2} \mathrm{O}$, and total sulfur, and are shown in Figure 33. One key finding was that reported values are, in general, close to the SAE J2719 target values. As previously reported, all but one sulfur data point are at the detection limits of the hardware used. While the target for sulfur is 4 parts per billion (ppb), results ranged from 1-70 ppb. Therefore, either new cost-effective techniques to get real measurements at such low concentrations should be developed, or the target should be raised to something that can effectively be measured with confidence.

- $\mathrm{H}_{2}$ Infrastructure Maintenance: An evaluation of all of the maintenance required on refueling station equipment found that roughly $1 / 2$ of all labor hours were unplanned, accounting for $60 \%$ of the maintenance events (Figure 34). With the large volume of infrastructure maintenance items over the past three years, there is no significant shift between the planned and unplanned maintenance events.

- Infrastructure Safety: With respect to hydrogen refueling infrastructure, there has been one new report that was classified as an incident (making for a total of two over the entire project). This new report involved a hydrogen compressor that shut down due to excessive vibration. Upon inspection technicians discovered that some of the bolts on the compressor had fallen out, which could have caused a serious problem later if it had not been discovered. At a less severe level (see Figure 35), there were 23 events categorized as near-misses and over 100 non-events (over 70 were alarms-only). All but five of the near-misses involved a minor release of hydrogen with no ignition.

Figure 36 shows that no single primary factor led to the majority of infrastructure safety reports, but over 30 of them were due to calibration/settings or software controls. Figure 37 shows that the number of refuelings normalized by the number of safety reports per quarter had improved by a factor of 10 (higher is better) since the beginning of the project, but then dipped down to $60-80$ as new stations came online. It has since gone back up to around 100 refuelings/report; however no new stations have come online in the last nine months. Figure 38 also shows the apparent correlation between new stations coming online and a higher number of safety reports. On most of the safety CDPs we have now added the DOE definition of incident and near-miss that are being used for this project to remove any questions about what they mean.

- Vehicle Refueling Rates: Hydrogen vehicle refueling needs to be as similar as possible to conventional vehicle refueling to allow an easier commercial market introduction. Over 8,700 refueling events have been analyzed to date, and the refueling amount, time, and 
rate have been quantified. The average time to refuel was 3.43 minutes with $87 \%$ of the refueling events taking less than 5 minutes (Figure 39). The average amount per fill was $2.25 \mathrm{~kg}$, reflecting both the limited storage capacity of these vehicles ( $\sim 4 \mathrm{~kg}$ max) and peoples' comfort level with letting the fuel gauge get close to empty (see Figure 40 for the shape of the distributions), which will be shown in a separate analysis. DOE's target refueling rate is $1 \mathrm{~kg} /$ minute, and these Learning Demonstration results indicate an average of $0.79 \mathrm{~kg} / \mathrm{min}$, with $24 \%$ of the refueling events exceeding $1 \mathrm{~kg} /$ minute (Figure 41). Therefore, we can conclude that high-pressure gases are approaching adequate refueling times and rates for consumers; however, the challenge is still in packaging enough high-pressure hydrogen onboard to provide adequate range, or finding alternate advanced hydrogen storage materials that can replace the need for high-pressure tanks.

- Communication vs. Non-Communication Fills: The previous refueling histograms included all types of refueling events. There has been much interest from industry and from the codes and standards community about the potential for communication fills to occur at a higher rate and with a more complete fill. A communication fill means that the vehicle communicates data about the state of its hydrogen storage tank(s) to the refueling station, such as tank temperature, pressure, and max pressure rating. Figure 42 shows two curves: the red curve is a spline fit to the histogram for non-communication fills while the blue curve represents the communication fills. The center part of the graph shows a similar rate of fill for the communication and non-communication fills, however the communication fills are capable of having a higher fill rate (up to around $1.7 \mathrm{~kg} / \mathrm{min}$ ). There is also a group of vehicle/station combinations still doing non-communication fills at the slower rate of $\sim 0.2 \mathrm{~kg} / \mathrm{min}$ on the left portion of the graph. This rate of fill was established many years ago in California to provide a conservative and safe approach for refueling vehicles before much real-world experience had been gained. Figure 43, which shows the fill rates by year, indicates that this slower refueling rate was heavily used in 2006 but has been almost completely phased out in 2007 . With these differences in distribution in mind, the average fill rate for all communication fills is $0.94 \mathrm{~kg} / \mathrm{min}$ vs. $0.66 \mathrm{~kg} / \mathrm{min}$ for non-communication fills, with $36 \%$ and $20 \%$, respectively, exceeding DOE's $1 \mathrm{~kg} / \mathrm{min}$ target.

- Level in Fuel Tank When People Refuel: As previously mentioned, with limited hydrogen refueling infrastructure and limited on-board hydrogen storage, some drivers do not like to let the tank get close to empty to minimize the risk of running out of fuel. To investigate this further, NREL used the data submitted in a new and unique way, which was to look at what the fuel level in the tank was just prior to each refueling event. In some cases these data came from on-board data based on the pressure in the tank, and in other cases they came from refueling logs where each fill was assumed to be to the "full" level, allowing a subtraction of the amount fueled to determine the initial tank level.

Figure 44 shows the results from this analysis, where a histogram has been placed radially on an image of a fuel gauge to make interpreting the graph as intuitive as possible. The level at which people most commonly refuel the Learning Demonstration vehicles is at just over $1 / 4$ full; this covers $15 \%$ of the refuelings. While some drivers are letting the tank get even lower than that, few let it get close to being empty. Additionally, we have placed a green needle on the chart which indicates the median tank level at fill ( $1 / 2$ above, $1 / 2$ below), which is a little above $3 / 8$ of a tank ( $40 \%$ of full). Figure 45 shows 
the collection of medians for each of the 92 vehicles in the Learning Demonstration fleet to show that there is a large spread in when individuals choose to refuel their vehicles, with several vehicles being refueled more than half of the time with greater than a halffull tank, but the majority being refueled between $1 / 4$ and $1 / 2$ full. In the future, we would like to compare these data results to data from conventional liquid fueled vehicles, if they exist, to see if people are refueling their fuel cell vehicles differently than their conventional vehicles.

- Time of Day When People Refuel: We also looked at the time of day people refueled in order to understand the usage patterns at the hydrogen refueling stations and better allow new stations to understand the potential demand by time of day. For traditional liquid fuels, with big tanker truck deliveries periodically, the time of day people refuel does not normally matter. Instead, the station operator must simply ensure that the next tanker comes before he runs out of fuel. For today's hydrogen fuel stations, with very limited storage capacity and some sites producing hydrogen throughout the day, it is important to know the time of day that people refuel in order to match the supply (on-site production) with the demand.

Figure 46 shows a radial histogram of the time of day Learning Demonstration vehicles were refueled between 6 a.m. and 6 p.m., with Figure 47 showing the time between 6 p.m. and 6 a.m. We found that $86 \%$ of the fills occurred between 6 a.m. and 6 p.m., with $14 \%$ being done at night. The distribution is relatively uniform with steady usage between 8 a.m. and 4 p.m., and a mild peak at lunchtime (9\%). The conclusion from this analysis is that with a uniform distribution of when people refuel during the day, a station that has on-site production can either be sized to meet that demand during the day and then essentially shut off at night, or it can be sized (smaller) for the average over a 24hour period, have a larger on-site hydrogen storage buffer, and run continuously. Finally, we looked at what day of the week people were refueling (Figure 48) and found that the Learning Demonstration vehicles are primarily refueled Monday through Friday, with very few vehicles refueled on the weekend. This is consistent with the days of the week that people are driving the vehicles most and when the hydrogen stations that have attendants are open.

- Other Infrastructure Metrics: The amount of hydrogen produced or dispensed has also been tracked by quarter (blue diamonds) with the number of stations shown on the same graph (green squares) in Figure 49. Note that the amount of hydrogen produced is not the same as the amount dispensed because the project includes a power park where the unused hydrogen can be converted back into grid electricity during peak utility load periods in the afternoon (due to higher air-conditioning loads) using on-site fuel cells. As discussed in Figure 2, there are four major types of hydrogen refueling stations being demonstrated (shown in Figure 50) and the rate of introduction of these stations is shown in Figure 51. 


\subsection{Conclusions and Future Directions}

NREL has now analyzed data from almost three years of the five-year Learning Demonstration project with 92 vehicles deployed, 14 project refueling stations in use, and no fundamental safety issues identified. We have analyzed data from over 200,000 individual vehicle trips covering $1,100,000$ miles traveled and over 40,000 kg hydrogen produced or dispensed. With additional hours of operation accumulated on the stacks, the range of fleet average hours accumulated is now $\sim 200$ to 700 hours, with the range of fleet maximums spanning 300 to 1,200 hours. This is the first time, to our knowledge, that a light-duty passenger fuel cell car has accumulated more than 1,000 hours in real-world operation without repair, which is a significant project accomplishment. The four-team average projected time to a $10 \%$ voltage degradation is 1,200 hours. In the next six months NREL will improve the accuracy of its projections by adding a non-linear fit (or a two-step linear fit) to avoid overestimating the projected time as the accumulated hours continues to grow.

To understand what is causing the stacks to gradually degrade, NREL continues to characterize how each stack is used and perform multivariate analysis on this dataset to examine dominant variables affecting stack voltage degradation rates. Results to date indicate that trends across all four teams are probably not possible to extract due to differences among the teams, but that individual results may be useful to the teams individually and for feeding trends back into the R\&D program. We've analyzed fuel cell system efficiency at 1/4-power and compared it to the DOE target of $60 \%$; system efficiency results from the four teams ranged from $52.5 \%$ to $58.1 \%$. Using data on communication vs. non-communication fills we found that communication fills demonstrated a higher rate of fill than non-communication; the slowest of the noncommunication fill rates are being phased out. We also examined refueling and driving behavior, and found the Learning Demonstration fleet to be representative of national statistics with the exception of fewer late afternoon and weekend trips, an abundance of short trips, and a shorter average distance traveled per day. Finally, we've now published a total of 47 CDPs and made them directly accessible to the public through our Hydrogen Technology Validation Web site (http://www.nrel.gov/hydrogen/proj_learning_demo.html).

In the future, we will further explore the correlations of real-world factors influencing fuel cell degradation and strive to separate their interwoven dependencies. We will semi-annually (spring/fall) compare technical progress to program objectives and targets and provide results to the public by participating in technical conferences and writing reports such as this one. Specifically, we will create new and updated CDPs based on data through June 2008, and prepare those new results for publication at the Fuel Cell Seminar as the "Fall 2008" results. For the second-generation vehicles introduced this year, we will begin evaluating improvements in fuel cell durability, range, fuel economy, and safety, and publish results when there are sufficient second-generation vehicles to mask the companies' identities. As an important part of the project, we will identify opportunities to feed project findings back into HFCIT Program R\&D activities to maintain the project as a "learning demonstration." 


\subsection{Recent Publications/Presentations from 2007/2008}

1. Wipke, K., Sprik, S., Kurtz, J., "Composite Data Products for the Controlled Hydrogen Fleet and Infrastructure Demonstration and Validation Project," Golden, CO: National Renewable Energy Laboratory, updated February 2008. (presentation, online at http://www.nrel.gov/hydrogen/cdp topic.html).

2. Wipke, K., "Hydrogen Secure Data Center: Procedures to Protect Technical Data Submitted under the Controlled Hydrogen Fleet and Infrastructure Demonstration and Validation Project," Golden, CO: National Renewable Energy Laboratory, updated December 2007. (HSDC document)

3. Wipke, K., Sprik, S., Kurtz, J., Thomas, H., "FCV Learning Demonstration: Project Midpoint Status and Fall 2007 Results," EVS-23 Conference, Anaheim, CA, December 2007. (paper and presentation)

4. Kurtz, J., Wipke, K., Sprik, S., "FCV Learning Demonstration: Factors Affecting Fuel Cell Degradation," Fuel Cell Durability \& Performance, Miami, Florida, November 2007. (presentation).

5. Wipke, K., Sprik, S., Kurtz, J., Thomas, H., Garbak, J., "FCV Learning Demonstration: Project Midpoint Status and First-Generation Vehicle Results," ZERO REGIO Conference, Montecatini Terme, Italy, November 2007. (presentation)

6. Wipke, K., Sprik, S., Thomas, H., Welch, C., Kurtz, J., "Controlled Hydrogen Fleet and Infrastructure Analysis Project," 2007 DOE HFCIT Program Annual Progress Report, System Analysis Section VI.D.1, November 2007. (paper)

7. Wipke, K., presentation of Learning Demonstration results to FreedomCAR and Fuels Delivery Tech Team, November, 2007. (presentation)

8. Wipke, K., Sprik, S., Kurtz, J., Thomas, H., Garbak, J., "FCV Learning Demonstration: First-Generation Vehicle Results and Factors Affecting Fuel Cell Degradation," Fuel Cell Seminar, San Antonio, TX, October 2007. (presentation and extended abstract).

9. Wipke, K., Sprik, S., Kurtz, J., Thomas, H., Garbak, J., "Fuel Cell Vehicle and Infrastructure Learning Demonstration: Activities in California," H2 Infrastructure Forum Between National \& Local Governments and Industry, hosted by USFCC, Washington, DC, October 2007. (presentation)

10. Wipke, K., Sprik, S., Kurtz, J., Thomas, H., "Learning Demonstration Progress Report September 2007," National Renewable Energy Laboratory Technical Report NREL/TP-56042264, October 2007. (paper)

11. Wipke, K., presentation of Learning Demonstration results to Vehicle Technologies Program at DOE, October 2007. (presentation)

12. Wipke, K., presentation of Learning Demonstration results to FreedomCAR and Fuels Hydrogen Storage Tech Team, October, 2007. (presentation) 
13. Wipke, K., presentation of Learning Demonstration results to HFCIT Program at DOE, October 2007. (presentation)

14. Wipke, K., Sprik, S., Thomas, H., Welch, C., Kurtz, J., "Learning Demonstration Interim Progress Report - Summer 2007," National Renewable Energy Laboratory Technical Report NREL/TP-560-41848, July 2007. (paper)

15. Wipke, K., Welch, C., Thomas, H., Sprik, S., "Controlled Hydrogen Fleet and Infrastructure Analysis," 2007 DOE Annual Merit Review Meeting, Washington, DC, May 2007. (presentation)

16. Wipke, K., presentation on Learning Demonstration project to National Academy of Sciences, Washington, DC, April 2007. (presentation)

17. Wipke, K., Welch, C., Thomas, H., Sprik, S., Kurtz., J., "DOE's Controlled Hydrogen Fleet and Infrastructure Demonstration and Validation Project: Quarterly Validation Assessment Reports," (HSDC papers only)

- 4Q 2006, March 2007.

- 1Q 2007, June 2007.

- 2Q 2007, September 2007.

18. Wipke, K., Welch, C., Thomas, H., Sprik, S., Gronich, S., Garbak, J., Hooker, D., "Fuel Cell Vehicle Learning Demonstration: Spring 2007 Results," NHA Annual Hydrogen Meeting and Exposition, San Antonio, TX, March 2007. (presentation)

19. Wipke, K., presentation of Learning Demonstration results to California Hydrogen Business Council Meeting, January, 2007. (presentation)

\subsection{Acronyms}

CDP

DOE

FAT

FCV

FY

gge

$\mathrm{H}_{2}$

HFCIT

HSDC

MYPP

NHA

NREL

PLS

$R \& D$ composite data product

U.S. Department of Energy

Fleet Analysis Toolkit (software tool developed at NREL)

fuel cell vehicle

fiscal year

gallon of gasoline equivalent

hydrogen

Hydrogen, Fuel Cells \& Infrastructure Technologies (DOE program)

Hydrogen Secure Data Center (at NREL)

Multi-Year Program Plan (DOE document)

National Hydrogen Association

National Renewable Energy Laboratory

partial least squares

research and development 


\subsection{Composite Data Products Referenced in Previous Discussion}

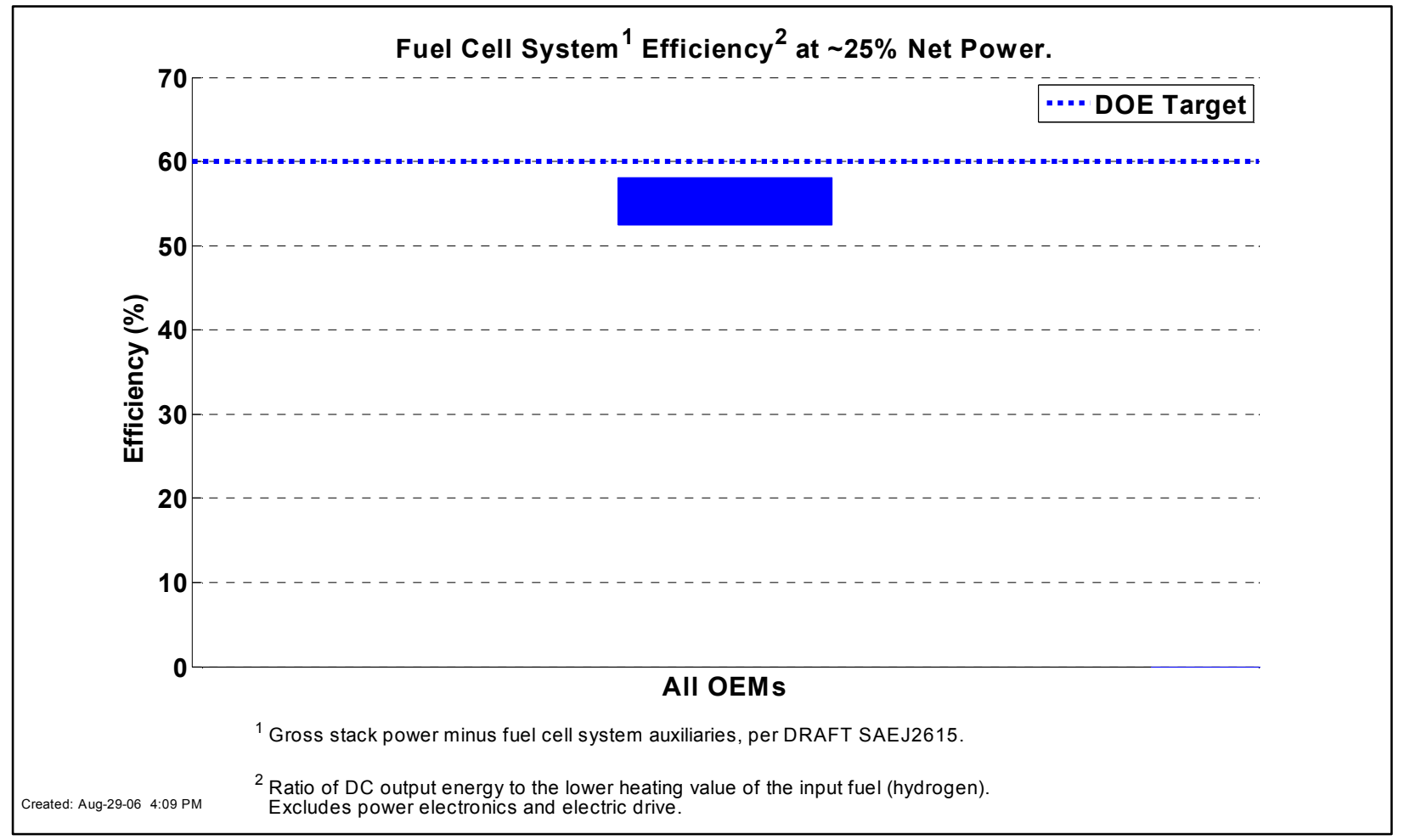

Figure 5: Fuel Cell System Efficiency at $\sim 25 \%$ Net Power (CDP8)

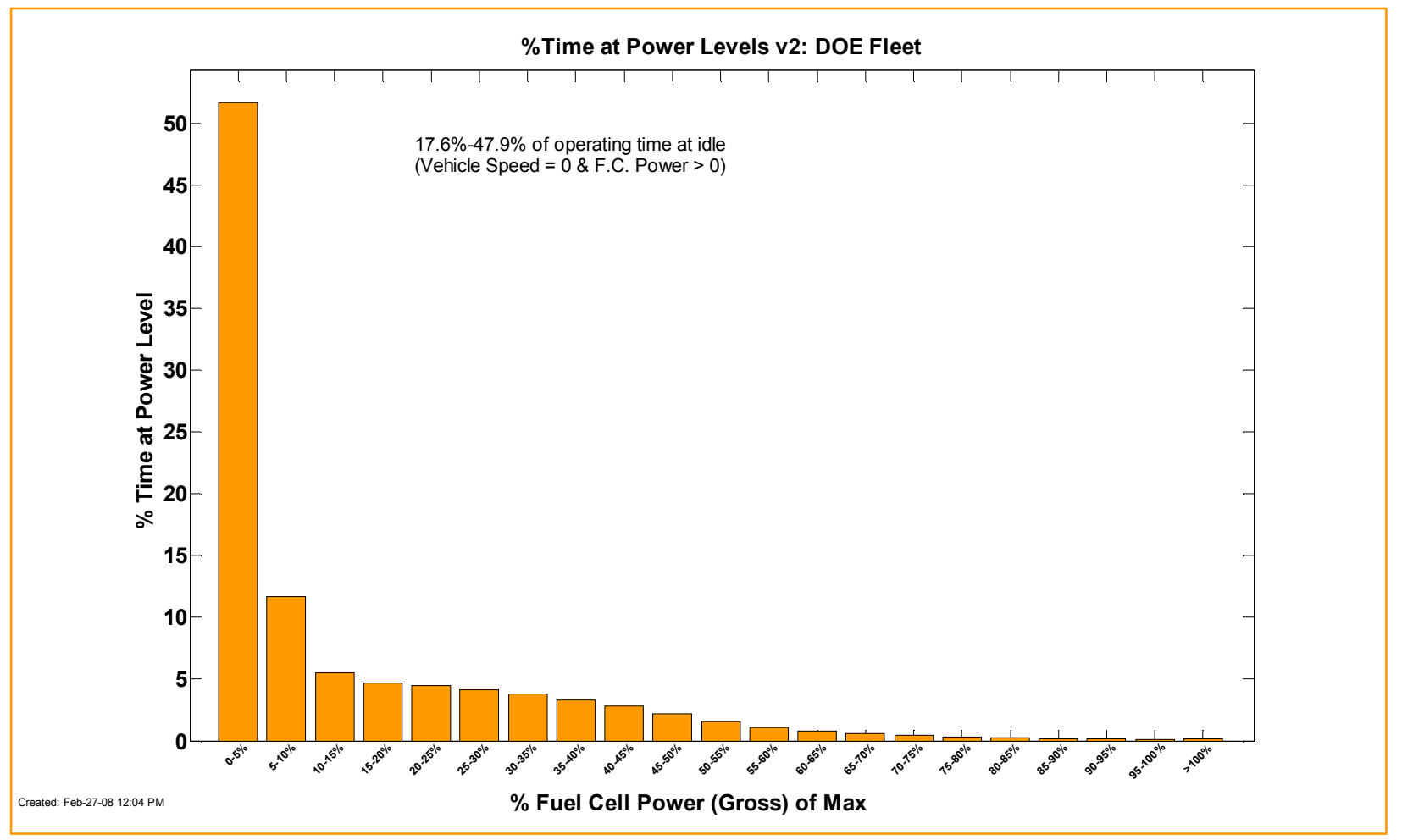

Figure 6: Histogram of Time Spent At FC Power Levels (CDP46) 


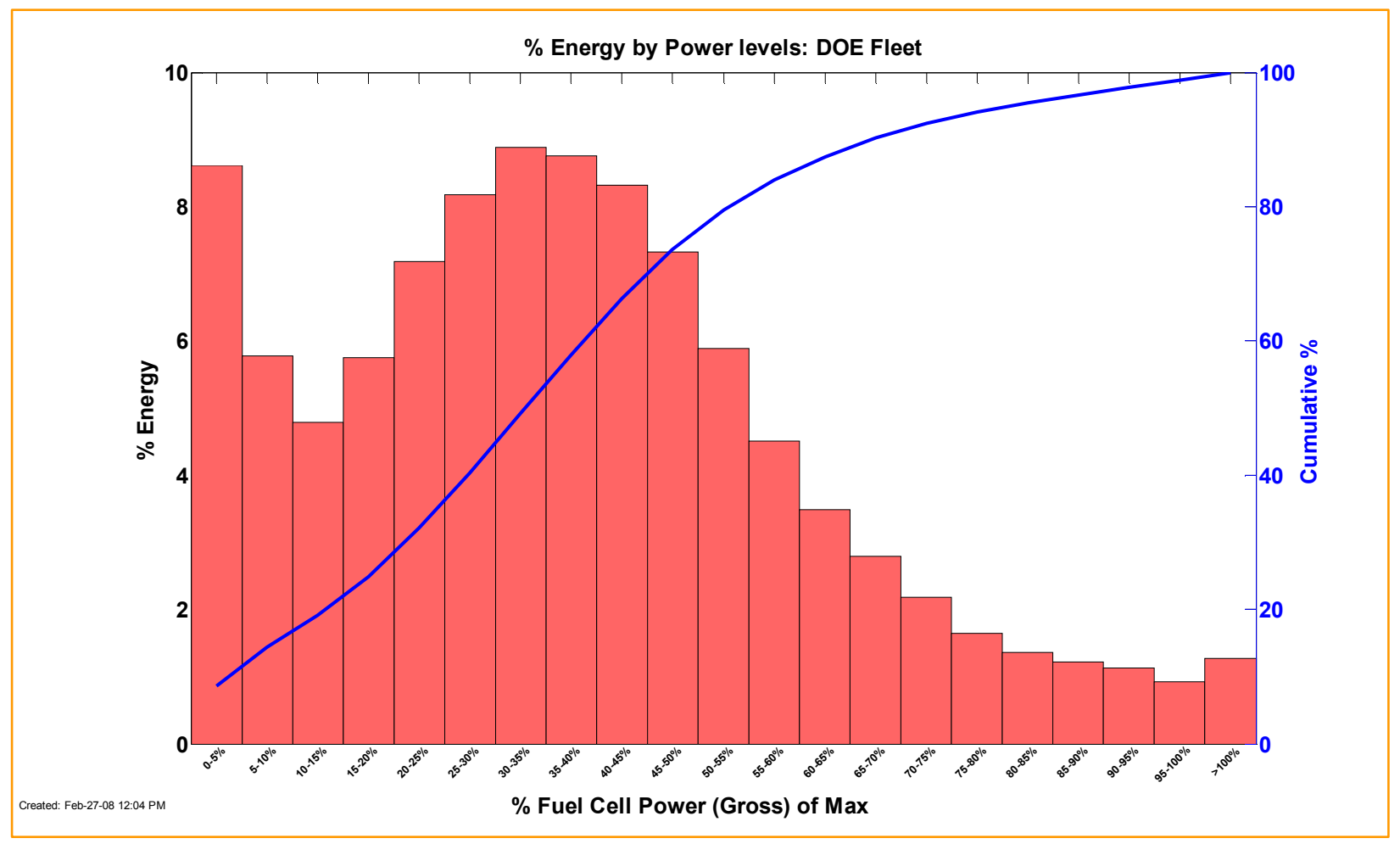

Figure 7: Fuel Cell System Energy within Power Levels (CDP53)

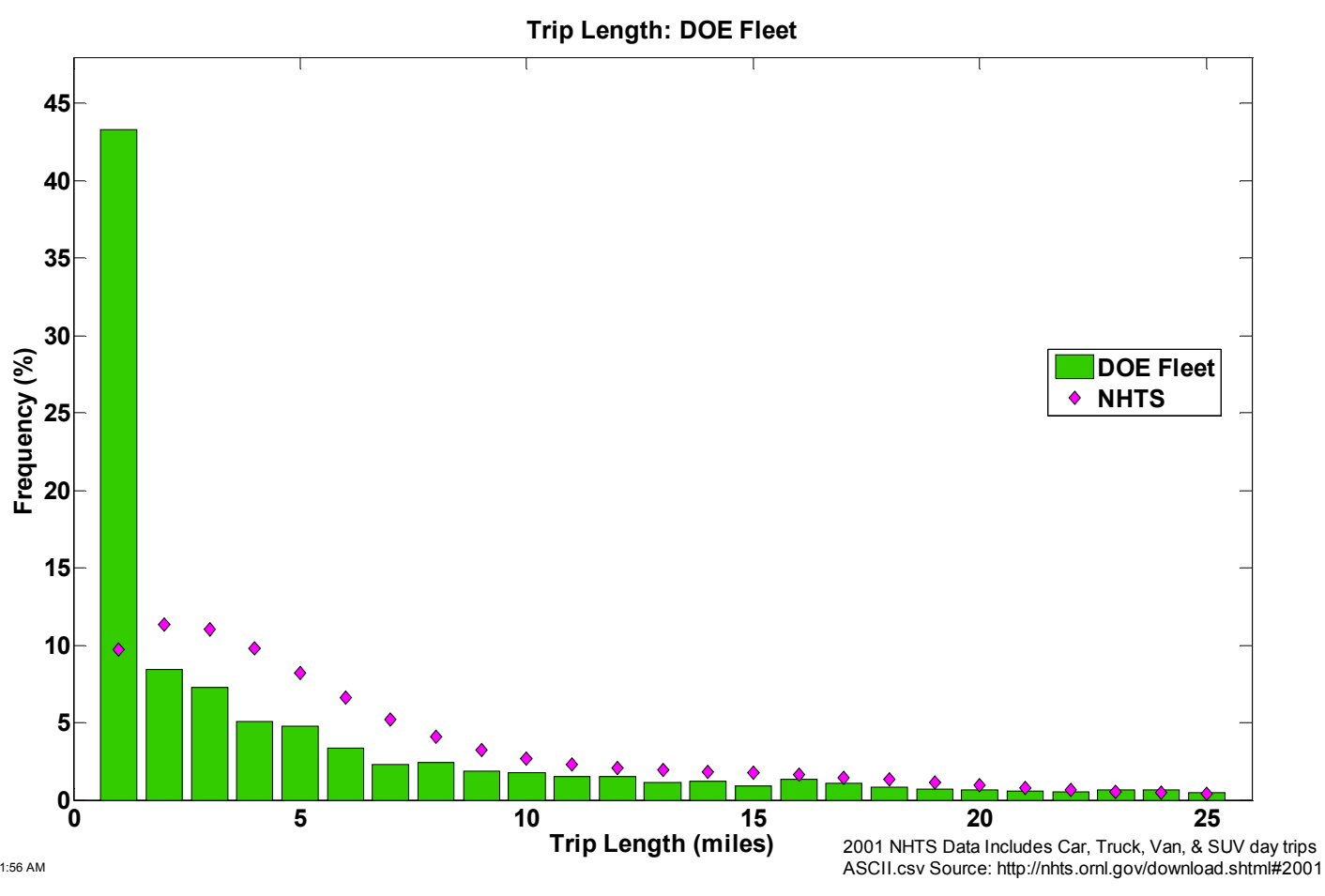

Figure 8: Trip Length (CDP47) 


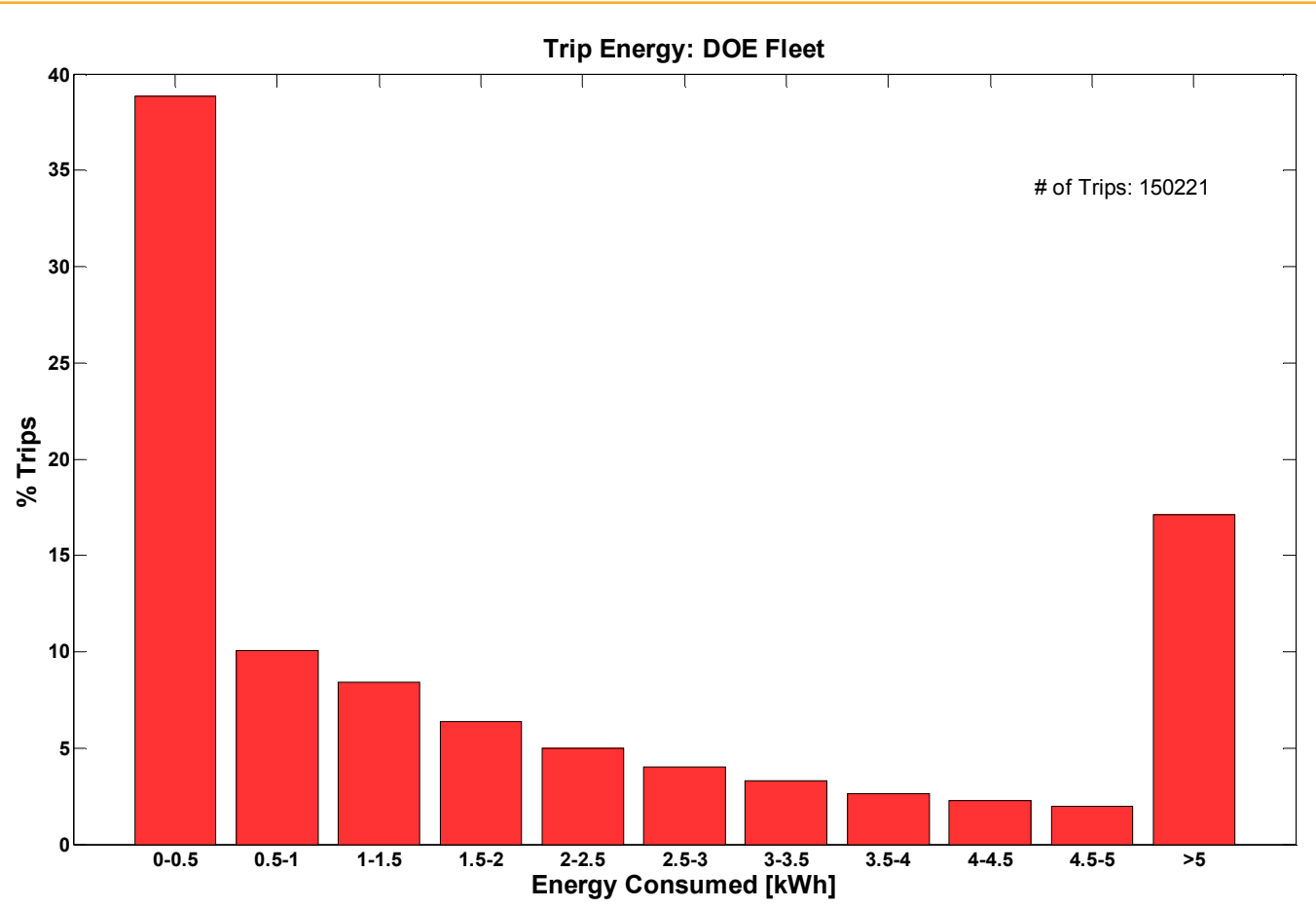

Figure 9: Fuel Cell System Energy by Trip (CDP55)

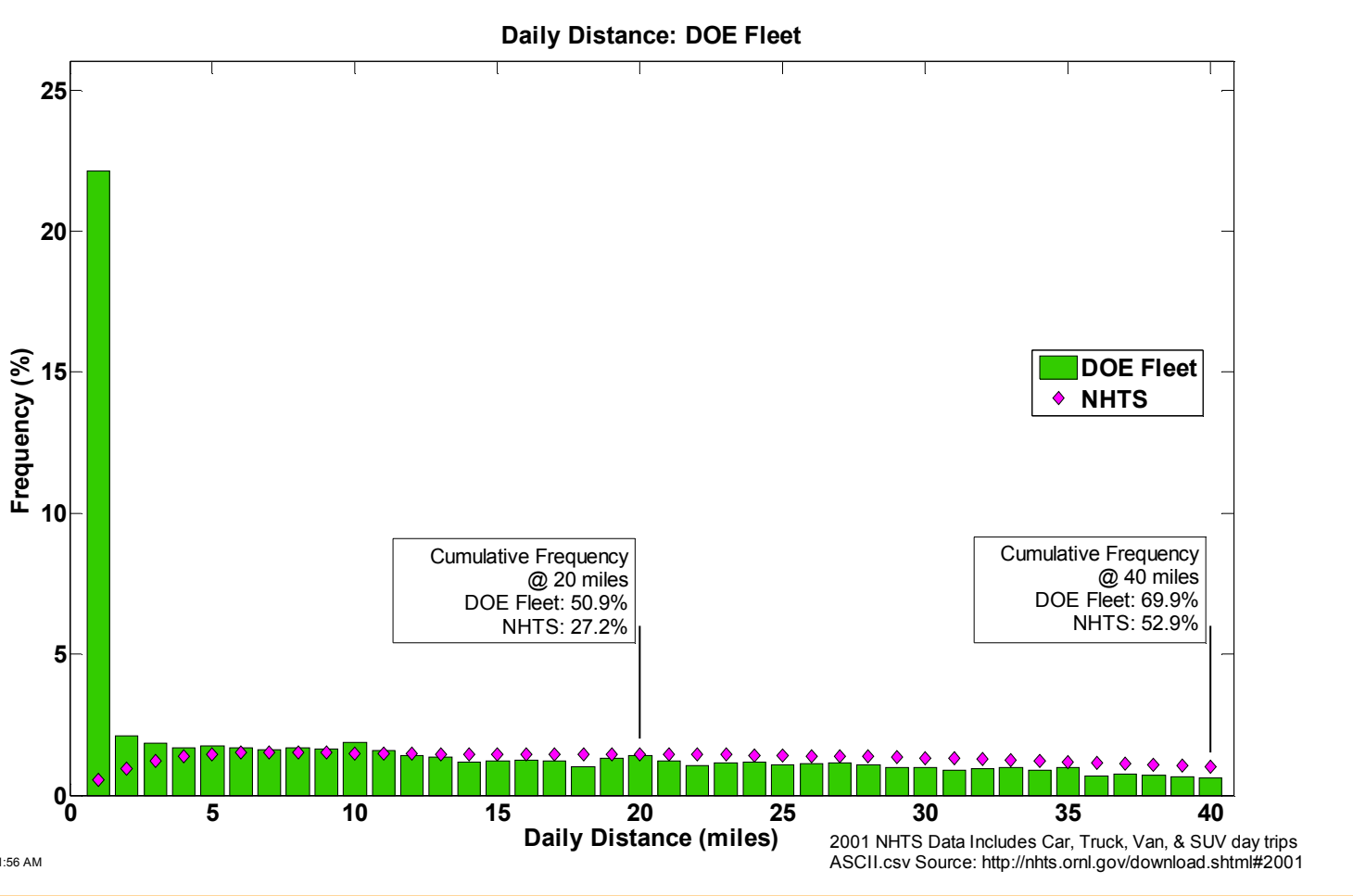

Figure 10: Daily Driving Distance (CDP56) 


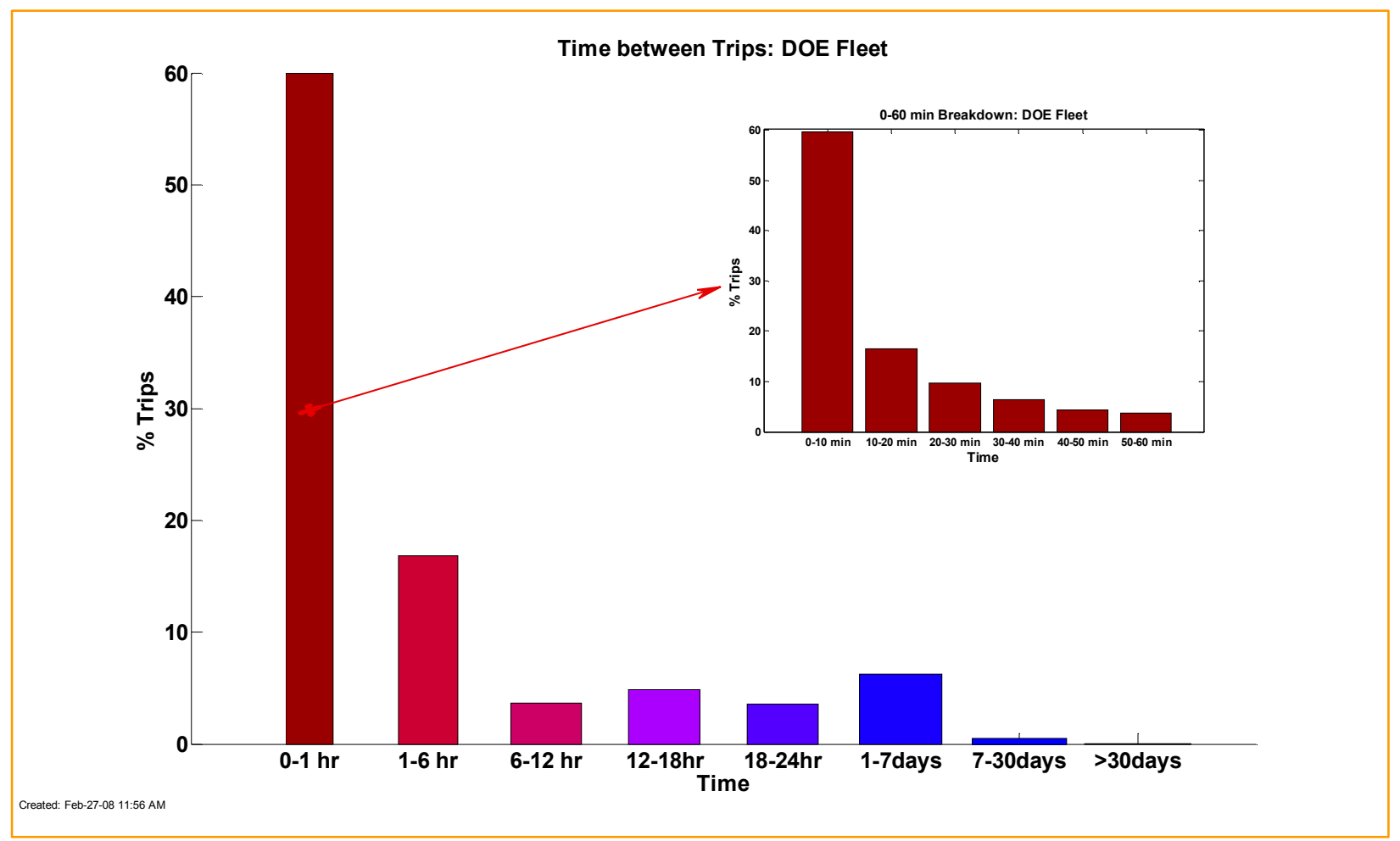

Figure 11: Time between Trips (CDP54)

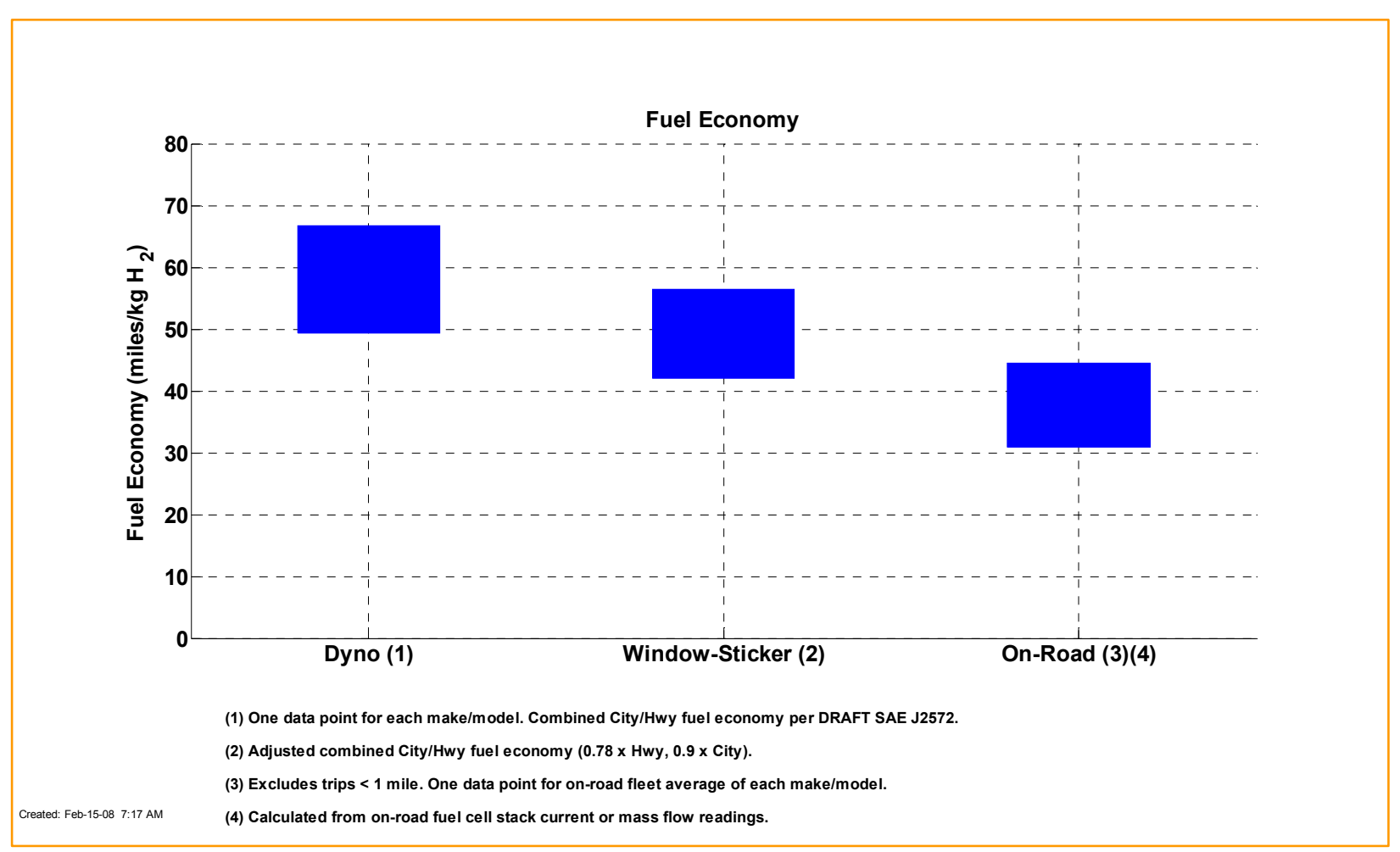

Figure 12: Fuel Economy (CDP6) 


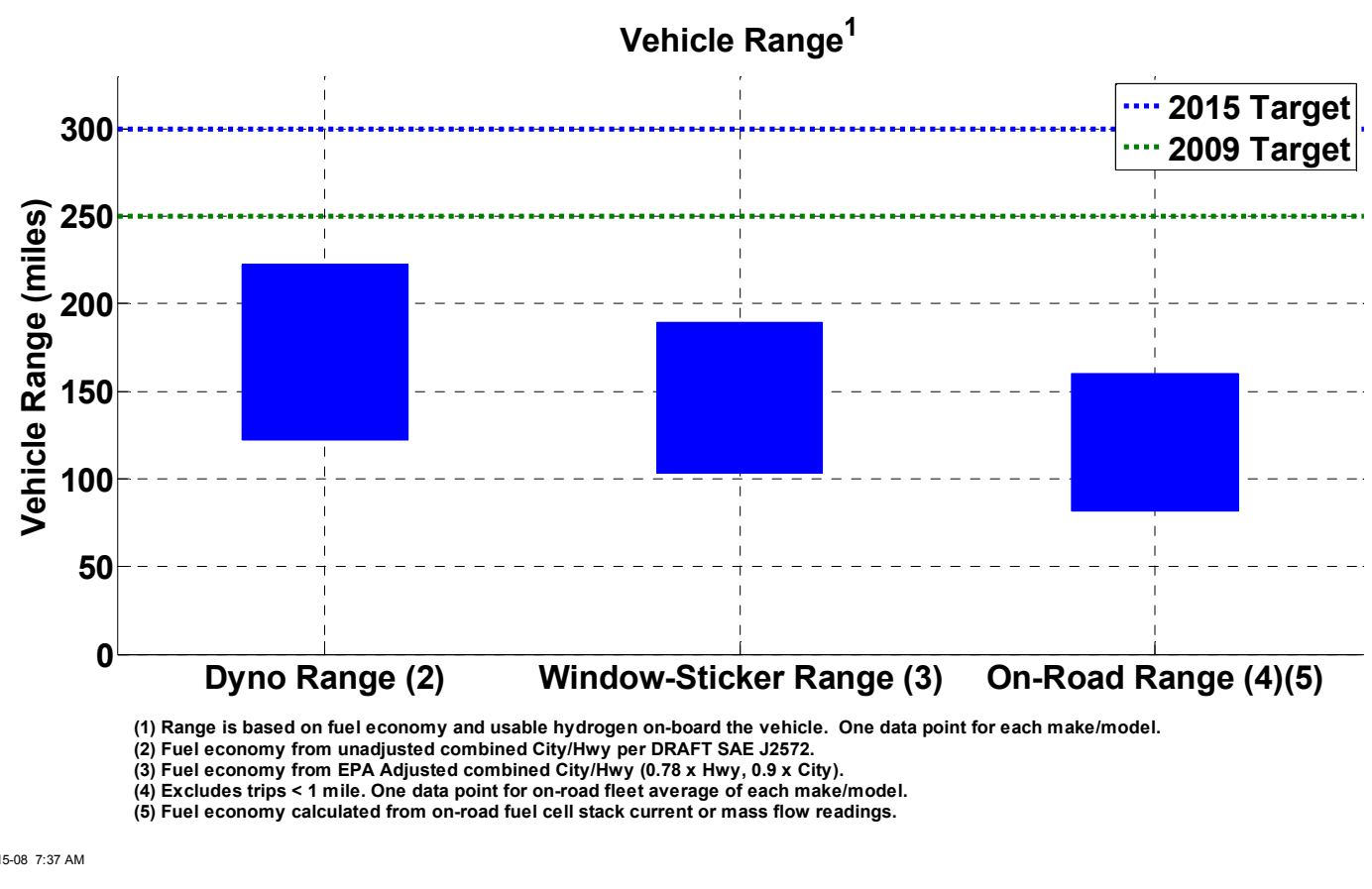

Figure 13: Vehicle Range (CDP2)

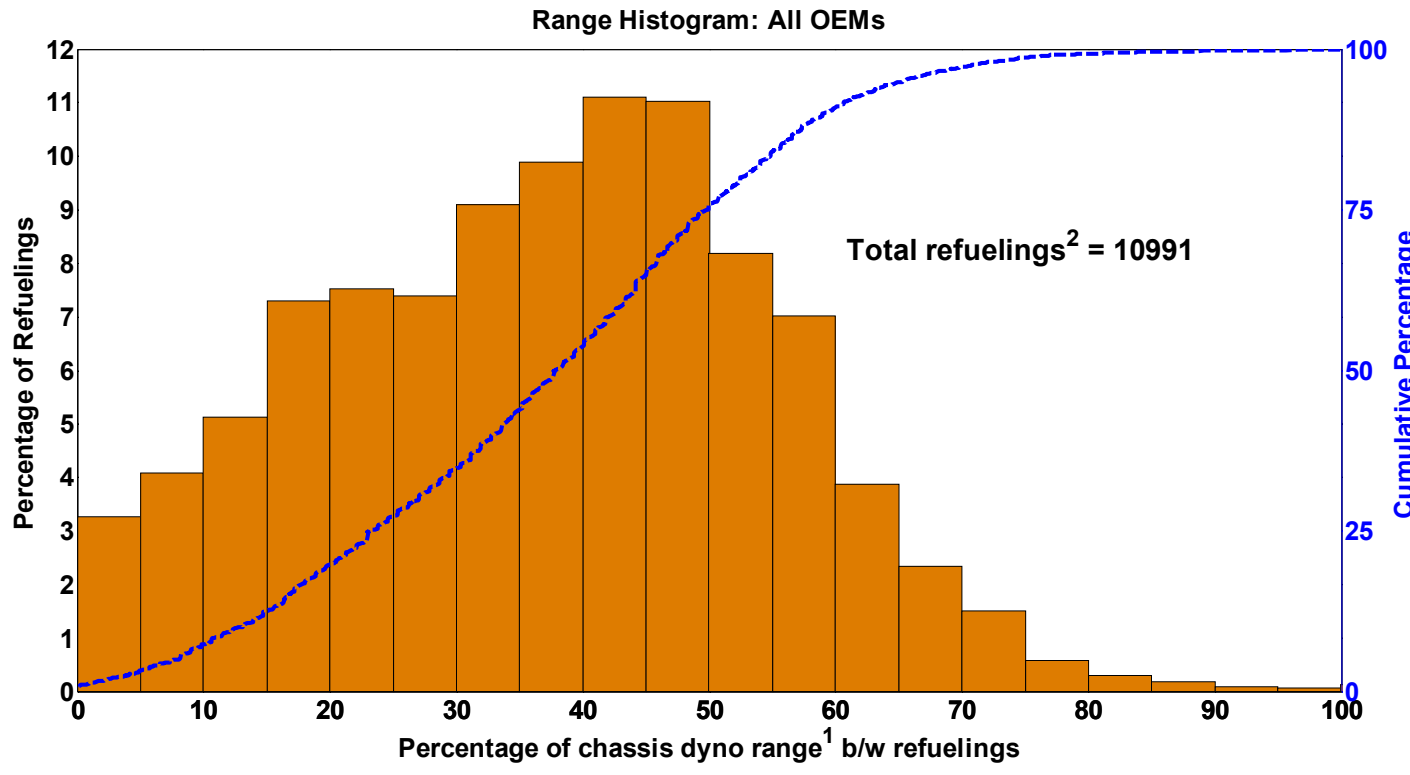

1. Range calculated using the combined City/Hwy fuel economy from dyno testing (not EPA adjusted) and usable fuel on board.

Created: Feb-15-08 9.20 AM $\quad 2$. Some refueling events are not detected/reported due to data noise or incompleteness.

Figure 14: Percentage of Theoretical Range Traveled between Refuelings (CDP33) 


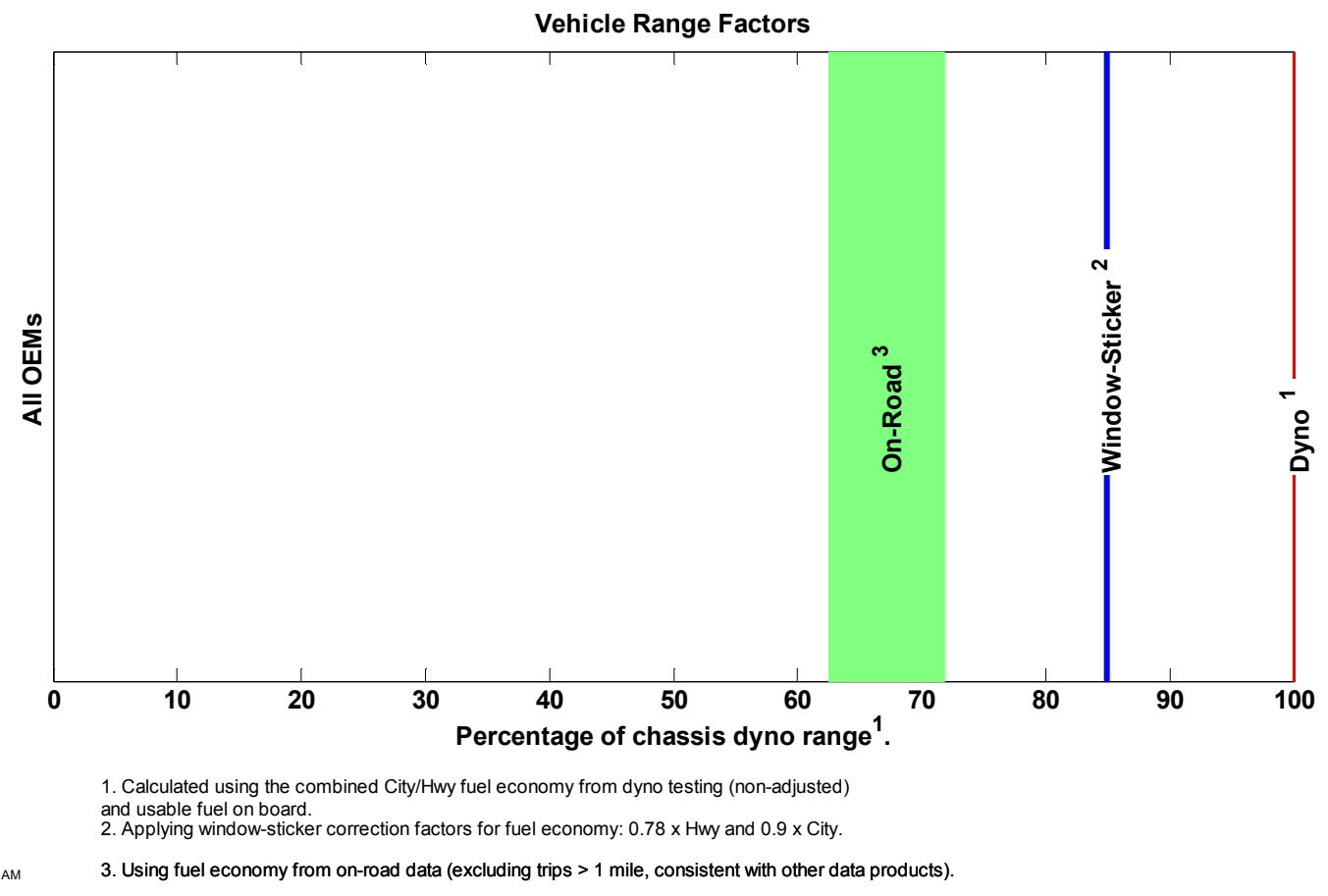

Figure 15: Effective Vehicle Range (CDP34)

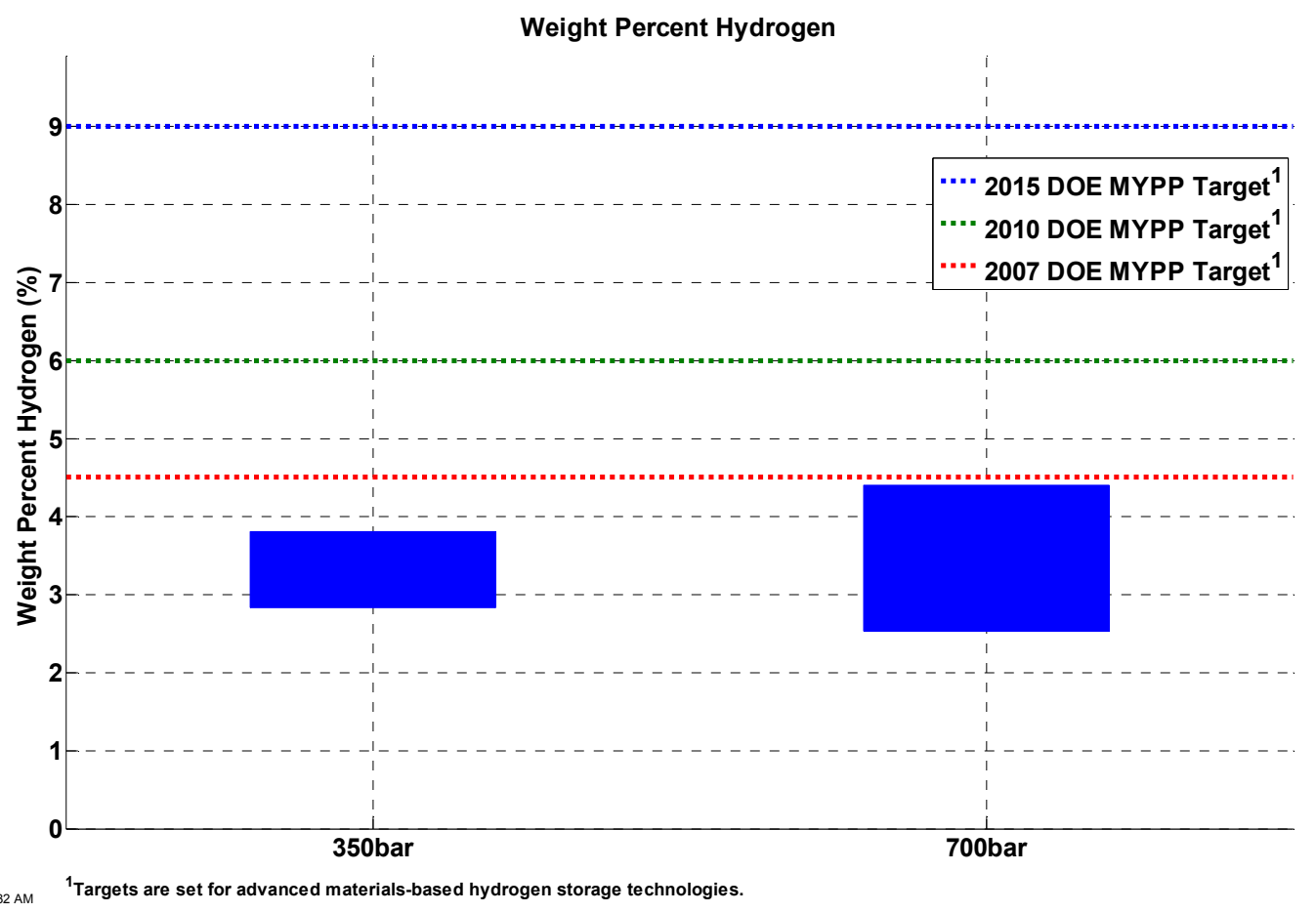

Figure 16: Weight \% Hydrogen Stored (CDP10) 


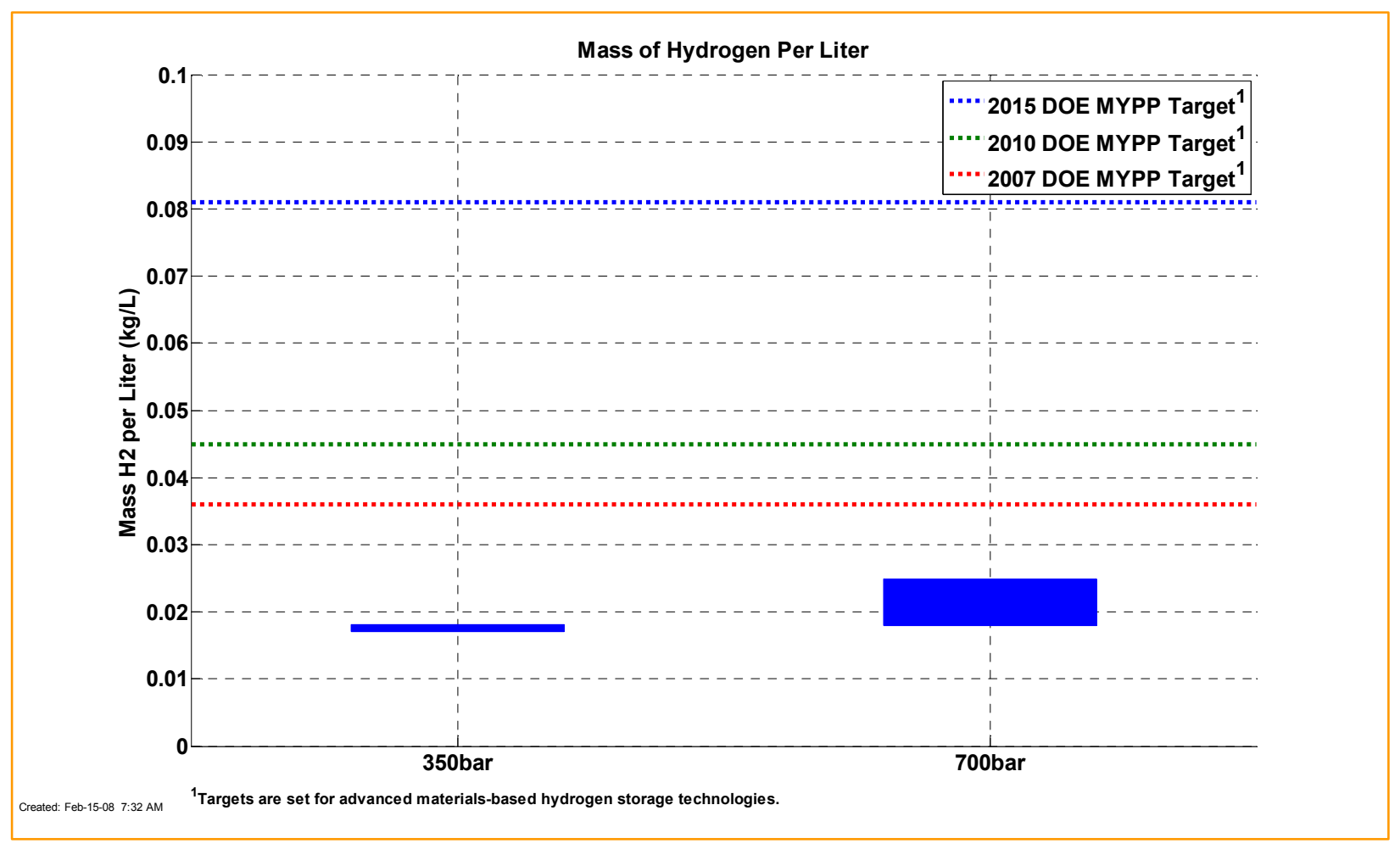

Figure 17: Volumetric Capacity of Hydrogen Storage (CDP11)

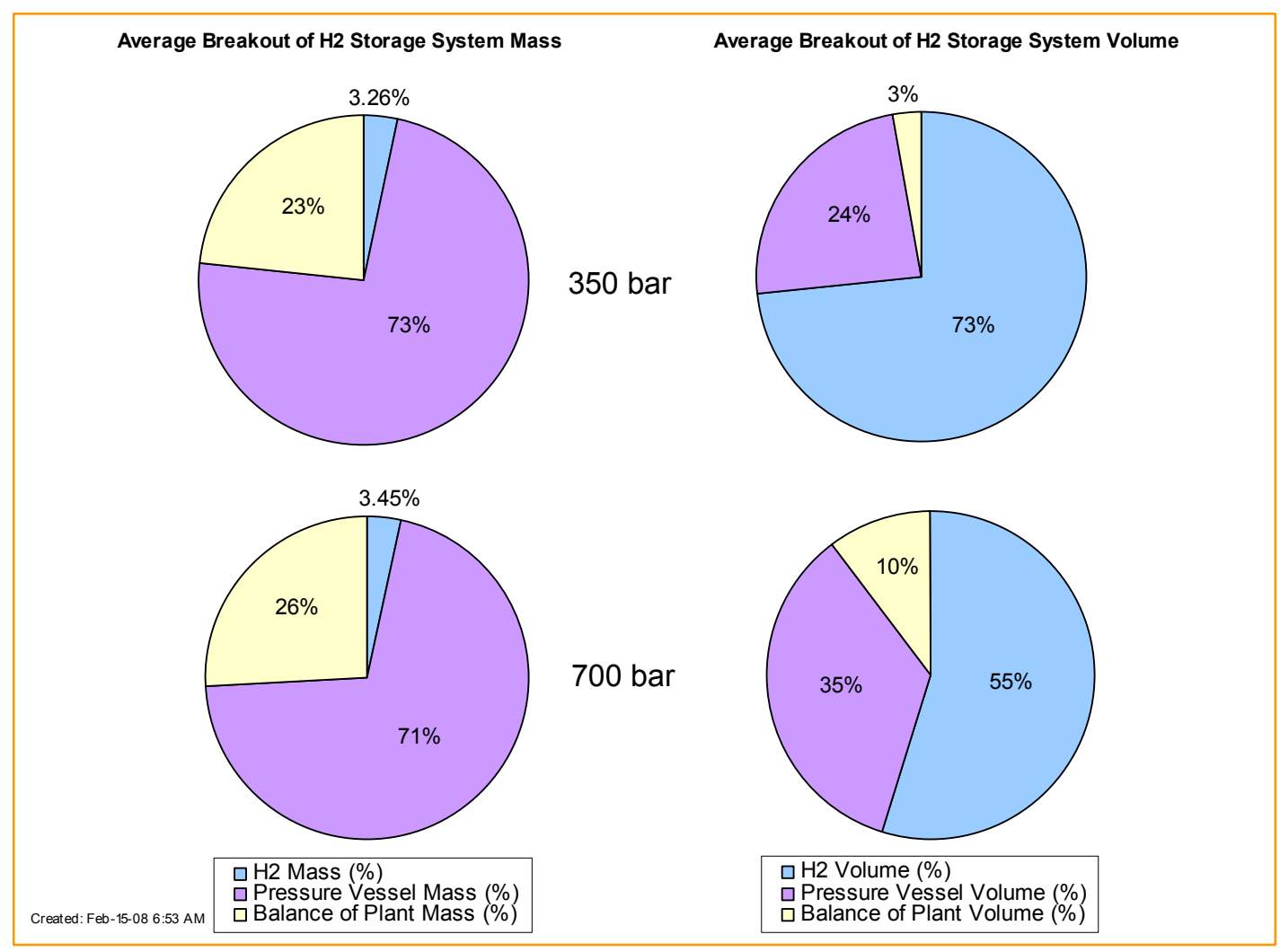

Figure 18: Hydrogen Storage System Mass and Volume Breakdown (CDP 57) 


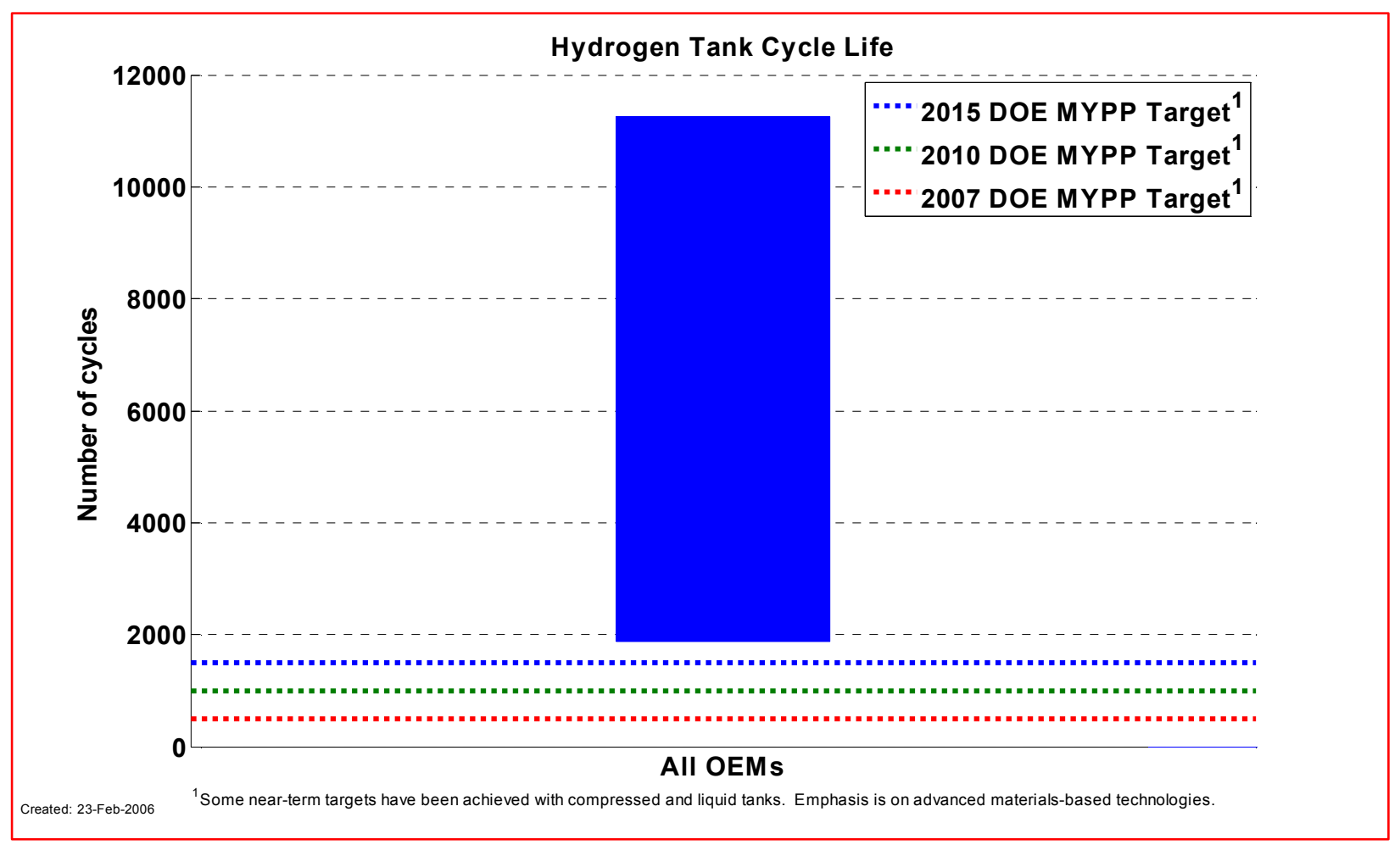

Figure 19: Vehicle Hydrogen Tank Cycle Life (CDP12)

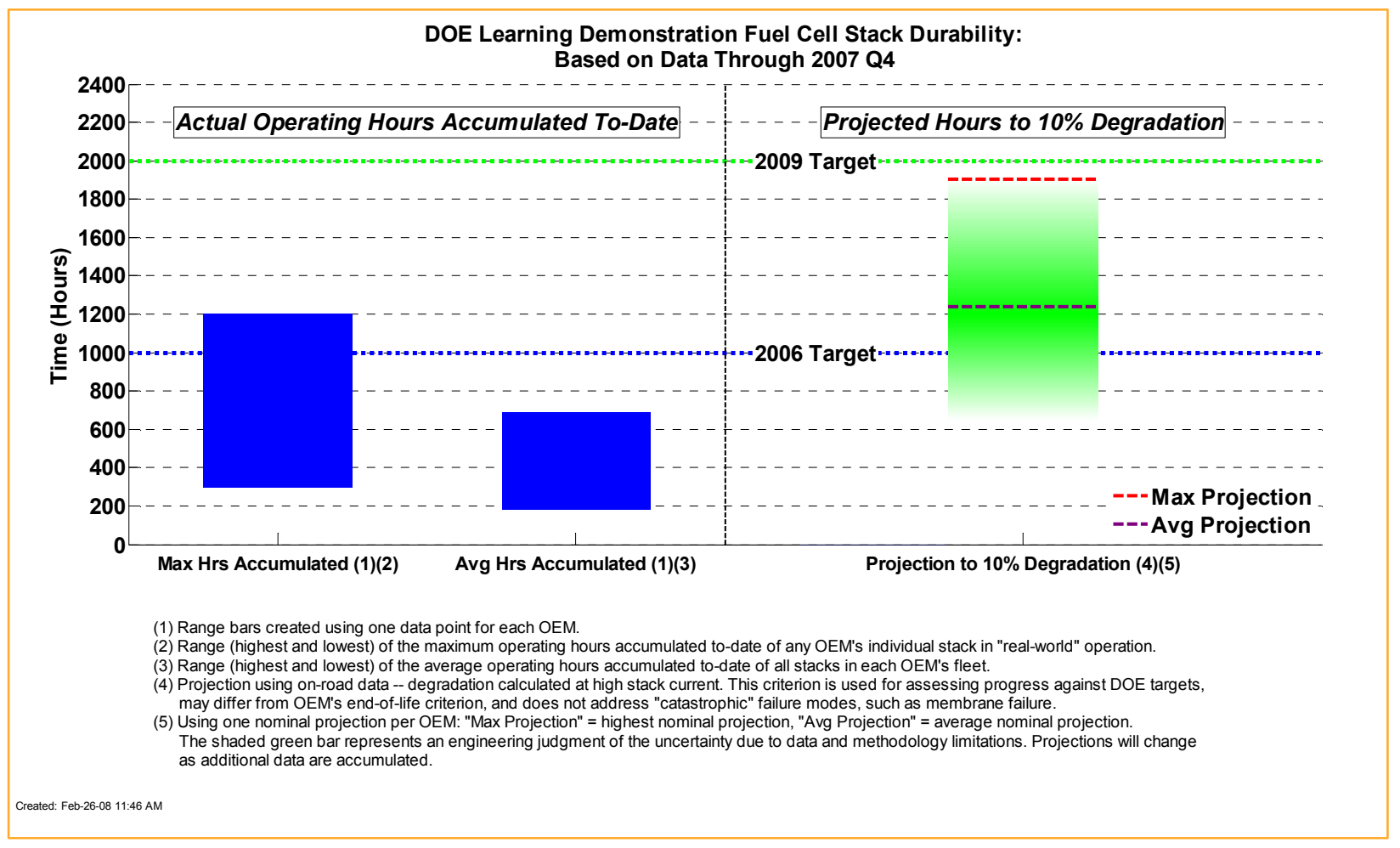

Figure 20: Hours Accumulated and Projected Hours to 10\% Stack Voltage Degradation (CDP1) 


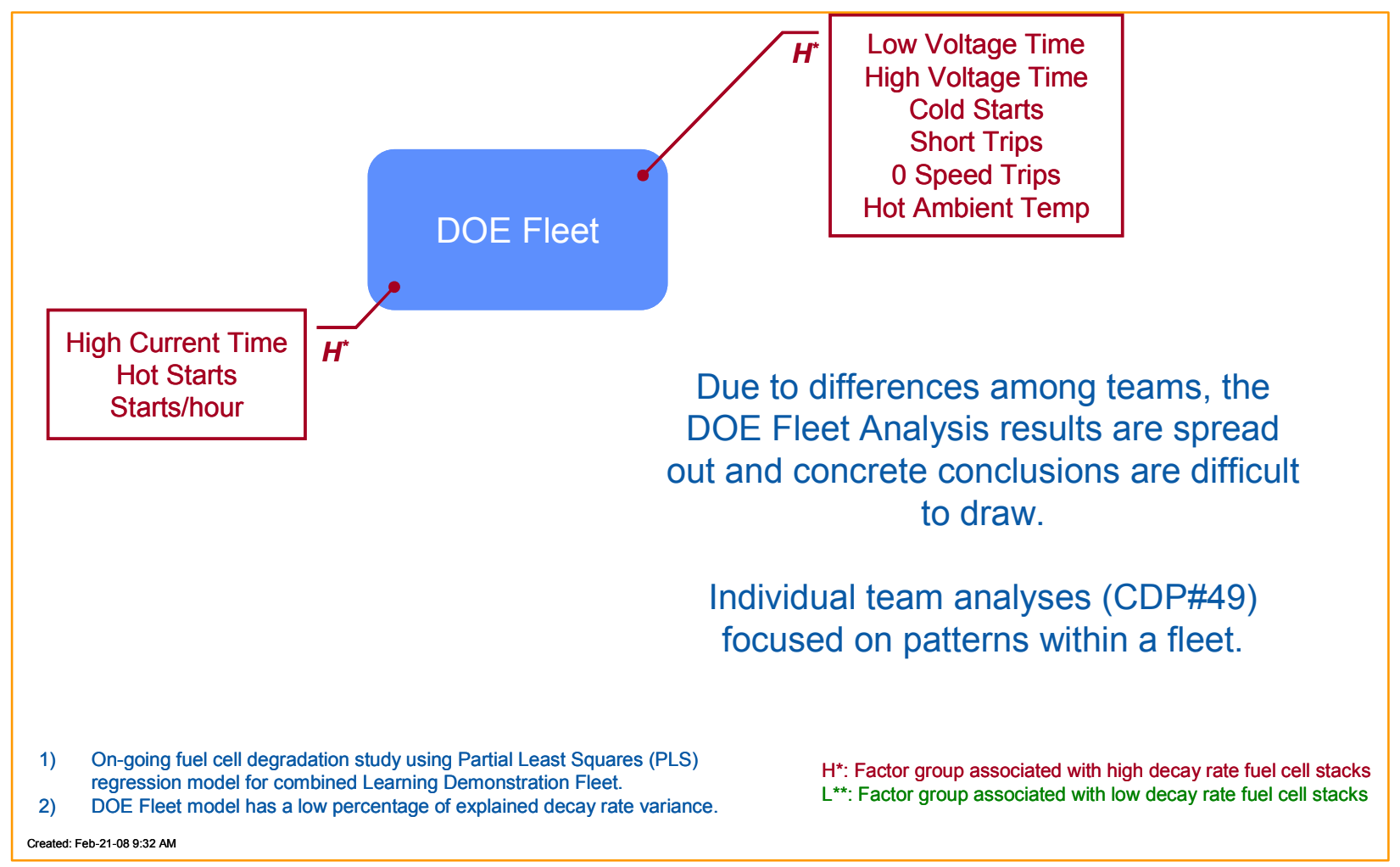

Figure 21: Primary Factors Affecting Learning Demo Fleet Fuel Cell Degradation (CDP48)

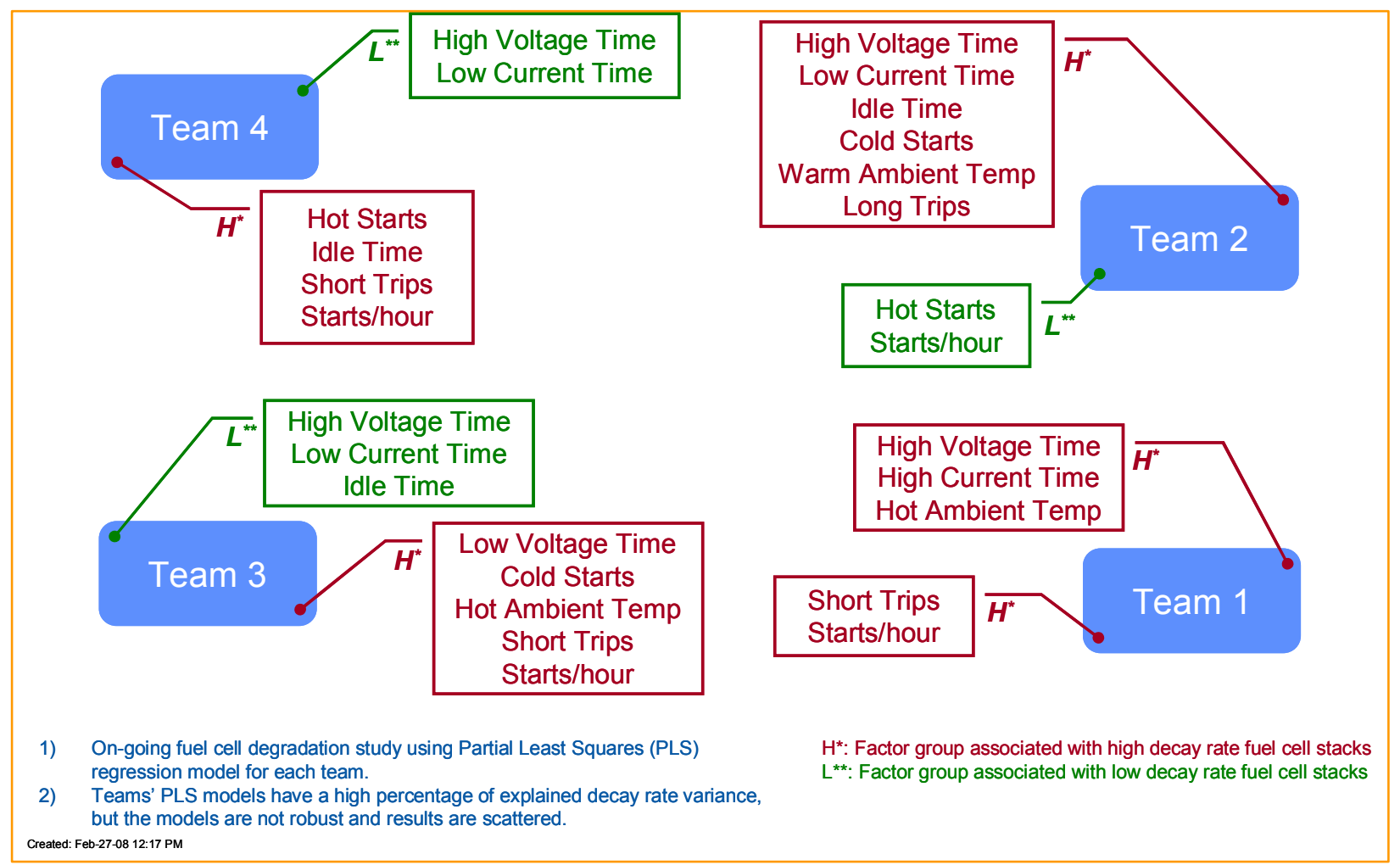

Figure 22: Primary Factors Affecting Learning Demo Team Fuel Cell Degradation (CDP49) 


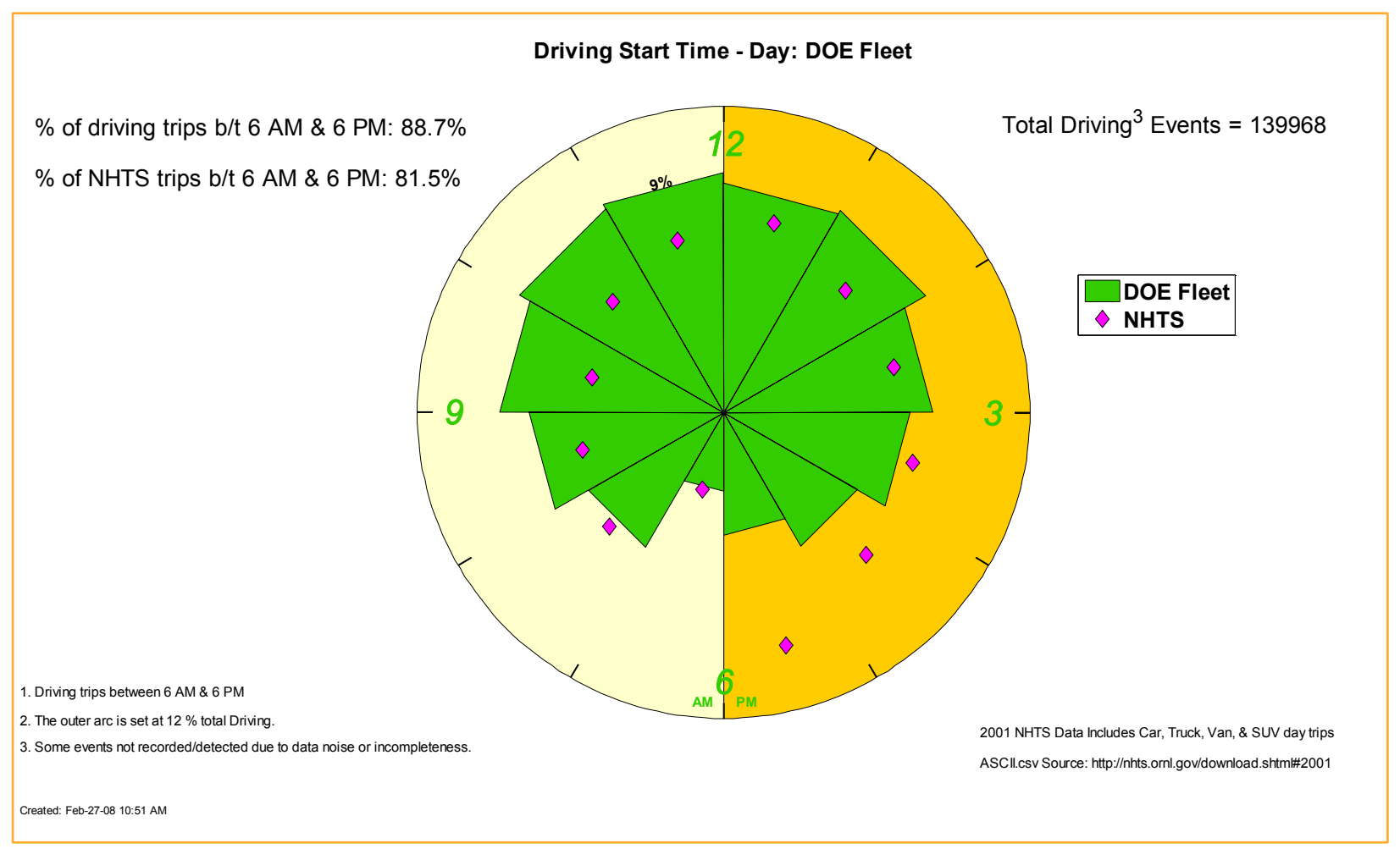

Figure 23: Driving Start Time - Day (CDP44)

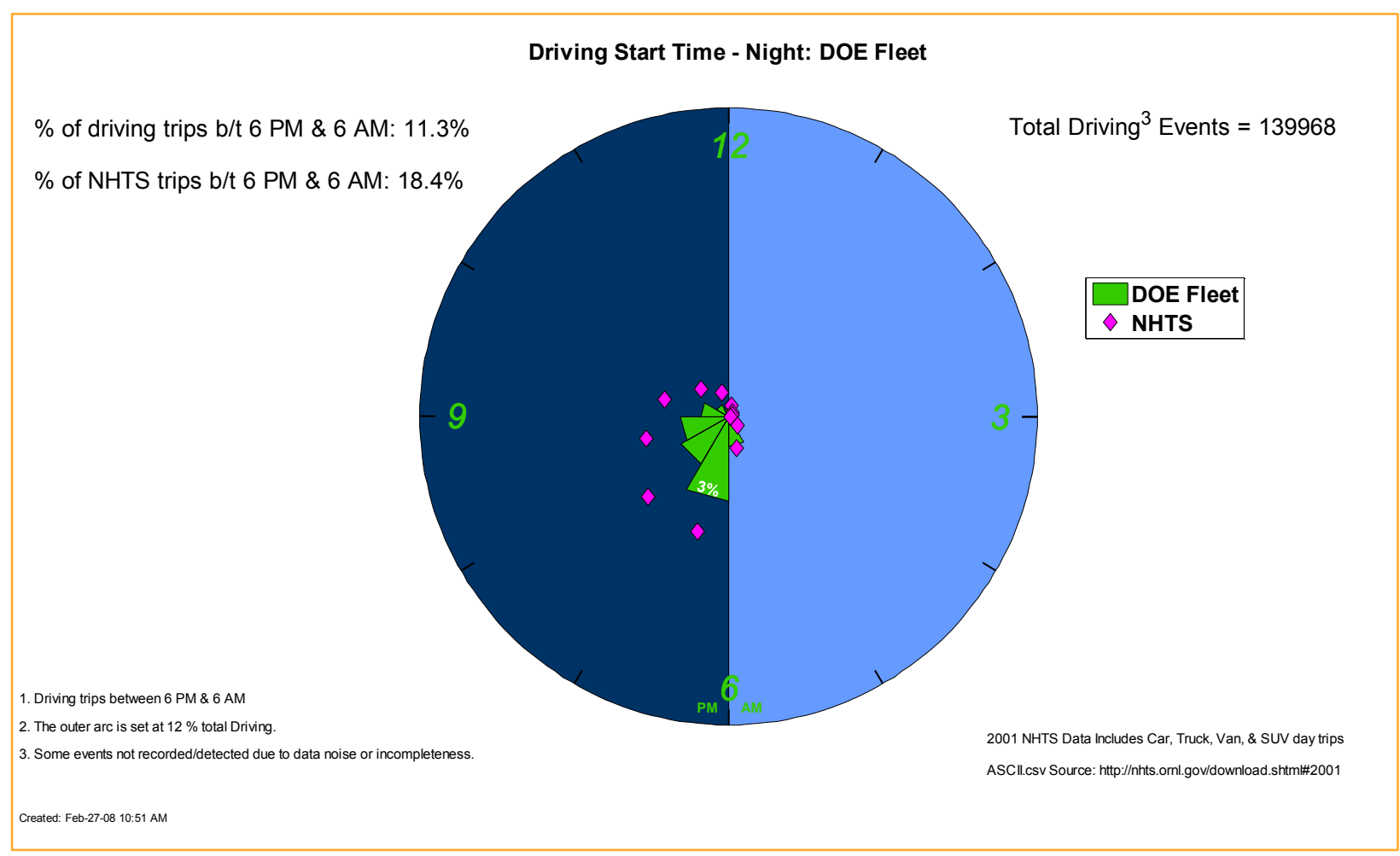

Figure 24: Driving Start Time - Night (CDP51) 


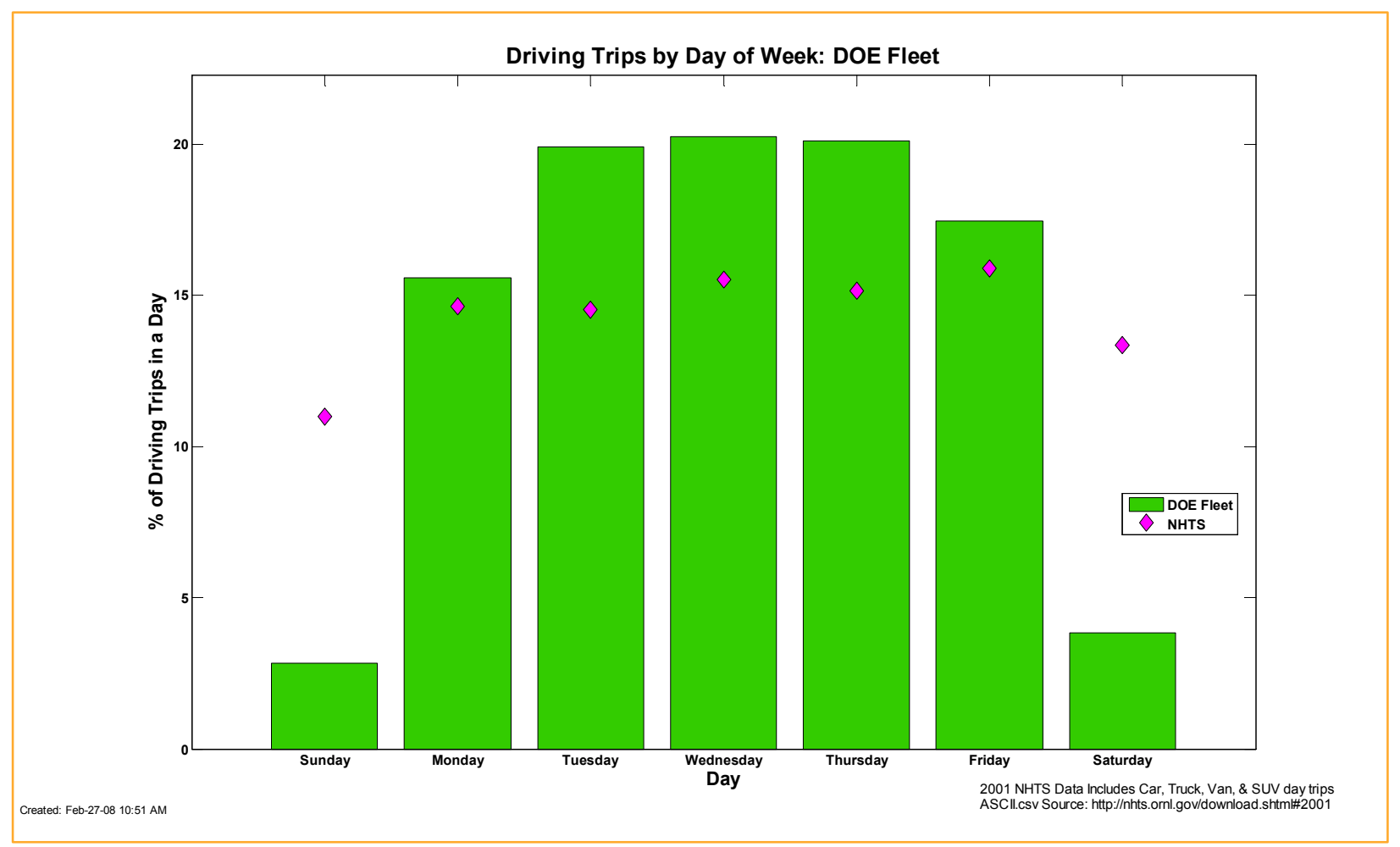

Figure 25: Driving by Day of Week (CDP45)

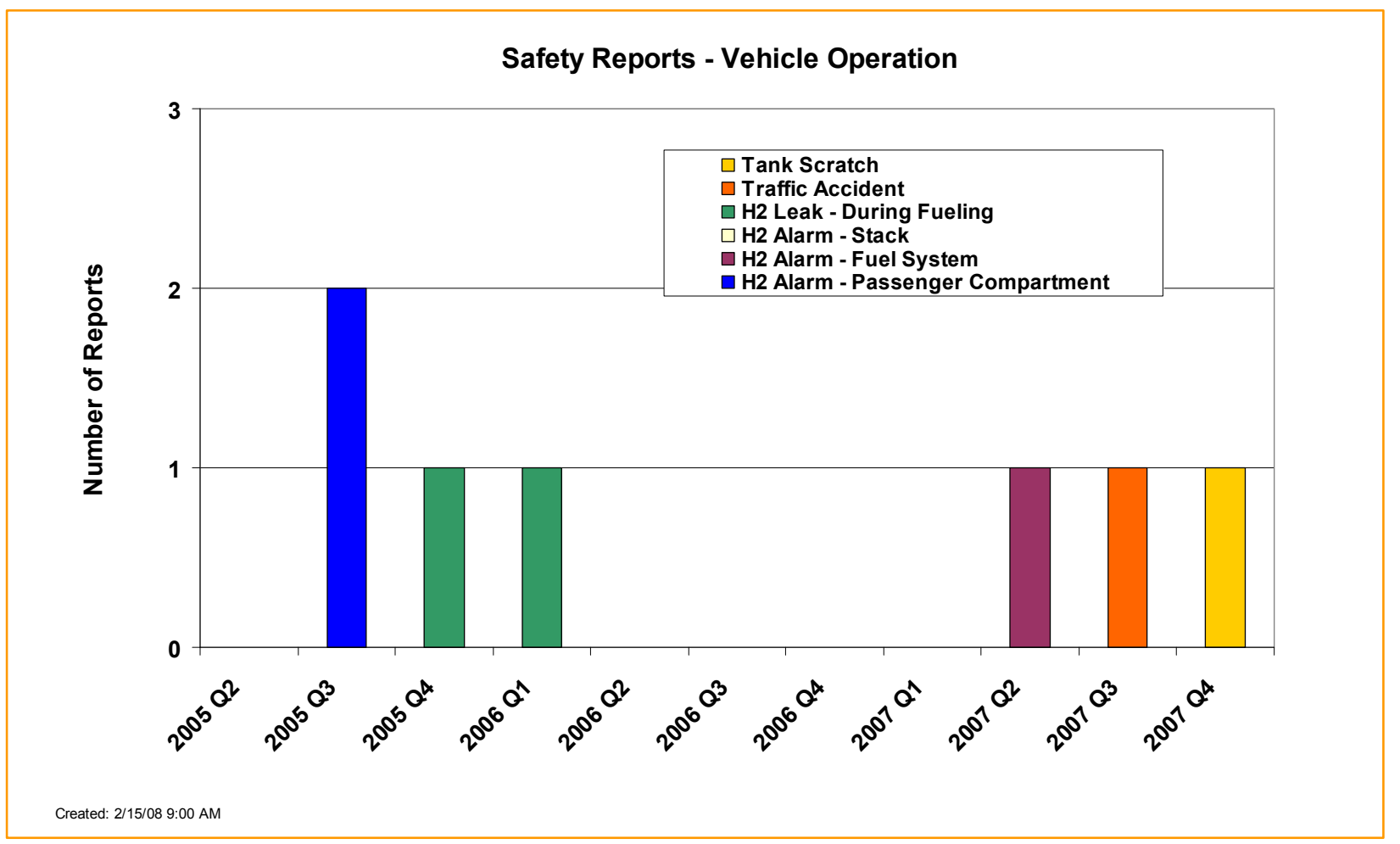

Figure 26: Safety Reports - Vehicles (CDP9) 


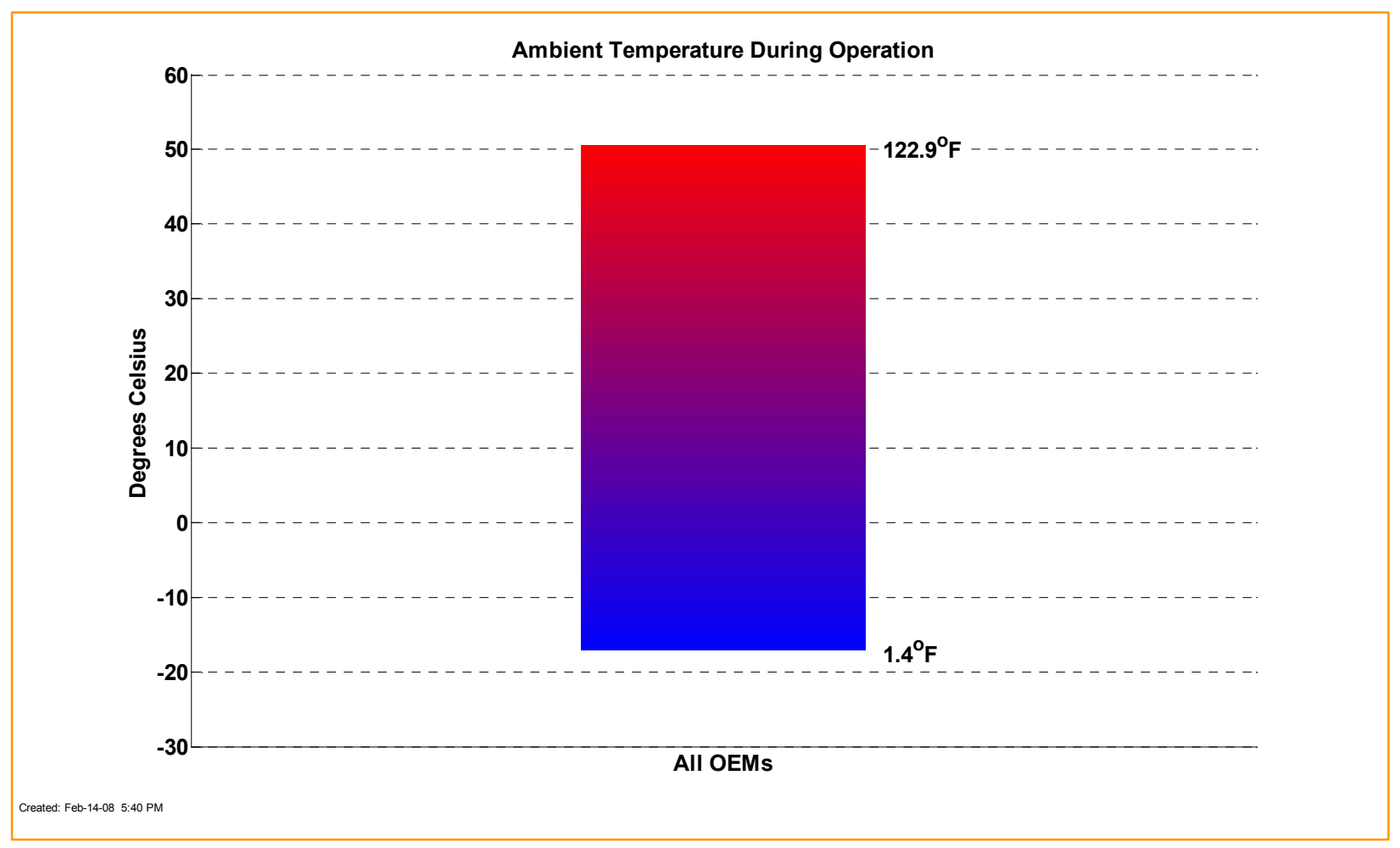

Figure 27: Range of Ambient Temperature during Vehicle Operation (CDP21)

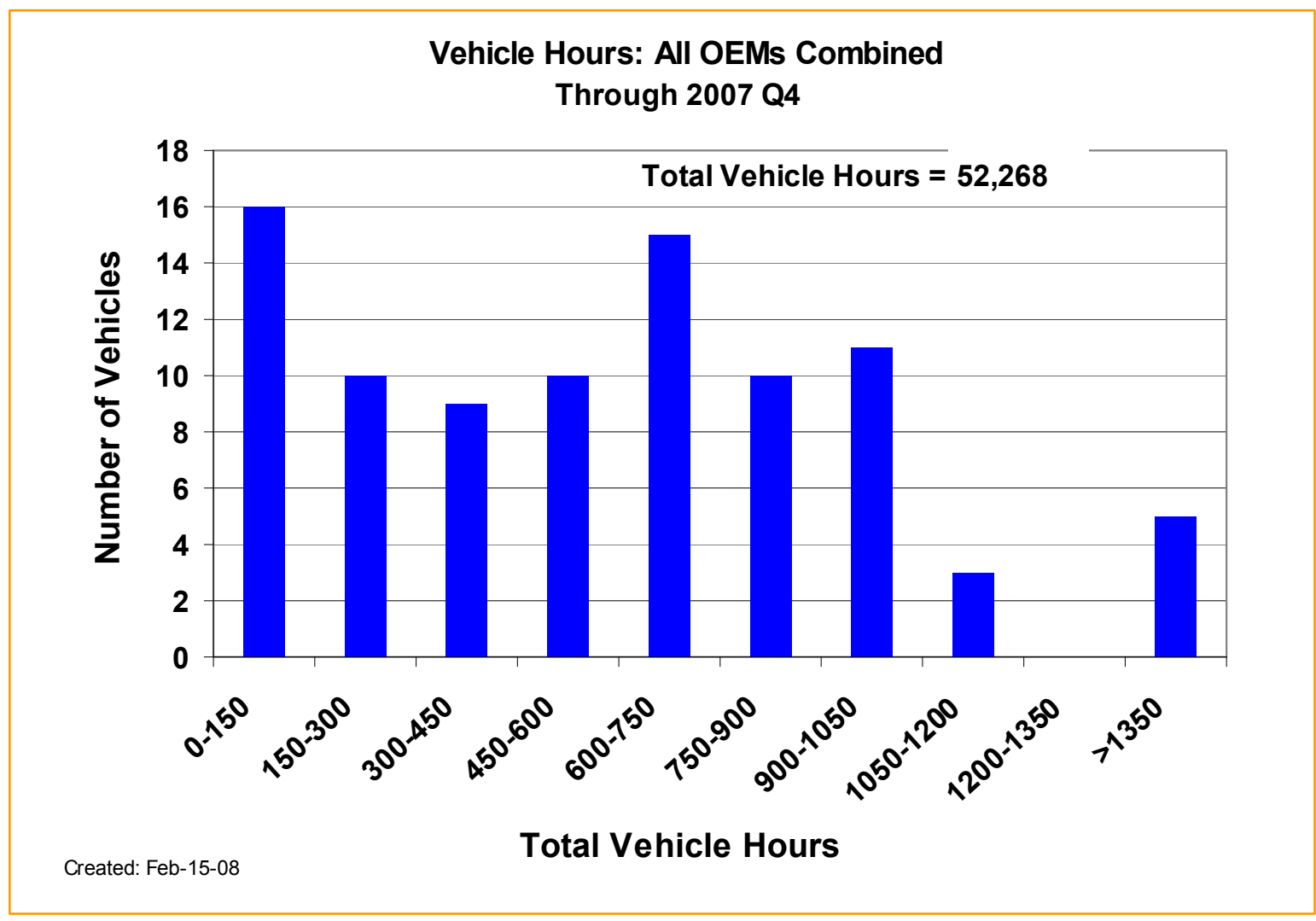

Figure 28: Vehicle Operating Hours (CDP22) 


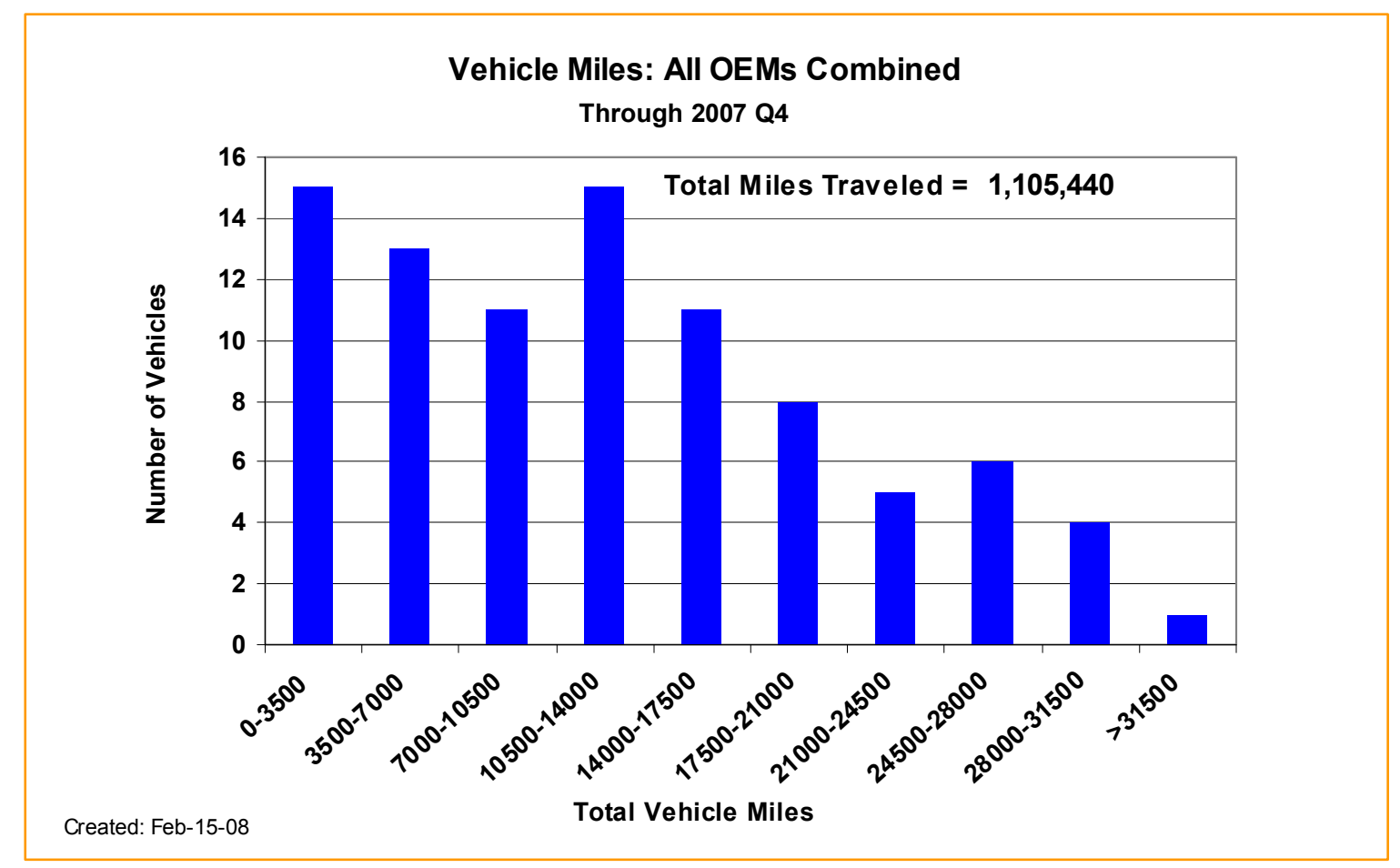

Figure 29: Vehicles vs. Miles Traveled (CDP23)

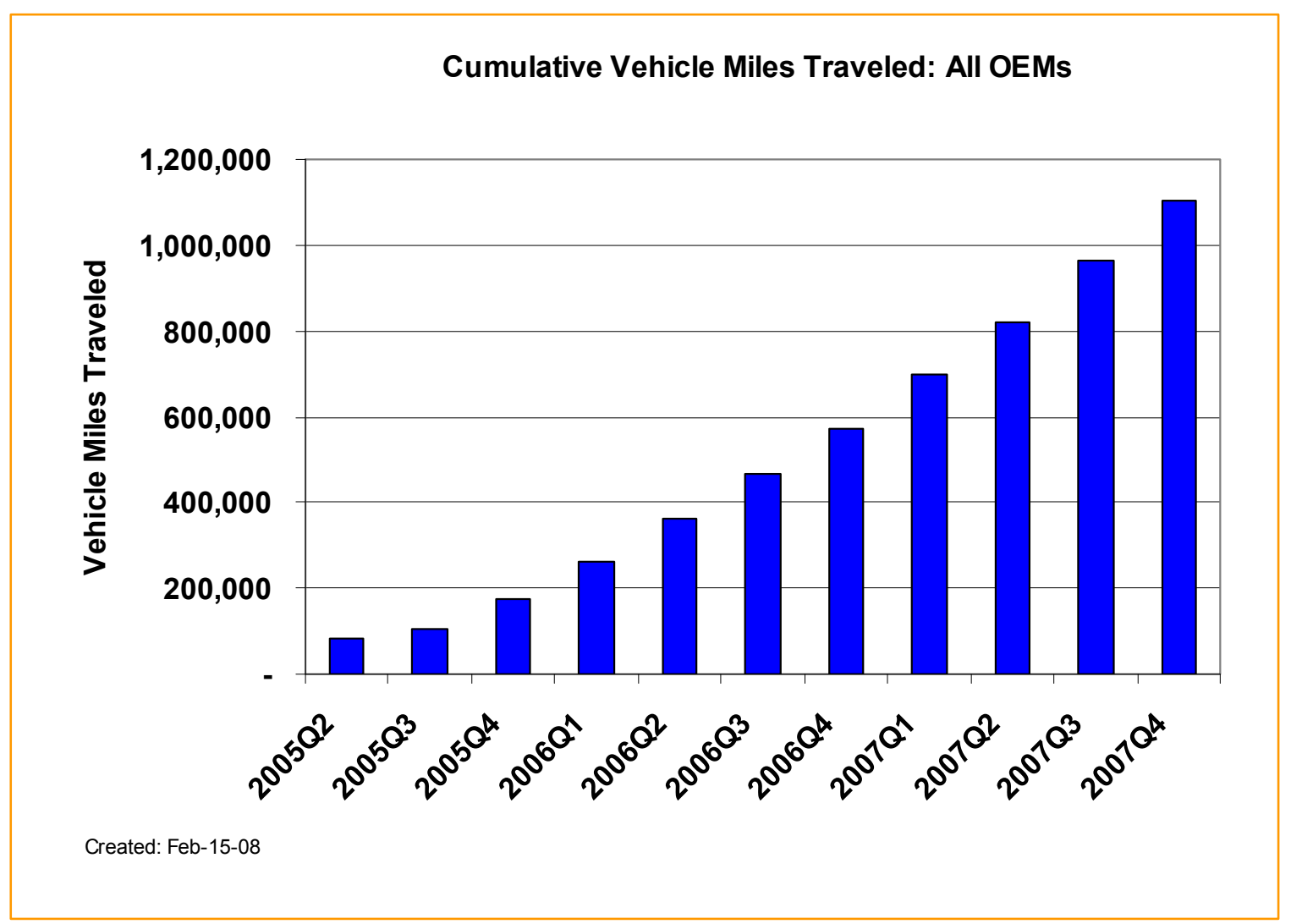

Figure 30: Cumulative Vehicle Miles Traveled (CDP24) 


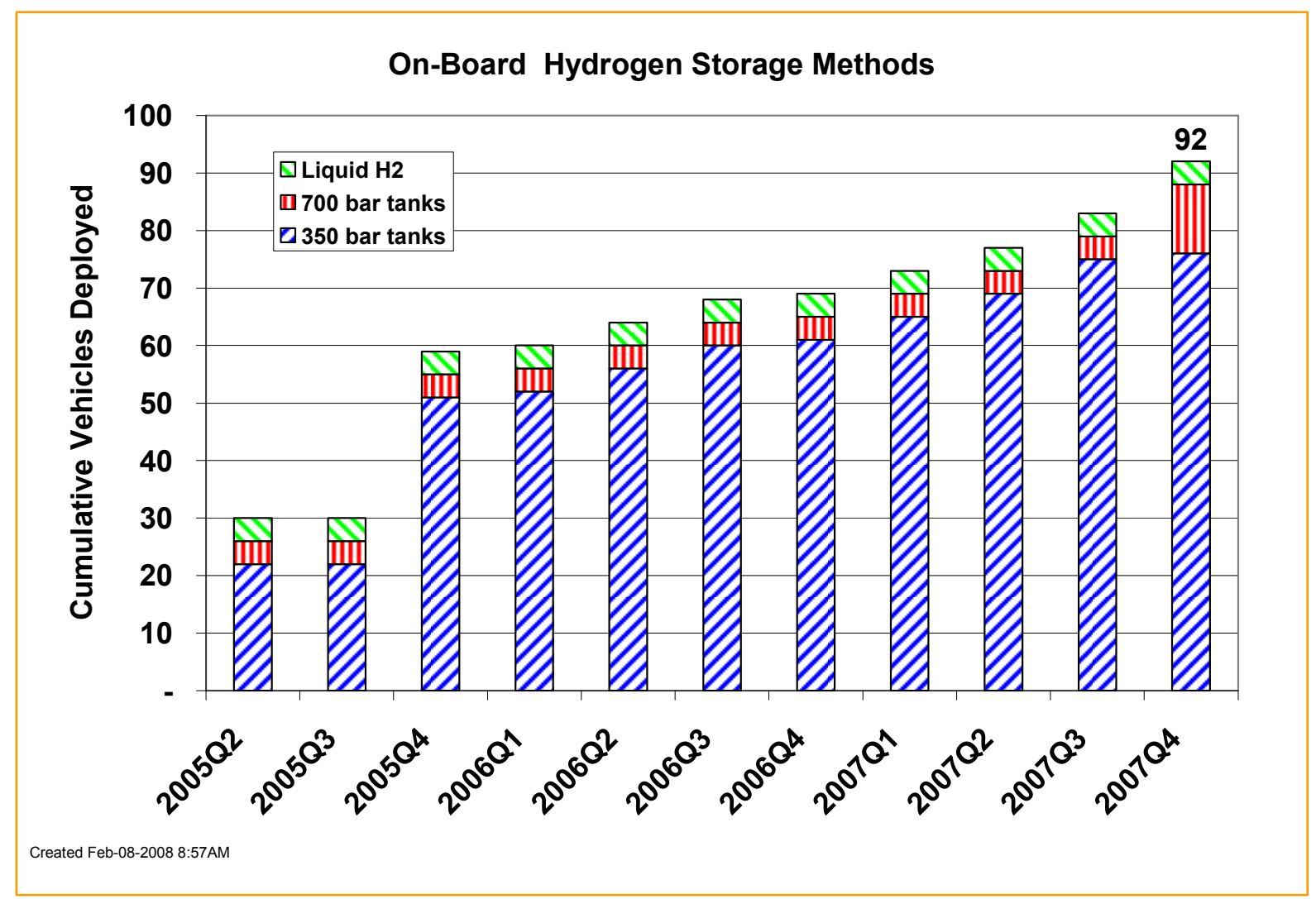

Figure 31: Vehicle Hydrogen Storage Technologies (CDP25)

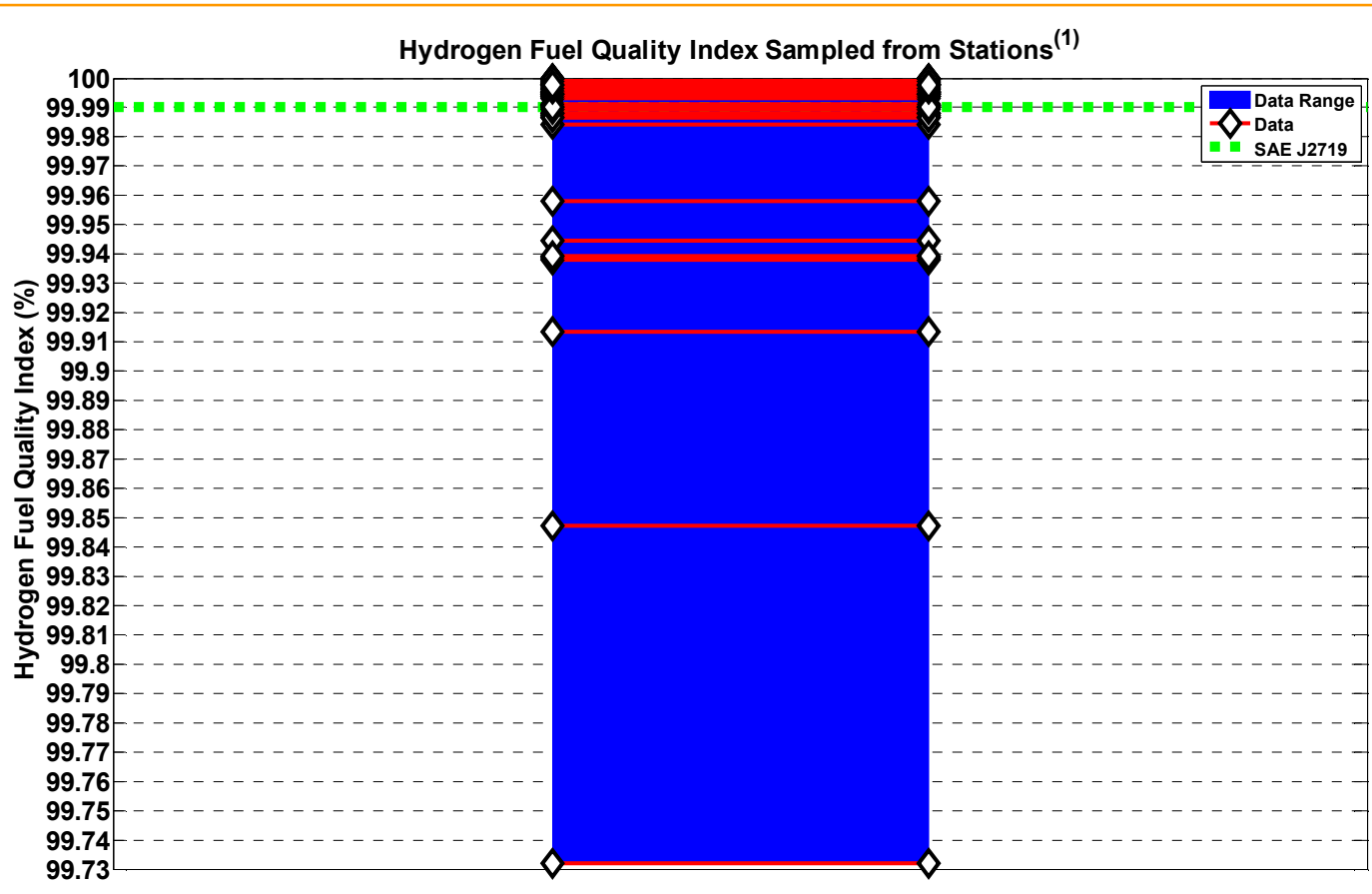

(1) Includes sampling from both electrolysis and reforming

Figure 32: Hydrogen Purity Scatter Plot (CDP27) 


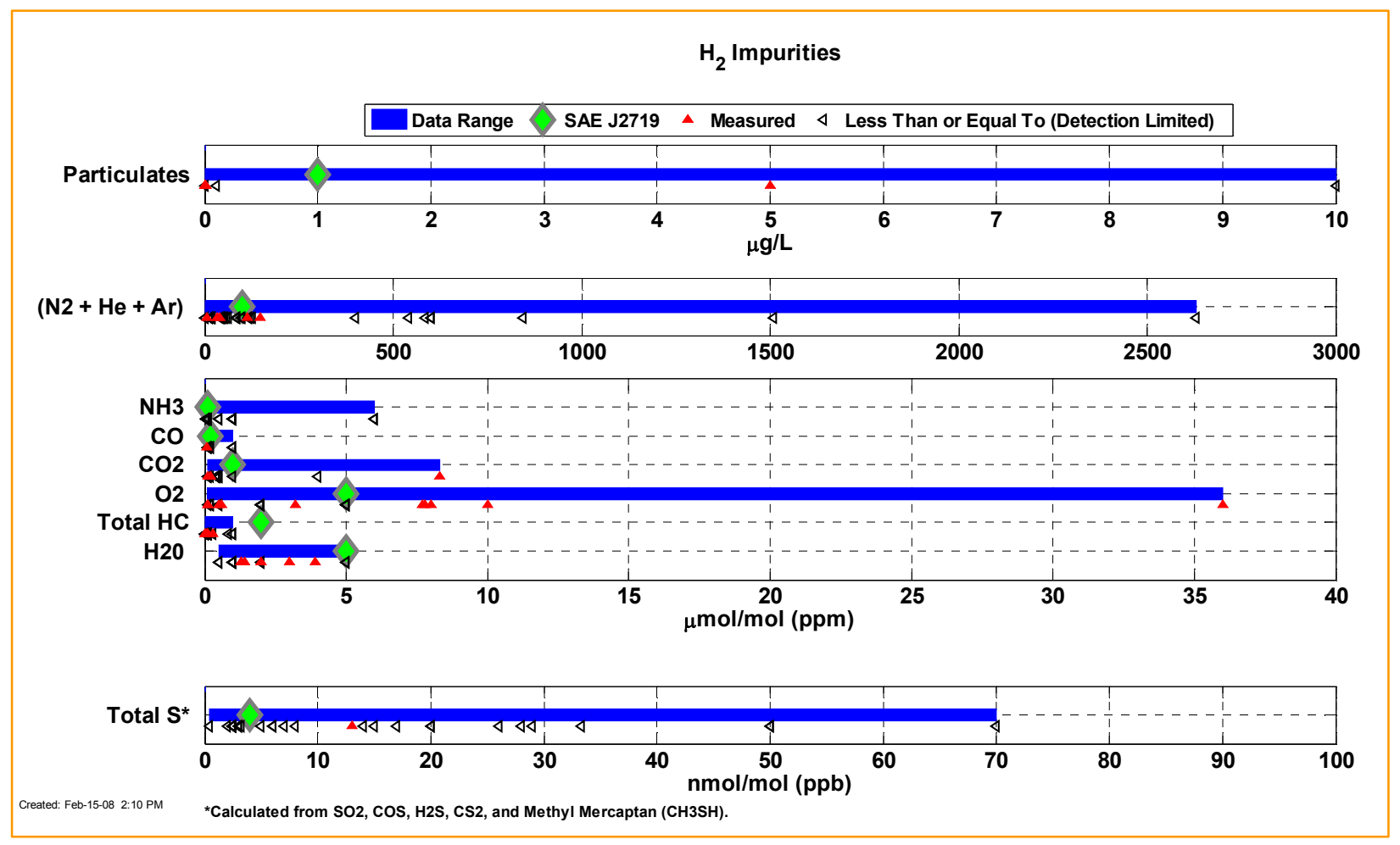

Figure 33: Hydrogen Impurities Scatter Plot (CDP28)

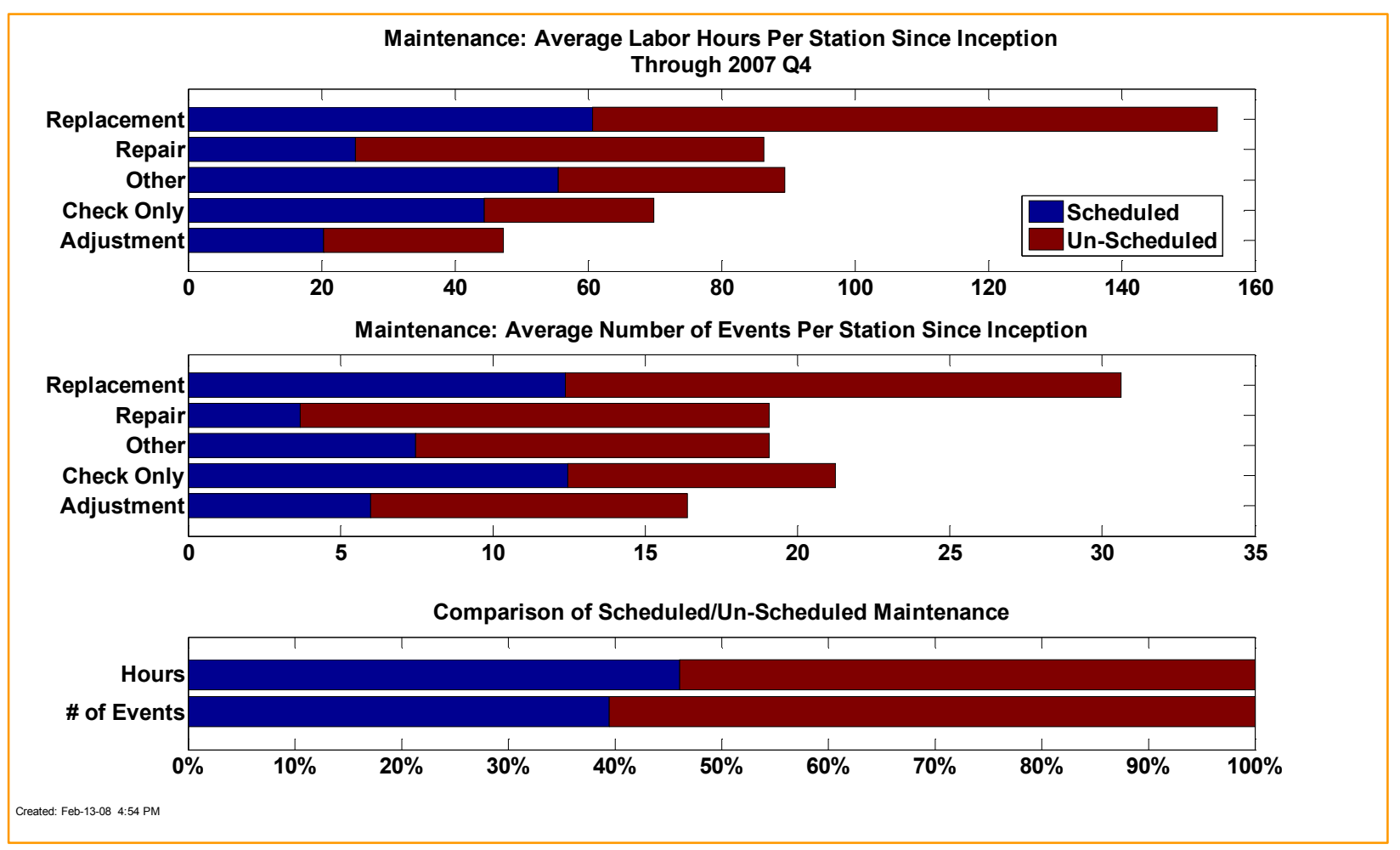

Figure 34: Infrastructure Maintenance (CDP30) 


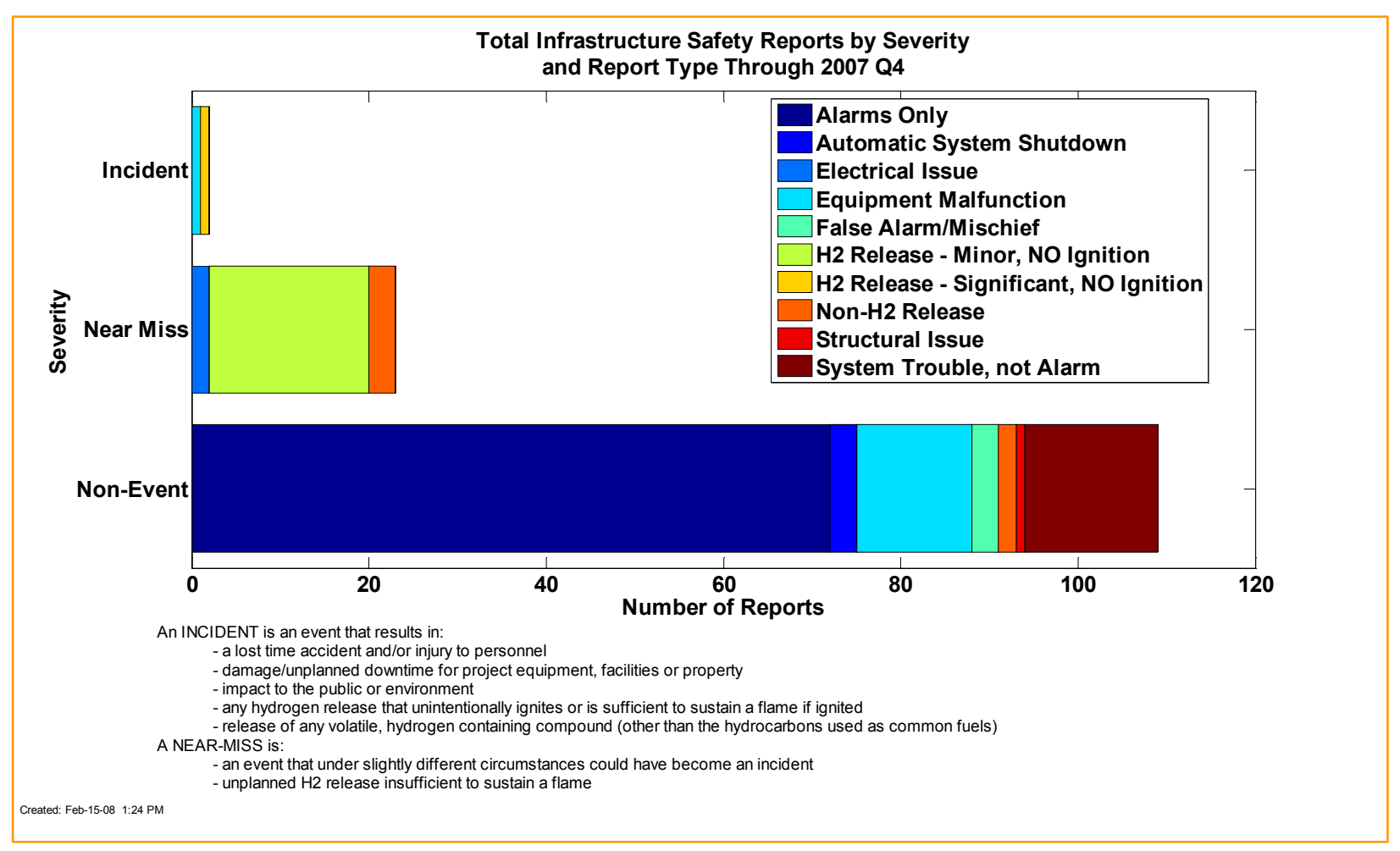

Figure 35: Safety Reports - Infrastructure (CDP20)

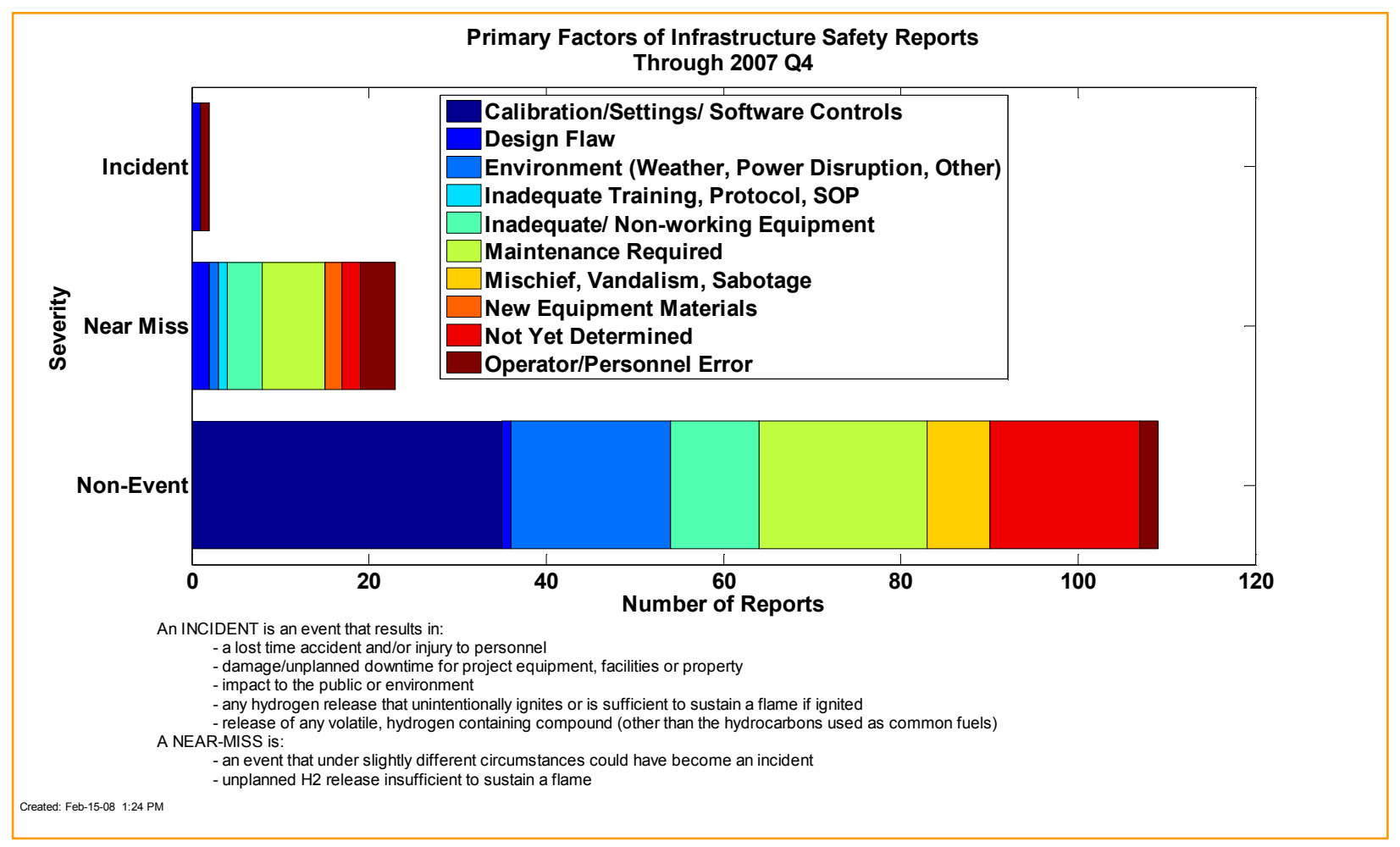

Figure 36: Primary Factors of Infrastructure Safety Reports (CDP37) 


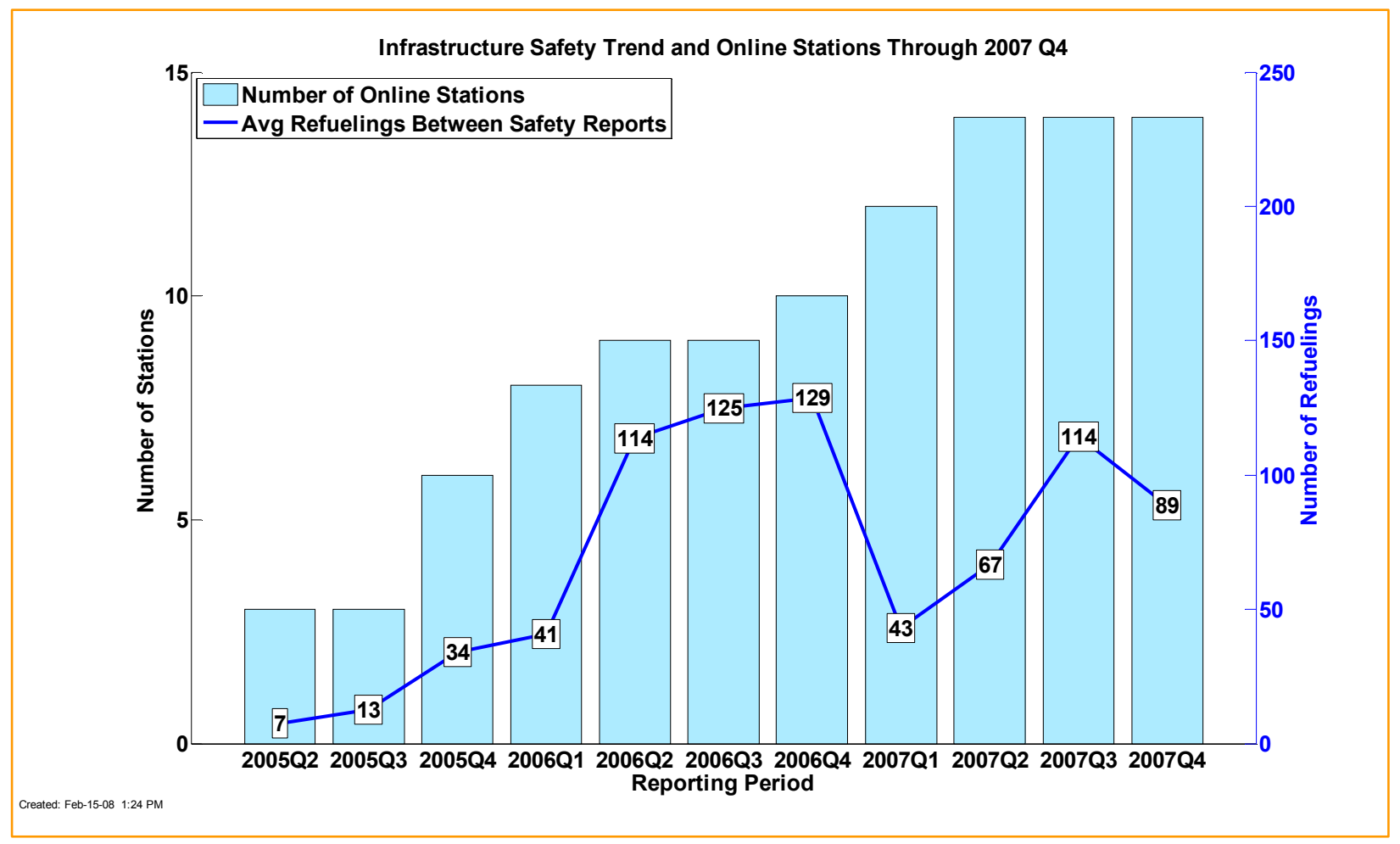

Figure 37: Average Refuelings between Infrastructure Safety Reports (CDP35)

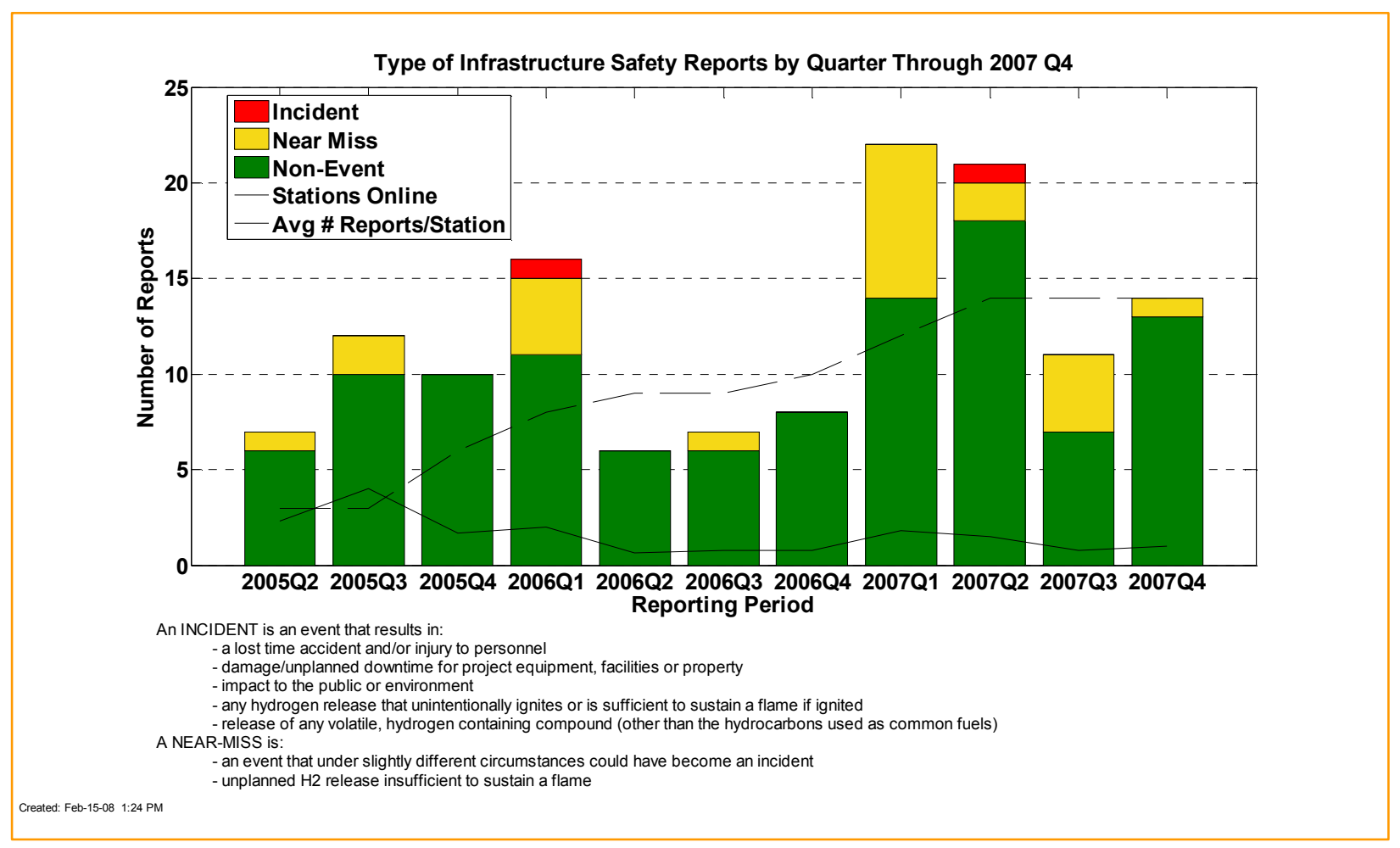

Figure 38: Type of Infrastructure Safety Report by Quarter (CDP36) 


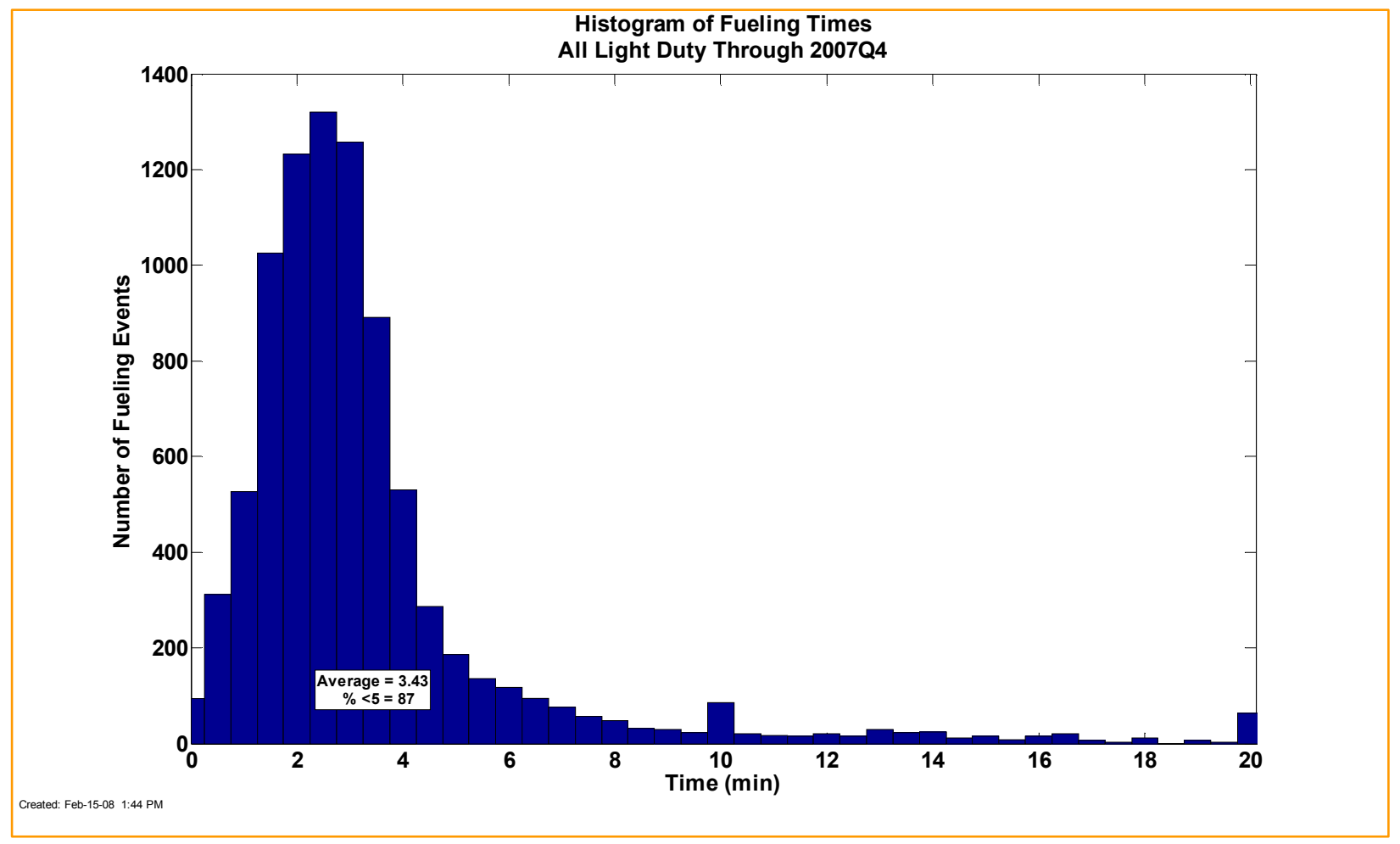

Figure 39: Refueling Times (CDP38)

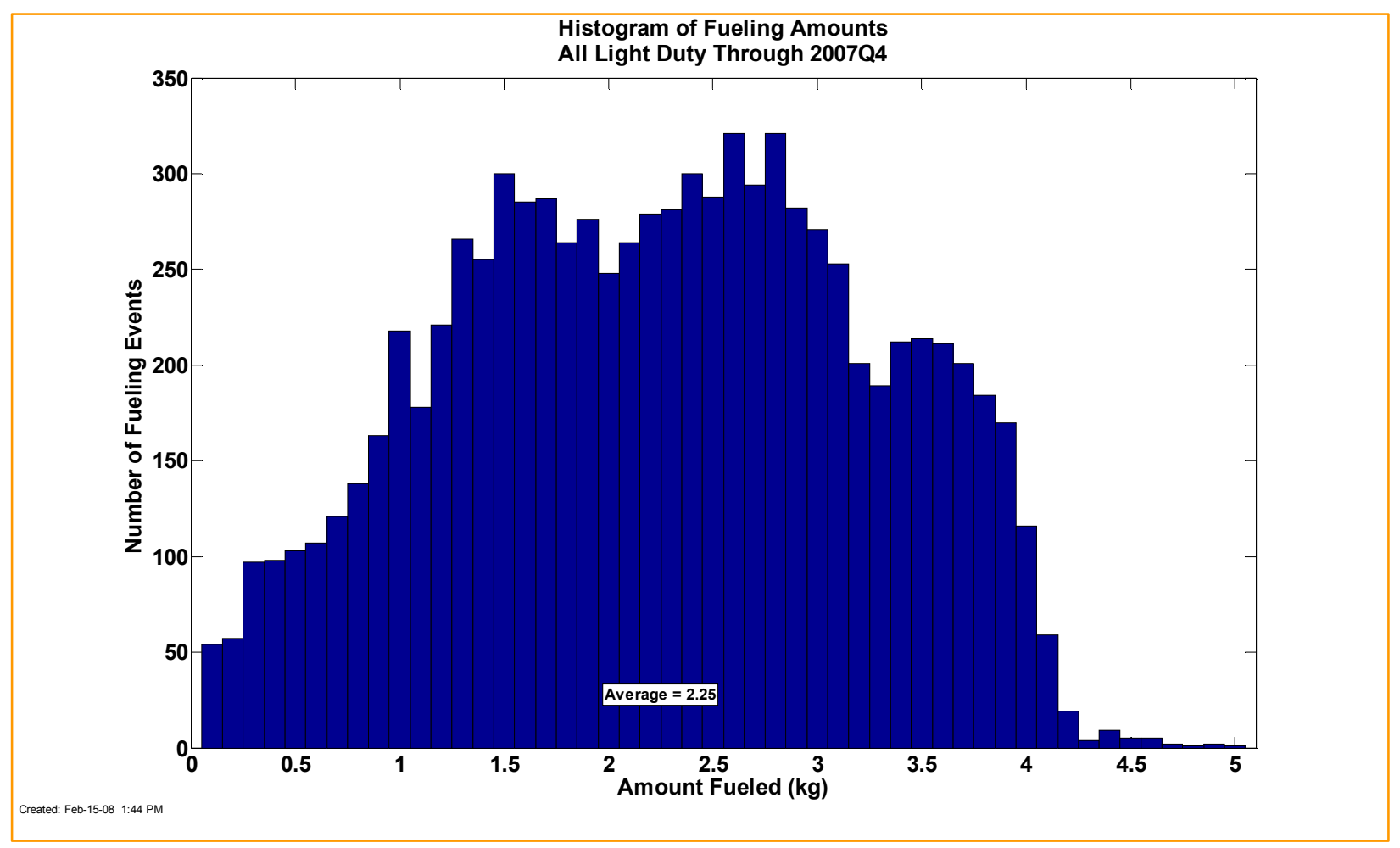

Figure 40: Refueling Amounts (CDP39) 


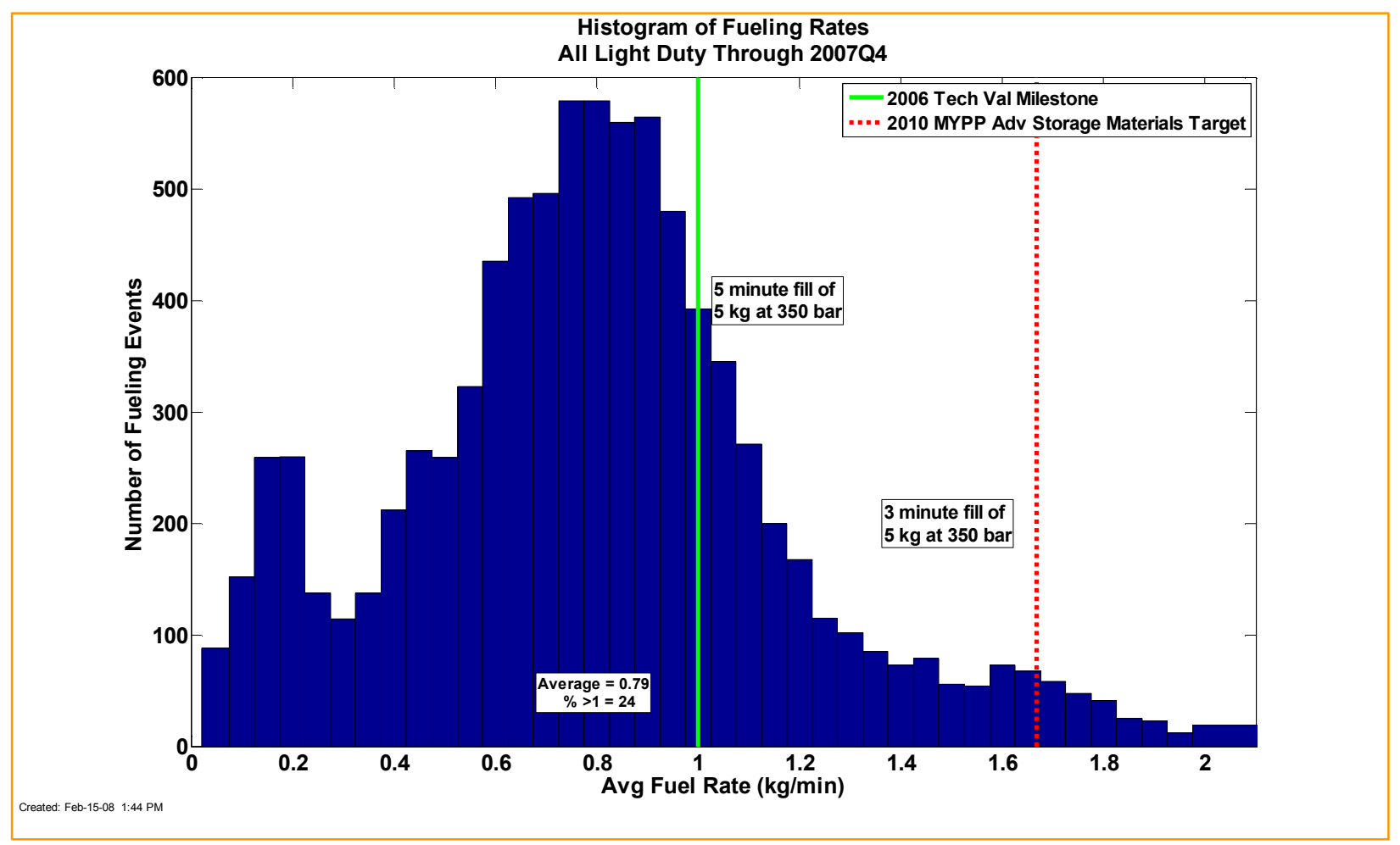

Figure 41: Refueling Rates (CDP18)

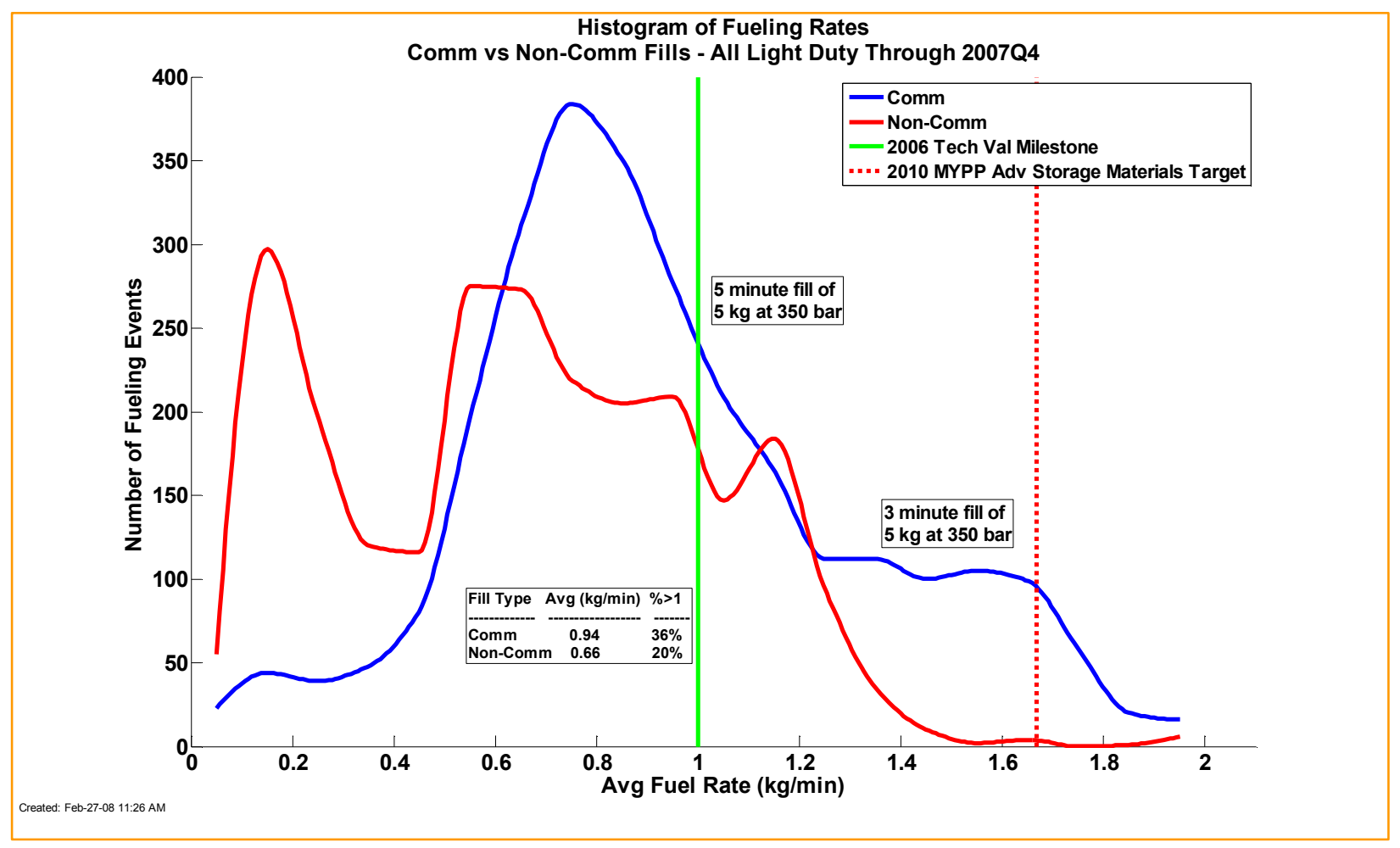

Figure 42: Fueling Rates - Communication and Non-Communication Fills (CDP29) 


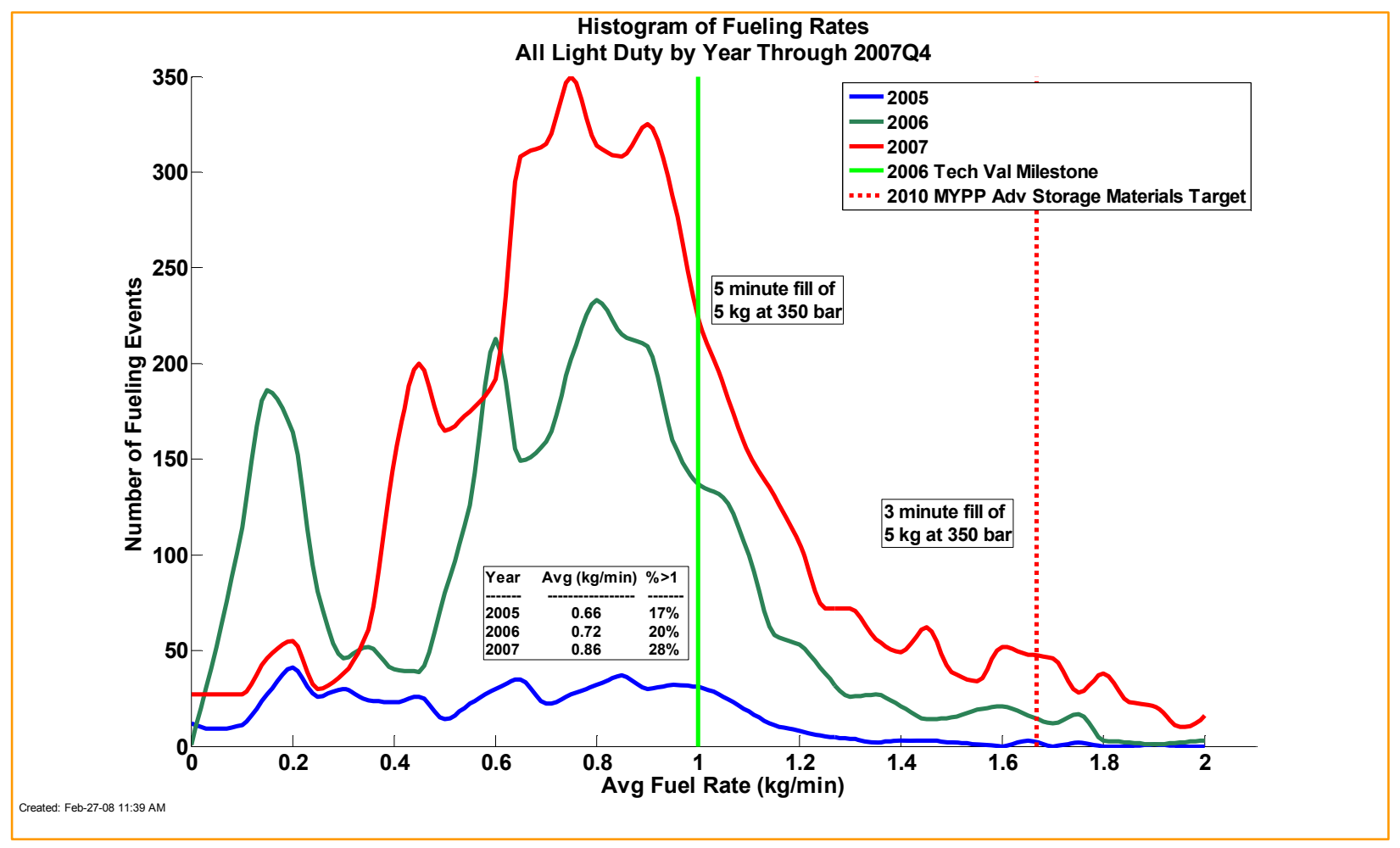

Figure 43: Refueling Data by Year (CDP52)

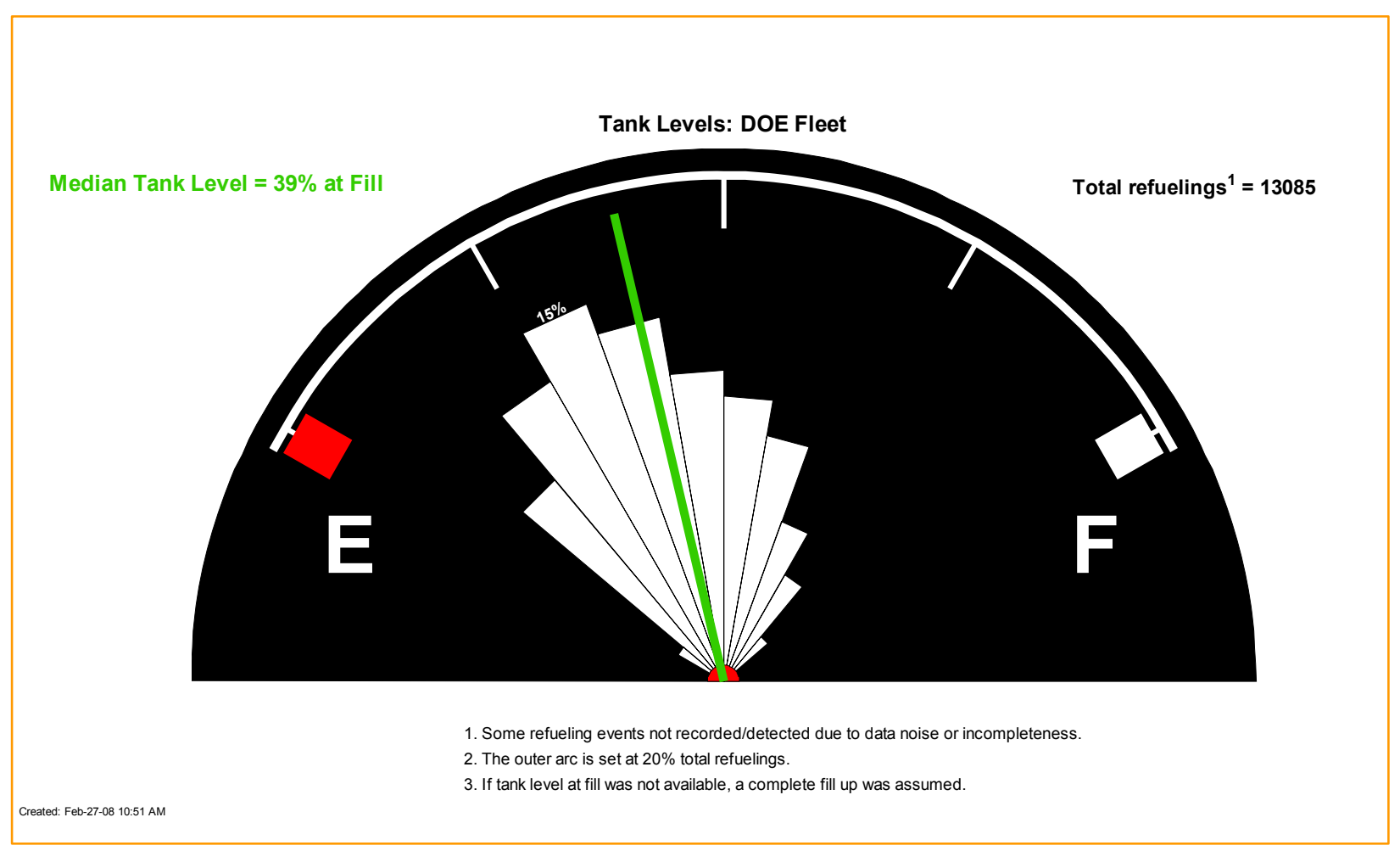

Figure 44: Hydrogen Tank Level at Refueling (CDP40) 


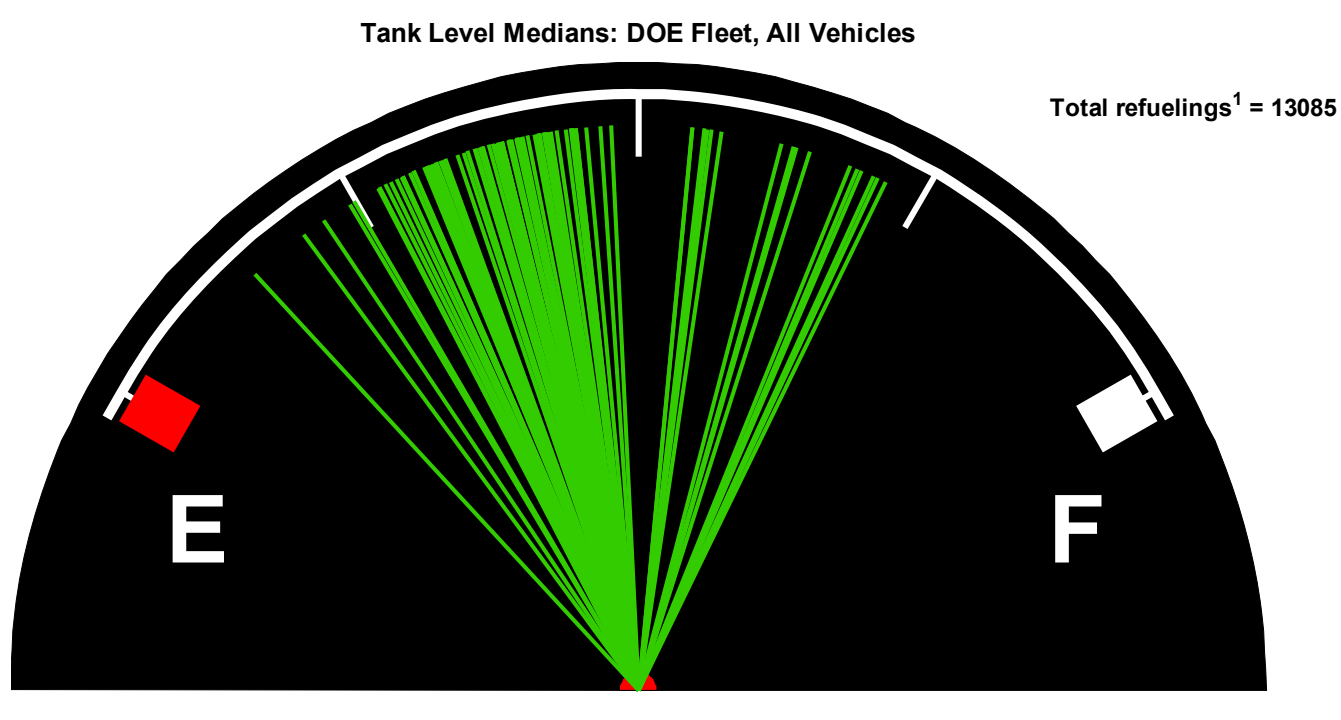

1. Some refueling events not recorded/detected due to data noise or incompleteness. 2. If tank level at fill was not available, a complete fill up was assumed.

Figure 45: Refueling Tank Levels - Medians (CDP41)

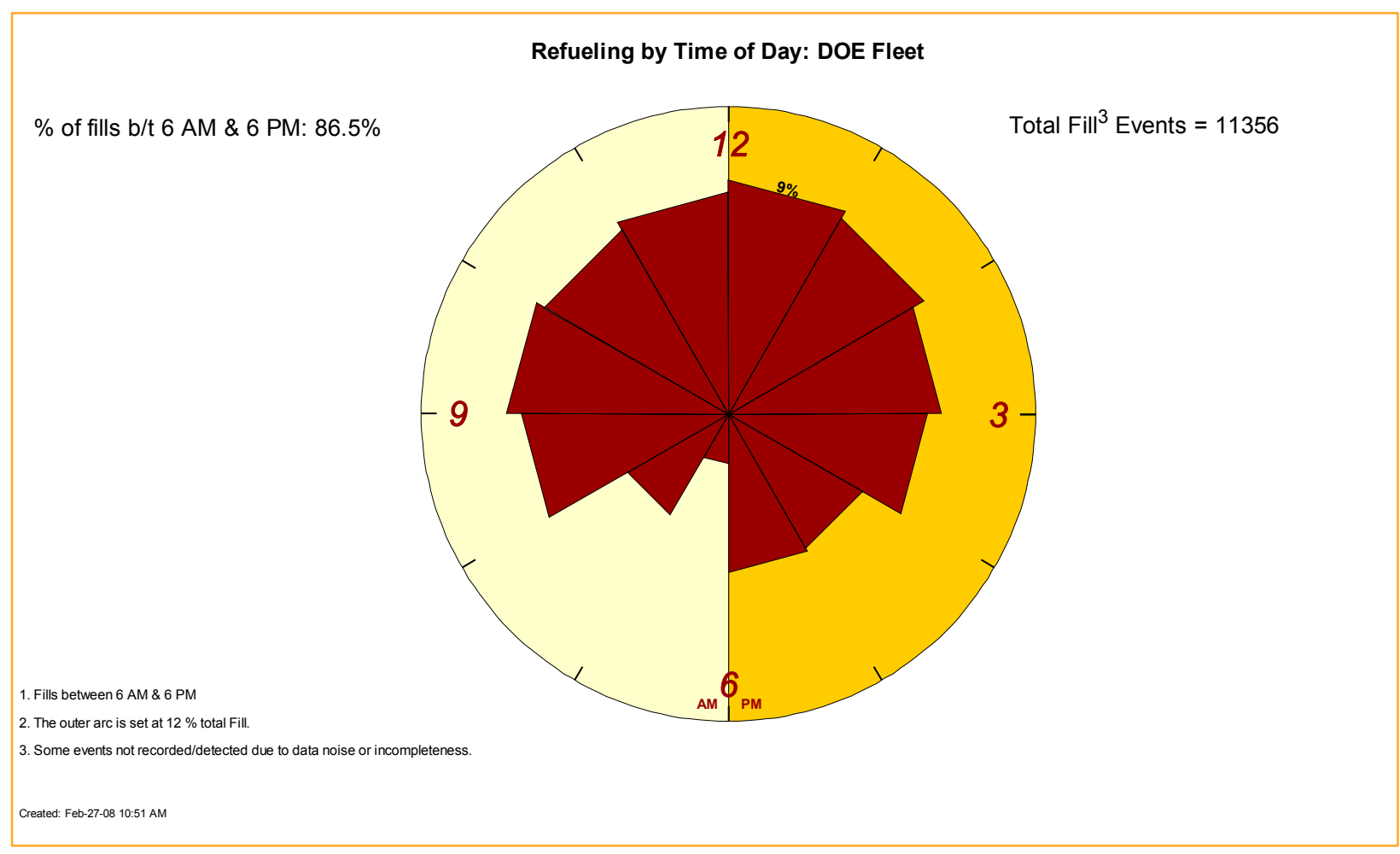

Figure 46: Refueling by Time of Day (CDP42) 


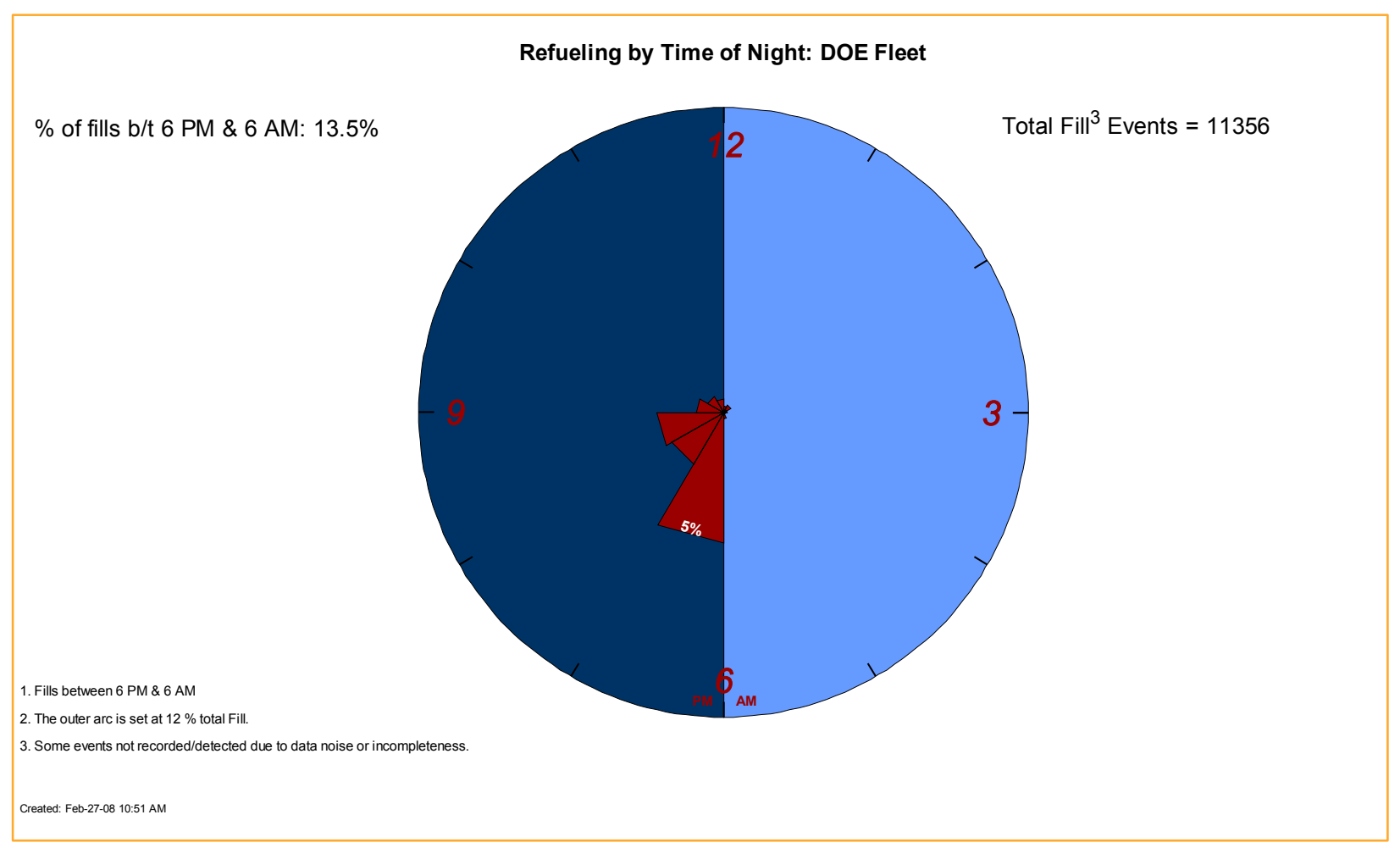

Figure 47: Refueling by Time of Night (CDP50)

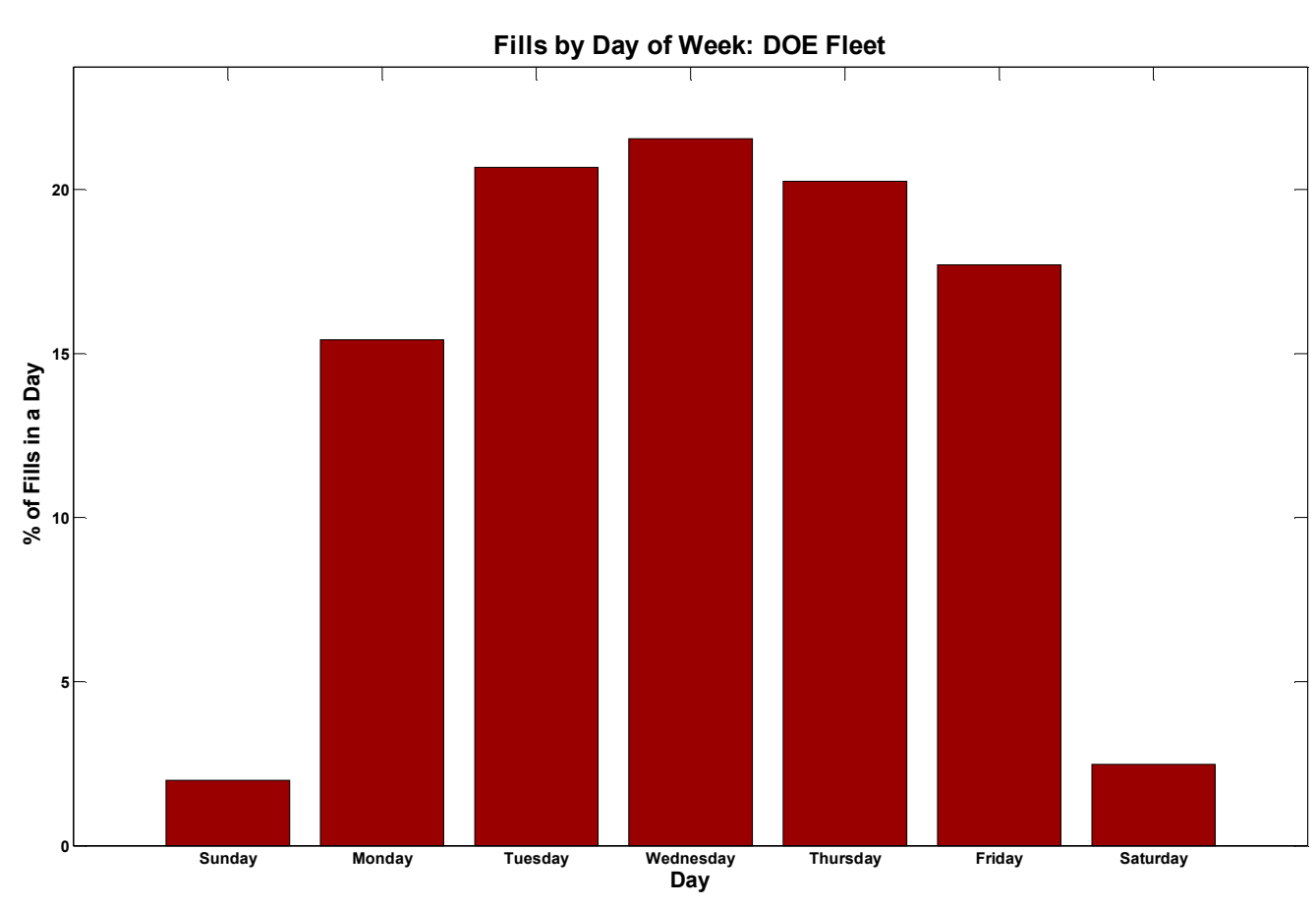

Figure 48: Refueling by Day of Week (CDP43) 


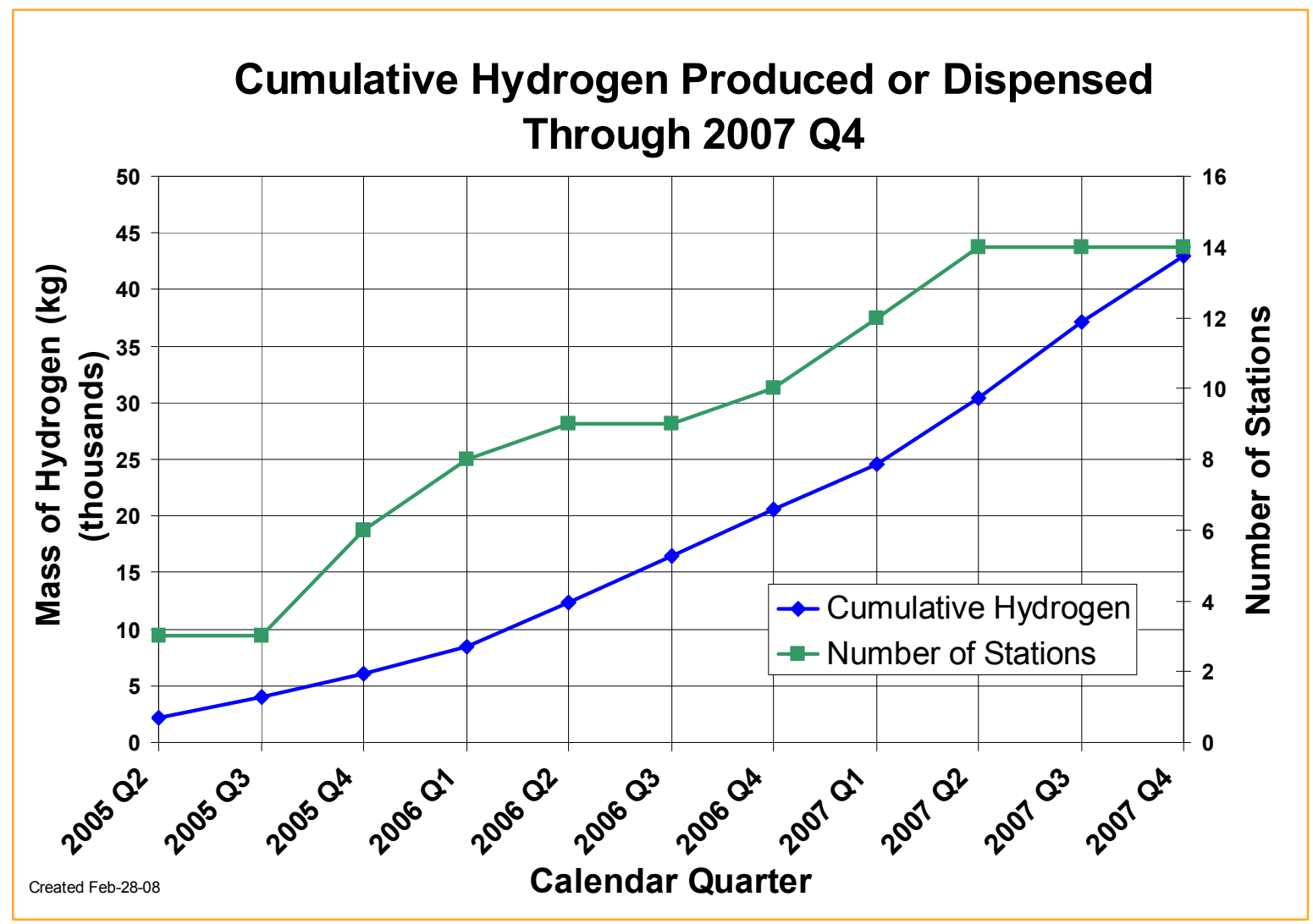

Figure 49: Cumulative Hydrogen Produced or Dispensed (CDP26)

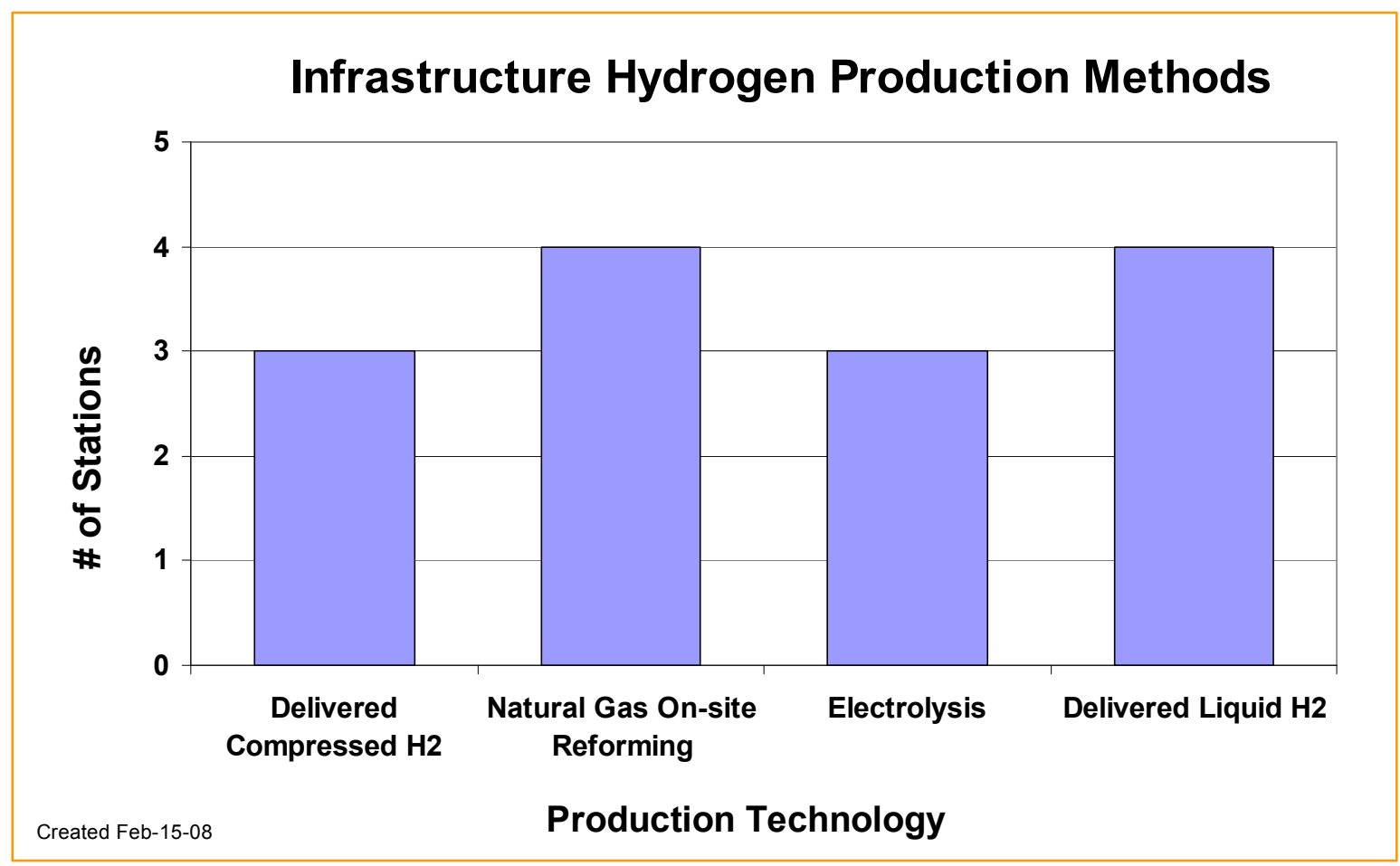

Figure 50: Infrastructure Hydrogen Production Methods (CDP32) 


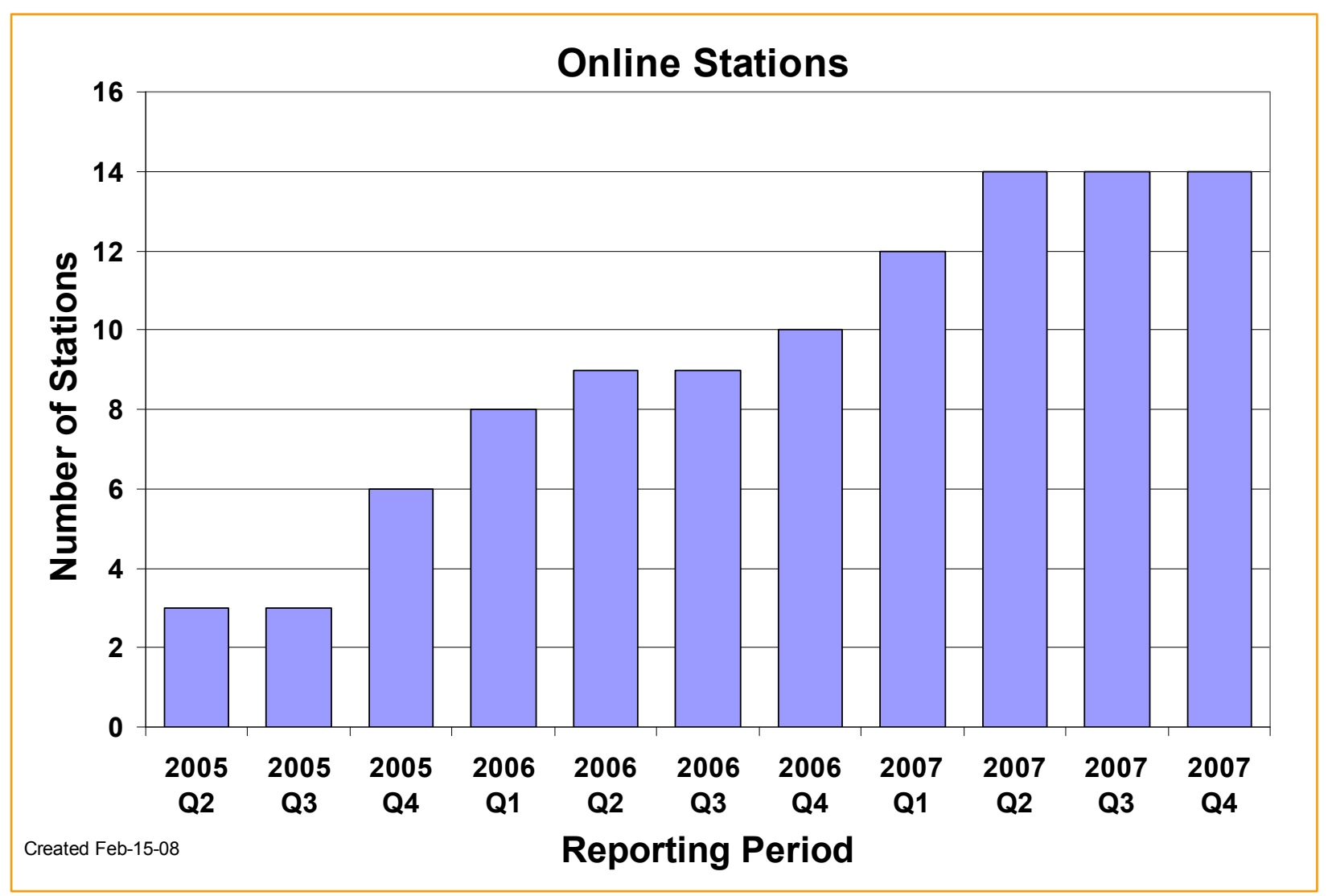

Figure 51: Number of Reporting Stations (CDP31) 


\section{REPORT DOCUMENTATION PAGE}

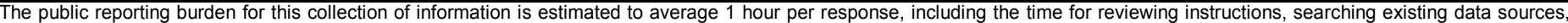

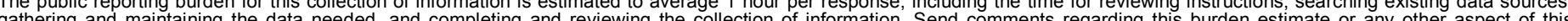

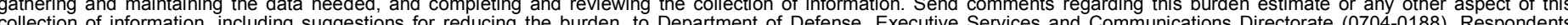

should be aware that notwithstanding any other provision of law, no $p$

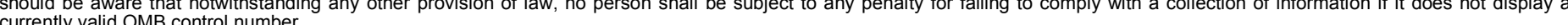

PLEASE DO NOT RETURN YOUR FORM TO THE ABOVE ORGANIZATION.

\begin{tabular}{l|l|l|l} 
1. REPORT DATE $(D D-M M-Y Y Y Y)$ & 2. REPORT TYPE & 3. DATES COVERED (FrOm - TO)
\end{tabular}

April 2008

Technical Report

4. TITLE AND SUBTITLE

Learning Demonstration Progress Report - Spring 2008

5a. CONTRACT NUMBER

DE-AC36-99-G010337

5b. GRANT NUMBER

5c. PROGRAM ELEMENT NUMBER

6. AUTHOR(S)

K. Wipke, S. Sprik, and J. Kurtz

5d. PROJECT NUMBER

NREL/TP-560-42986

5e. TASK NUMBER

H2708100

5f. WORK UNIT NUMBER

7. PERFORMING ORGANIZATION NAME(S) AND ADDRESS(ES)

National Renewable Energy Laboratory

1617 Cole Blvd.

8. PERFORMING ORGANIZATION REPORT NUMBER

Golden, CO 80401-3393

NREL/TP-560-42986

9. SPONSORING/MONITORING AGENCY NAME(S) AND ADDRESS(ES)

10. SPONSOR/MONITOR'S ACRONYM(S)

NREL

11. SPONSORING/MONITORING AGENCY REPORT NUMBER

12. DISTRIBUTION AVAILABILITY STATEMENT

National Technical Information Service

U.S. Department of Commerce

5285 Port Royal Road

Springfield, VA 22161

13. SUPPLEMENTARY NOTES

14. ABSTRACT (Maximum 200 Words)

This report documents key results from DOE's Controlled Hydrogen Fleet and Infrastructure Validation and

Demonstration Project based on data through December 2007.

15. SUBJECT TERMS

Hydrogen fleet; hydrogen vehicle; hydrogen infrastructure; demonstration; validation; fuel cell vehicle"

\begin{tabular}{|c|c|c|}
\hline 16. SECURIT & CLASSIFICAT & N OF: \\
\hline $\begin{array}{l}\text { a. REPORT } \\
\text { Unclassified }\end{array}$ & $\begin{array}{l}\text { b. ABSTRACT } \\
\text { Unclassified }\end{array}$ & $\begin{array}{l}\text { c. THIS PAGE } \\
\text { Unclassified }\end{array}$ \\
\hline
\end{tabular}

\begin{tabular}{l|l} 
17. & LIMITATION \\
OF ABSTRACT & $\begin{array}{l}\text { 18. } \\
\text { NUMBER } \\
\text { OF PAGES }\end{array}$ \\
&
\end{tabular}

19a. NAME OF RESPONSIBLE PERSON

19b. TELEPHONE NUMBER (Include area code) 